\title{
VII. Die Außenpolitik der Großen Koalition unter dem Druck der innenpolitischen Ereignisse
}

\section{Die innerparteiliche Entwicklung in der CDU/CSU: Kiesinger und die Stimmung in der Union gegen die Fortsetzung der Großen Koalition}

Außenpolitisch hatte sich Kiesinger mit seiner Art der liebenswürdigen Vermittlung und durch geschicktes Ausnutzen der äußeren Umstände jetzt zum zweiten Mal durchgesetzt. Das erste Mal war er darin erfolgreich, die pro-französische Fraktion und ihren Führer Adenauer über seine wahren Absichten im unklaren gelassen zu haben und dem Angebot de Gaulles ausgewichen zu sein. Jetzt war es ihm gelungen - vor allem mit Hilfe der Prager Tragödie -, die Zustimmung zum Sperrvertrag gegen den Willen der Supermächte und seines Außenministers aufzuschieben. Dabei war er in beiden Fällen seiner eigenen politischen Linie gefolgt und nicht etwa dem konservativen "Geflüster" seiner Berater oder gar der Fraktion erlegen. Beide Entscheidungen entsprachen seiner außenpolitischen Grundorientierung: Die Bundesrepublik sollte zwar eng mit Frankreich zusammenarbeiten, aber sich nicht unterwerfen. Der Sperrvertrag drohte die Aussicht auf ein geeintes Europa freier und gleicher Nationen - die Voraussetzung für das wiedervereinigte Deutschland - zunichte zu machen. In dieser Lage hatte Kiesinger das Beste aus seiner Sicht für die Bundesrepublik getan und den Charakter seiner außenpolitischen Grundüberlegungen gewahrt.

Vieles in Kiesingers Politik war ungewollt, von äußeren Umständen und Faktoren abhängig, auf die der Kanzler keinen Einfluß hatte. Trotzdem blieb er sich auf lange Sicht in seinen Grundüberzeugungen treu und handelte nach ihnen. Darin zeigt sich seine Unabhängigkeit von SPD und der Union. Im Herbst 1968 geriet er dennoch gegenüber seiner Fraktion in eine schwierige Lage, und dies geschah auf einem Feld, auf dem der Politiker Kiesinger schon frühzeitig große Schwächen hatte erkennen lassen: in der Innenpolitik, genauer: in der Frage der Präsidentschaftsnachfolge.

\section{Das Ende der Amtszeit Lübkes als Bundespräsident und die Frage seiner Nachfolge}

Immer wieder war Lübke seit seiner Wiederwahl im Jahre 1964 ins Gerede gekommen. Seine altersbedingten Ausfallerscheinungen und peinlichen Entgleisungen, vor allem bei Auslandsreisen, die von der heimischen Presse wortgetreu berichtet wurden, waren nur eine Ursache weitverbreiteten Kopfschüttelns ${ }^{1}$. Schwerer wog der Vorwurf, Lübke habe in der Kriegszeit als Architekt am Bau von Baracken für KZ-Häftlinge mitgewirkt. Die Anschuldigung stammte aus der DDR und stützte sich auf dort vorhandene, angeblich belastende Dokumente. Es stimmte davon allerdings nur so viel, daß Lübke in den frühen

\footnotetext{
1 Aufgrund einer Krankheit, die 1967 ausbrach; Hildebrand (Erhard, S. 389) spricht von Arteriosklerose; Baring (Machtwechsel, S. 38) von Zerebralsklerose.
} 
vierziger Jahren für die im Krieg zwangsverpflichtete Baugruppe Schlempp, ein privates Architekturbüro, gearbeitet hatte. Für das Raketenversuchsgelände Peenemünde und für eine andere Stätte bei Magdeburg plante er Arbeiterunterkünfte. Wer dort allerdings unterkommen sollte, lag nicht in der Entscheidungsmacht des Architektenbüros, sondern entschieden die Arbeitsämter. Dies erklärte zumindest Walter Schlempp im August 1966. Daß tatsächlich KZ-Häftlinge in den Baracken untergebracht worden waren, schloß der ehemalige Chef Lübkes für den Zeitraum bis 1944 aus. Über die folgende Zeit, in der die Briten mit der Bombardierung der Gelände begannen, konnte Schlempp keine Angaben machen. Er hatte die Baugelände seit jener Zeit nicht mehr betreten².

Der Versuch der DDR-Propaganda, Lübke als „KZ-Baumeister“ zu denunzieren, konnte sich also nicht auf vorhandene Beweismittel stützen. So sah das auch die Frankfurter Staatsanwaltschaft, die das Material aus Ost-Berlin prüfte und die Einleitung eines Verfahrens gegen Lübke mangels jeglichen Tatverdachts im Januar 1967 ablehnte. Trotzdem waren die Enthüllungen - ein Magazin brachte in großer Aufmachung Pläne von Baracken mit der Unterschrift Lübkes - Anlaß für eine öffentliche, polemisch geführte Kampagne, die sich gegen die Person des Bundespräsidenten richtete. Lübke sah sich zu einer öffentlichen Erklärung gezwungen. Über alle Rundfunk- und Fernsehanstalten betonte er am 1. März 1968, daß die Baugruppe oder das Büro zu keiner Zeit Einrichtungen plante oder bearbeitete, die „den Charakter eines Konzentrations- oder Sträflingslagers" hatten. Er könne sich allerdings nicht mehr an jedes Schriftstück erinnern, das er ein Vierteljahrhundert zuvor unterzeichnet habe ${ }^{3}$.

Die Bundesregierung machte gleich im Anschluß an die Erklärung erneut deutlich, daß sie sich „schützend vor den Bundespräsidenten“ stelle, der sich in der Zeit der Weimarer Republik und der nationalsozialistischen Herrschaft "untadelig“ verhalten habe. Lübke sei als „überzeugter Demokrat" Verfolgung und Haft ausgesetzt gewesen, hieß es. Lübke war im Februar 1934 tatsächlich für zwanzig Monate in Untersuchungshaft genommen worden, weil man bei dem damaligen Reichstagsabgeordneten des Zentrums Briefe des emigrierten früheren Reichskanzlers Heinrich Brüning fand. Jetzt, 30 Jahre später, sahen die Bonner Parteien in den Beschuldigungen Machenschaften des Ostens. Schmidt zog sogar Parallelen zu den Verleumdungskampagnen gegen den ersten sozialdemokratischen Reichspräsidenten, Friedrich Ebert: Auch heute gäbe es Leute, die Vorwände suchten, um durch Angriffe auf den gegenwärtigen Bundespräsidenten die demokratischen Institutionen lächerlich zu machen. Und Heck meinte verächtlich, es gebe manche, die „vor 1945 unserem Volk Herrn Hitler angepriesen haben und heute in diese perfide Kampagne miteinstimmen“4.

Lübke hatte nicht sofort zugegeben, am Bau von Baracken beteiligt gewesen zu sein. Das stimmte nachdenklich und ließ die Frage nach einer früheren Beendigung seiner Amtszeit aktuell werden. Hinzu kam, daß die Wahl seines Nachfolgers, falls Lübke bis zum Ende seiner Amtszeit aushielt, zeitlich genau in den Bundestagswahlkampf fallen würde. Dadurch, so befürchtete man bei den Regierungsparteien, werde die Wahl eines Kandidaten erschwert, wenn nicht gar unmöglich gemacht, der die Stimmen aller wichtigen demokratischen Kräfte auf sich vereinigen könnte.

2 Vgl. Baring, Machtwechsel, S. 38.

3 Süddeutsche Zeitung, 2.3.1968; dort auch die folgenden Zitate. Die Erklärung war ein Rückzug von der Behauptung, die auch die Bundesregierung zuvor verbreitet hatte, daß Lübke nie Pläne abgezeichnet habe und die Dokumente aus dem Osten daher schlicht Fälschungen seien.

${ }^{4}$ Vgl. Süddeutsche Zeitung, 29.2.1968. 
Die Union bemühte sich daher seit dem Frühjahr 1968 darum, Lübke zu einem vorzeitigen Rücktritt von seinem Amt zu überreden. Um den Eindruck zu vermeiden, dieser Schritt sei ein Eingeständnis seiner Schuld, sollte allerdings eine gewisse Zeit bis zum Ausscheiden verstreichen. Etwa um die Weihnachtszeit - so lautete eine der Vorstellungen, die an die Öffentlichkeit gelangten - könnte der Bundespräsident seinen Verzicht aus Gesundheitsgründen erklären. Zeitweise versuchte die Union, Lübke den Abtritt dadurch zu erleichtern, daß man ihm anbot, generell die Amtszeit von bis dahin maximal zwei Perioden von je fünf Jahren auf eine Periode von sieben Jahren zu reduzieren. Der Bundespräsident zeigte sich dem Vorschlag gegenüber aufgeschlossen. Wenn sich das durchsetzen lasse, meinte Lübke gegenüber Barzel im April 1968, dann wäre seine letzte Amtshandlung die Unterzeichnung dieses verfassungsändernden Gesetzes ${ }^{5}$.

Aber die SPD stimmte diesem Vorhaben nicht zu. Man dürfe nicht das Grundgesetz ohne Not „ad hoc“ verändern, nur um eines bestimmten Bundespräsidenten willen. Insgesamt standen die Sozialdemokraten einem vorzeitigen Rücktritt Lübkes zunächst zurückhaltend gegenüber. Zwar war es auch in ihrem Sinne, wenn die Nachfolgefrage zu einem frühen Zeitpunkt geklärt würde. Aber Wehner fand es empörend, daß die vertraulichen Versuche hoher CDU-Funktionäre, Lübke zum vorzeitigen Rücktritt zu überreden, in der Presse ausführlich diskutiert werden konnten. Am 25. April 1968 schrieb er an den Bundeskanzler, es bleibe ihm nichts anderes übrig, als "Ihnen kurz mit diesen Zeilen zu verstehen zu geben, wie unvertretbar ich es empfinde, daß zur selben Stunde, in der der Bundespräsident eine Reise antritt, diese neue Welle in Gang gesetzt worden ist". Was auch unmittelbar daraus werden möge, für die sachgemäße Beratung werde dies „nicht gut" sein und könne nur „neuen Zündstoff“ bieten. Ihm sei unter diesen Umständen nur die Möglichkeit verblieben, dem Sprecher des Vorstandes der SPD zu sagen, er möge erklären, daß der Vorsitzende der SPD zu gegebener Zeit mit den in Frage kommenden Herren sprechen werde; sonst solle er sich auf keine Erläuterungen einlas$\operatorname{sen}^{6}$.

Wehner hatte sich in den Jahren zuvor häufig für den Bundespräsidenten eingesetzt, da sich Lübkes Befürwortung einer Großen Koalition mit seiner Sicht der SPD-Interessen deckte. Öffentlich verteidigte er frühzeitig und nachdrücklich das Recht Lübkes, für die Bildung einer Großen Koalition einzutreten, wie dieser das etwa nach der Bundestagswahl 1965 getan hatte. So erklärte Wehner beispielsweise im Januar 1966, er verstehe nicht, warum ausgerechnet dem ersten Bürger des Staates verboten sein solle, seinen Sorgen über die amtierende Regierung Ausdruck zu verleihen. Er halte es für „unanständig“, wenn man dem Bundespräsidenten deswegen eine Überschreitung seiner Kompetenz vorwerfe ${ }^{7}$.

Wehner und Lübke waren sich auch menschlich sympathisch und verstanden sich "prächtig“8. Häufig war Wehner Gast in der Villa Hammerschmidt. Wenn der Sozialdemokrat zum Tee kam, durfte niemand aus dem Mitarbeiterkreis des Bundespräsidenten an den Gesprächen teilnehmen. Lübke war aufgrund seiner Erfahrungen vor 1933 für eine Große Koalition in Bonn. In dieser Haltung und in seiner Funktion als Vermittler zwischen Union und SPD glich er dem langjährigen Minister und CDU-Fraktionsvorsitzenden, Krone, sowie dem Zentrumsabgeordneten im Reichstag und erfolg-

\footnotetext{
5 Vgl. Der Spiegel, 29.4.1968, S. 27.

6 AdKASt, Kiesinger I - 226, D/IV.6, Wehner an Kiesinger vom 25.4.1968.

7 Süddeutsche Zeitung, 10.1.1966.

${ }^{8}$ Herwarth, Gespräch mit dem Verfasser, 23.10.1986.
} 
reichen Plantagenbesitzer, Johannes Schauff. Er hatte die Weimarer Koalition, zumal in Preußen, als stabilisierendes Element der ersten deutschen Republik erlebt. Wehner spielte bei den christdemokratischen Befürwortern des politischen Großbündnisses als ehemaliger Kommunist und Spitzenrepräsentant der Sozialdemokratie die entscheidende Rolle. Er war ihr „Aushängeschild“, wie Barzel das nannte. „Im Grunde war es ihnen egal, welcher Kanzler die Regierung führte, nur Wehner war ihnen wichtig."

Auch nach der Entstehung der Großen Koalition blieben die Sozialdemokraten dem Bundespräsidenten wohlwollend gesonnen. Aber im Sommer 1968 wurde ihnen die Notwendigkeit einer zeitlichen Vorverlegung der Bundespräsidentenwahl bewußt. In einem Brief an den Bundeskanzler schrieb Schmidt: „Ich möchte gleichwohl noch einmal feststellen, daß ich selbst Herrn Bundespräsident Lübke gegenüber allen politischen Angriffen, die mit Ereignissen in den Jahren 1933-1945 zusammenhängen, nachdrücklich verteidige, daß ich ebenso aber aus anderen Gründen einen vorzeitigen Rücktritt für dringend notwendig halte. " ${ }^{10} \mathrm{Er}$ hoffe, im Laufe des Monats Gelegenheit $\mathrm{zu}$ haben, diese seine Meinung auch dem Bundespräsidenten persönlich nahebringen zu können.

In der Präsidentschaftsnachfolgefrage kalkulierte Schmidt wie die anderen Sozialdemokraten: Die SPD hatte frühzeitig durch ihren Vorsitzenden angekündigt, daß sie diesmal einen eigenen Kandidaten aufstellen würde. Nach einem liberalen Präsidenten Heuss und dem Christdemokraten Lübke müsse endlich ein Sozialdemokrat die Republik repräsentieren. Daher teilte Brandt Kiesinger am 7. August 1967 schriftlich mit, das Präsidium der SPD habe seine Ankündigung bestätigt, wonach die Partei in der nächsten Bundesversammlung die Wahl eines aus ihren Reihen kommenden Bundespräsidenten anstreben werde ${ }^{11}$. Bei diesem Projekt rechnete die SPD, und hier besonders Wehner, auf die Zustimmung des Koalitionspartners. Falls aber die Wahl des Präsidenten zeitgleich mit der Bundestagswahl stattfinden sollte, so befürchtete die SPD, würde sich die Union schwertun, einem sozialdemokratischen Kandidaten ihre Stimme zu geben. Die Gefahr bestand, daß die Entscheidung über Lübkes Nachfolger in den Sog parteipolitischer Interessengegensätze geriet. Das wollten die Führer der SPD nicht riskieren.

\section{Die Union präsentiert einen eigenen Kandidaten}

Aber die Entwicklung verlief nicht zum Vorteil der sozialdemokratischen Pläne. Zunächst verschleppte sich die endgültige Zusage Lübkes, vorzeitig sein Amt niederzulegen. Im Mai 1968 erklärte er zwar dem Sonderbeauftragten des Bundeskanzlers für Berlin und früheren Reichstagsmitglied der Deutschen Demokratischen Partei, Lemmer, er werde im Herbst, spätestens Anfang des nächsten Jahres zurücktreten ${ }^{12}$. Aber nur wenige Wochen später erreichten den Kanzler ganz andere Informationen. Diesmal hatte Lübke Landwirtschaftsminister Höcherl zu Gast und machte ihm deutlich, daß seine Rücktrittsvorstellungen sich auf einen späteren Zeitpunkt bezögen: „Zur Präsidentenwahl erklärte der Herr Bundespräsident, daß er den Wahltermin durch freien Rücktritt auf April/Mai 1969 vorziehen möchte. Keinesfalls möchte sich der Herr Bundespräsident zu einem früheren Termin bewegen lassen. Er beabsichtigt noch einige Auslands-

\footnotetext{
9 Barzel, Gespräch mit dem Verfasser, 10.6.1988.

10 AdKASt, Kiesinger I - 226, D/IV.6, A 007, Schmidt an Kiesinger vom 22.7.1968.

11 Vgl. AdKASt, Kiesinger I - 226, D/IV.6, A 001, Brandt an Kiesinger vom 7.8.1967; siehe auch Hildebrand, Erhard, S. 389.

12 Vgl. Der Spiegel, 20.5.1968, S. 25.
} 
termine, u. a. einen Besuch in Dänemark, der für April/Mai vorgesehen ist, durchzuführen", berichtete Höcherl13.

Mit einem Termin im Mai/April 1969 war man bei der CDU nicht einverstanden. Das galt auch für den Bundeskanzler. Kiesinger drang bei Lübke darauf, er solle noch im späten Herbst 1968 zurücktreten. Aber der Bundespräsident blieb hart, wie Dufhues dem Kanzler am 16. Juli noch einmal bestätigte: „Mein Gesprächspartner ist, wie er mir gegenüber bereits früher zum Ausdruck gebracht hat, bereit, einen Termin zu akzeptieren, der zu Beginn des Monats im Mai liegt. Gegenüber dem Vorschlag, im Interesse des Amts und der Person einen im Spätherbst gelegenen Termin ins Auge zu fassen, verhielt er sich jedoch sehr zurückhaltend, wenn nicht ablehnend." 14

Kiesinger antwortete Dufhues eine Woche später, die von ihm berichtete Sache bereite ihm "große Sorge“. Er sei natürlich selbst auch nicht untätig gewesen, wolle Dufhues darüber aber lieber nach den Ferien mündlich berichten, fügte er geheimnisvoll hinzu ${ }^{15}$. Was immer der Kanzler auch in Erfahrung zu bringen vermocht hatte, es änderte allerdings an der Entscheidung des Bundespräsidenten nichts. Lübke widersetzte sich hartnäckig jeder Vorverlegung. Gleichzeitig zog er sich zurück, ging Gesprächen mit Mitgliedern seiner Partei aus dem Weg. Wie in einer Festung verbarrikadierte sich Lübke in der Villa Hammerschmidt. Ohne die Regierung zu informieren, suchte er nach Wegen, das Ende der Amtszeit so weit wie möglich hinauszuschieben. Heck berichtete besorgt am 18. August 1968, der Herr Bundespräsident habe unter Umgehung seines Staatssekretärs und seiner Beamten dem Protokoll des Auswärtigen Amtes direkt Weisung erteilt, seinen Besuch in Afrika und in Dänemark vorzubereiten. „Was dies im einzelnen bedeutet, vermag ich nicht zu sagen“, fügte Heck hinzu. „Es könnte aber durchaus so sein, daß eine solche Vorbereitung, wenn sie weiter fortgeschritten ist, Fakten schüfe, mit denen der Herr Bundespräsident ein längeres Verbleiben in seinem Amt vor sich, vor uns und vor der Öffentlichkeit rechtfertigen bzw. erzwingen könnte. "16

Schließlich gab Lübke aber am 14. Oktober 1968, seinem 74. Geburtstag, doch den erwarteten vorzeitigen Rücktritt bekannt. Er werde das Amt am 30 . Juni 1969 verlassen. Das war später als erhofft, aber noch früh genug, um die Wahl des Nachfolgers im März 1969 durchzuführen. Damit trat die Frage der möglichen Kandidaten in den Vordergrund. Und hier erfuhr die SPD-Führung eine große Enttäuschung. Sie war davon ausgegangen - und Kiesinger hatte sie zunächst in dieser Annahme bestärkt -, daß die Union ihr den Posten des Bundespräsidenten überlassen werde. Aber Anfang Mai 1968 änderte sich die Lage: Das Präsidium der CDU beschloß, einen eigenen Kandidaten für die Nachfolge Lübkes aufzustellen.

Die Entscheidung war Folge eines neu gefundenen Selbstbewußtseins der Partei. Bei den Landtagswahlen in Baden-Württemberg vom 28. April 1968 gewann sie zwar nur 2,1 Prozent der Stimmen hinzu; sie steigerte ihren Stimmenanteil von 44,1 auf 46,2 Prozent. Entscheidend für den eigenen Stimmungsaufschwung war aber die hohe Niederlage der Sozialdemokraten. Die SPD hatte einen Verlust von 8,2 Prozent der Wählerstimmen hinnehmen müssen und war unter die 30-Prozent-Marke, auf 29,1 Prozent, abgerutscht. Ermutigt von diesem Ergebnis, drängten die Berater um Kiesinger, vor allem Heck und der junge rheinland-pfälzische Landesvorsitzende Helmut Kohl, den „Sozis“

\footnotetext{
13 AdKASt, Kiesinger I - 226, D/IV.6, A 004, Höcherl an Kiesinger vom 4.7.1968, S. 1.

14 AdKASt, Kiesinger I - 226, D/IV.6, A 003, Dufhues an Kiesinger vom 16.7.1968, S. 1.

15 AdKASt, Kiesinger I - 226, D/IV.6, A 003, Kiesinger an Dufhues vom 23.7.1968.

16 AdKASt, Kiesinger I - 226, D/IV.6, A 004, Heck an Kiesinger vom 18.8.1968, S. 6.
} 
das Amt nicht kampflos zu überlassen. Kiesinger schwenkte jetzt scheinbar um. Scheinbar, denn er ermutigte zwar Heck und Kohl, als sie ihn auf einen CDU-Kandidaten festlegen wollten, aber er entschied sich innerlich noch nicht für diese Lösung. Vermutlich wollte er ebenso Zeit gewinnen, wie er dies bei anderen Fragen auch versuchte, etwa beim Sperrvertrag. Aber mit dieser Taktik hatte er diesmal weniger Glück. Der Druck aus der Fraktion in dieser Frage wuchs ständig. Ende Juni 1968 gab er dem von Wehner protegierten Leber keine Chance mehr, von der Union mitgewählt zu werden. Zwar galt der katholische Gewerkschaftsführer allgemein als aussichtsreicher Kandidat. Leber war erst 47 Jahre alt und hatte sich durch den Vermögensbildungsplan, der 1963 in die Tarifverträge der Bau-Industrie aufgenommen worden war, als erfolgreicher Sozialpolitiker profiliert. Aber der Bundeskanzler glaubte angesichts der Bedeutung einer Präsidentschaftswahl ein halbes Jahr vor den Bundestagswahlen nicht mehr an die Integrationskraft seines Verkehrsministers. Am 24. Juni 1968 suchte ihn Leber auf, um die Chancen seiner Kandidatur zu erkunden. Kiesinger antwortete ihm mit der Frage, ob er damit rechne, daß vor allem seine Wahl zum Bundespräsidenten der SPD bei der Bundestagswahl Stimmen einbringen werde. Leber antwortete ihm, das könne er ehrlicherweise nicht bestreiten. „Meine Antwort war", erzählte Kiesinger später, „er [Leber] könne daraus schließen, wie die Union auf seine Kandidatur reagieren würde. “ ${ }^{17}$

Allerdings schien Leber den Hinweis nicht als Entmutigung aufzufassen. Bis kurz vor der Wahl hat der Sozialdemokrat daher auch geglaubt, die CDU/CSU würde ihn am Ende doch wählen. Er stützte sich vermutlich auf ein Wort Wehners. Wie Wehner später erklärte, hatte ihm Kiesinger versprochen, die Union werde Leber zum Präsidenten wählen. Das Wort sei damals „ehrlich gegeben worden“, meinte der SPD-Politiker im Jahre 1980. Aber ab August 1968 sei klar gewesen, daß „es dadurch keinen Boden mehr hatte, daß diejenigen, die das gegeben hatten, nicht mehr Herr ihrer Anhänger waren in dieser Frage"18. Kiesinger - nur er war hier gemeint - hatte Wehner also offenbar über die veränderte Lage informiert. Er mußte dem Sozialdemokraten eingestehen, daß ihm in dieser Sache das Heft entglitten war und ihm die eigenen Leute nicht mehr folgen würden. Die Union wolle einen eigenen Kandidaten präsentieren ${ }^{19}$.

\section{Die SPD nominiert Heinemann}

Trotz der Aufstellung eines Unionskandidaten für die Wahl des Bundespräsidenten hielten sich die Sozialdemokraten bis zum Ende alle Möglichkeiten offen. Selbst als sie am 1. November 1968 den Bundesjustizminister Heinemann für das Präsidialamt nominierten, ließen sie den Kanzler wissen, daß damit noch keine endgültige Entscheidung in der Sache gefallen sei. Das war allerdings angesichts dieses Kandidaten nicht sehr glaubhaft. Denn mit Heinemann stellte die SPD einen Kampfkandidaten auf. Man mußte sich in der Parteispitze darüber im klaren sein, daß das frühere prominente CDU-Mitglied keine Stimme von der Union erwarten konnte. Heinemann hatte aus Protest gegen Adenauers Angebot einer deutschen Wiederbewaffnung 1950 sein Amt als Innenminister nieder-

17 AdKASt, Kiesinger I - 226, E/IV.1, A 355, Kiesinger an Dichgans vom 9.1.1980, S. 6; vgl. Hildebrand, Erhard, S. 390.

18 Terjung (Hrsg.), Der Onkel, Wehner im NDR am 5.1.1980, S. 160.

19 Vgl. Hildebrand (Erhard, S. 390), der meint, Kiesinger habe hier eine Chance verpaßt. Er hätte frühzeitig die Weichen für die Fortsetzung der Großen Koalition stellen können. Baring (Machtwechsel, S. 50) macht vor allem die Entschlußlosigkeit des Kanzlers dafür verantwortlich, daß man sich nicht auf einen gemeinsamen Kandidaten verständigen konnte. Kiesinger habe die Entscheidung über den Präsidentschaftskandidaten einfach zu lange hinausgezögert. 
gelegt und zwei Jahre später die CDU verlassen. Seine Abrechnung mit Adenauers Deutschlandpolitik während einer Bundestagsdebatte im Januar 1958 ist wegen der Schärfe und Bitterkeit seiner Äußerungen lange in Erinnerung geblieben ${ }^{20}$. Bekannt wurde der Jurist und Volkswirt aus dem Ruhrgebiet in den sechziger Jahren für seine liberalen rechtspolitischen Überzeugungen und für das Verständnis, das er der kritischen Jugend entgegenbrachte. Seine Fernseh- und Rundfunkrede anläßlich der Osterunruhen 1968 enthielt die berühmte Mahnung, wer mit dem „Zeigefinger allgemeiner Vorwürfe auf den oder die vermeintlichen Anstifter oder Drahtzieher zeigt, sollte daran denken, daß in der Hand mit dem ausgestreckten Zeigefinger zugleich drei andere Finger auf ihn selbst zurückweisen“. All das sprach für einen Kandidaten, der auch von den damals oppositionellen Liberalen mitgetragen werden konnte ${ }^{21}$.

Aber Wehner, Schmidt und auch Brandt achteten darauf, daß die Nominierung des Sozialdemokraten von der CDU/CSU nicht als endgültiger Bruch verstanden wurde. Man war sogar bereit, am Wahltag Heinemann zugunsten von Leber zu „opfern“, falls sich die Union noch zu diesem gemeinsam zu wählenden SPD-Kandidaten verstehen sollte. Ahlers erläuterte Kiesinger im Auftrag des SPD-Vorsitzenden die Hintergründe der sozialdemokratischen Entscheidung: „Im Auftrag von Herrn Brandt soll ich Sie weiter davon in Kenntnis setzen, daß die Nominierung von Minister Heinemann nur für den ersten Wahlgang gelten soll. Die Fraktion der SPD in der Bundesversammlung werde sich für die weiteren Wahlgänge freihalten, auch einen anderen Kandidaten vorzuschlagen, falls sich herausstellen sollte, daß Minister Heinemann nicht gewählt werden kann.“

Dieser Hinweis ziele auf Minister Leber, der von zahlreichen führenden Sozialdemokraten, darunter von Wehner und Schmidt, als idealer Gemeinschaftskandidat der Koalitionsparteien angesehen werde, setzte Ahlers seinen Brief fort. Man glaube aber bei der SPD nicht, daß Leber eine Chance habe, die erforderlichen Stimmen der FDP zu erhalten. Diese Chance erscheine bei Heinemann durchaus gegeben, und im übrigen werde angenommen, daß eine Nichtwahl Heinemanns durch die FDP all jene enttäuschen müßte, die seit Bildung der Großen Koalition sich von der SPD ab- und der FDP zugewandt hätten. Wörtlich fuhr Ahlers fort: „In diesem Zusammenhang muß ich Sie darauf aufmerksam machen, daß die Herren Wehner, Leber und Schmidt enttäuscht darüber sind, daß Sie sich nicht stärker für einen Koalitionskandidaten Leber eingesetzt hätten. “ Dann folgte noch einmal ein indirekter Appell: Der Gedankengang sei, daß die Wahl Lebers mit den Stimmen der SPD und der CDU ein „krönender und insgesamt versöhnlicher Abschluß“ der großen Koalition gewesen wäre, außerdem zu einer „Verbesserung des Staatsbewußtseins und einer Förderung der Integration der Arbeitnehmerschaft in den Staat" geführt haben würde. Ahlers empfahl, daß der Kanzler im persönlichen Gespräch diese Enttäuschung auszuräumen versuche 22 .

Die Führung der SPD machte also Kiesinger für das Scheitern verantwortlich. Sie hielt sich dennoch die Möglichkeit offen, nach dem ersten Wahlgang Leber als gemeinsamen Kandidaten zu präsentieren. Doch hierfür war es jetzt zu spät. Die Union zeigte sich entschlossen, einen eigenen Mann durchzusetzen. Aber wer sollte das sein? Viele $\mathrm{Na}$ -

20 Vgl. VdDB, 3. Wahlperiode, 9. Sitzung vom 23.1.1958, S. 406.

21 Vgl. Baring, Machtwechsel, S. 70; nach seiner Meinung handelte es sich bei der Fernsehansprache geradezu um eine Kandidatenrede für das Bundespräsidentenamt. Brandt notiert in seinen Begegnungen (S. 299): „Die Konstellation sprach für Heinemann. “ Hildebrand (Erhard, S. 391) betont, daß Heinemann die Eigenschaften, Sicherheitsverlangen und Risikobereitschaft, vertrat, die für die neue Generation der zu Ende gehenden 1960er Jahre so typisch war.

22 AdKASt, Kiesinger I - 226, D/IV.6, A 001, Brief Ahlers an Kiesinger vom 30.10.1968. 
men wurden genannt, aber nur zwei kamen in die nähere Auswahl: Schröder und Richard von Weizsäcker. Schröder hatte inzwischen selbst seine Kandidatur betrieben. Seit der Rückkehr aus dem Sanatorium Tegernsee, meldete Der Spiegel im April 1968, zeige Schröder Interesse an der Nachfolge Lübkes ${ }^{23}$. Auch Kiesinger war zunächst an dieser Nominierung interessiert. Denn damit wäre sein stärkster Konkurrent als Kanzleranwärter nicht mehr in Frage gekommen. Doch dann änderte er seine Meinung. Im Laufe des Oktobers 1968 unterstützte er nunmehr Weizsäcker. Kiesinger hat diesen Meinungswechsel genau datiert, auf den Besuch des FDP-Parteivorsitzenden Scheel am 23. Oktober $1968^{24}$. Scheel habe ihm dabei in voller Offenheit erklärt, Schröder werde in der Bundesversammlung keine Stimme der FDP erhalten. Dagegen würde bei einem anderen CDU-Kandidaten, wie etwa Herrn von Weizsäcker, mit Sicherheit ein Teil der FDP-Wahlmänner für diesen stimmen. Angesichts der Mehrheitsverhältnisse in der Bundesversammlung werde dieser gewählt werden ${ }^{25}$.

\section{Zweifel an Kiesingers Darstellung der eigenen Motivation}

Obwohl Heck diese Darstellung bestätigt ${ }^{26}$, sprechen Gründe dagegen, daß Kiesinger sich tatsächlich von den Motiven leiten ließ, die er Jahre später nannte. Zwar stellte Weizsäcker als Präsident des Evangelischen Kirchentages eine attraktive Persönlichkeit dar. Er wurde von den Liberalen respektiert und besaß in allen Lagern Sympathien. Aber mit seiner Ausstrahlung und seinem Einfluß konnte er sich 1969 nicht entfernt mit Schröder messen. Der Verteidigungsminister galt 1966 als der christdemokratische Kanzlerkandidat schlechthin, als Alternative zu Kiesinger. Er hielt während der Verhandlungsphase im November 1966 Kontakt zum stellvertretenden FDP-Fraktionsvorsitzenden Mischnick. Falls die Union Schröder zu ihrem Kandidaten kürte - das mußte die große Sorge Scheels sein ${ }^{27}$-, würden die Anhänger des christlich-liberalen Bündnisses, die ausgebooteten Parteileute wie etwa der frühere Vorsitzende Mende oder der Fraktionsvorsitzende Knut von Kühlmann-Stumm, für den Christdemokraten votieren. Gerade bei Schröder konnte der neue FDP-Vorsitzende nicht sicher sein, daß es ihm gelingen würde, alle FDP-Wahlmänner für einen SPD-Kandidaten zu mobilisieren. Warum stellte er aber dann bei Kiesinger die gegenteilige Behauptung auf?

Scheel stand unter Erfolgszwang. Die FDP mußte geschlossen für den SPD-Kandidaten stimmen, ihm zur Mehrheit verhelfen. Erst wenn das gelungen war, würde sie nicht länger als bloßer „Wahlverein der Union“28 gelten. Zwischen den beiden großen Parteien etabliert, würde sie an Unabhängigkeit, Wahlmöglichkeiten und Wählerstimmen gewinnen. Wer die Lage genau betrachtete, mußte sich eingestehen, daß Schröder in größerem Maße als Weizsäcker in der Lage war, dieses Ziel Scheels zu vereiteln. Denn die FDP

${ }^{23}$ Vgl. Der Spiegel, 15.4.1968, S. 32.

24 Vgl. AdKASt, Kiesinger I - 226, E/IV.1, A 355, Kiesinger an Dichgans vom 9.1.1980, S. 6.

25 Vgl. Baring, Machtwechsel, S. 105 f.

26 Vgl. Heck, Gespräch mit Journalisten (Dreher), 6.12.1983. Dort heißt es: „Scheel hat gesagt: ,Wenn Sie Schröder aufstellen, bringe ich meine Mannschaft geschlossen dagegen. Bei Weizsäcker würde mir das nicht gelingen, denn es gibt in jedem Fall einige Leute, die für den Kirchentagspräsidenten stimmen werden. ““

27 Vgl. Baring, Machtwechsel, S. 106; Scheel hatte erklärt, daß für die skeptische Einschätzung von Schröders Chancen die FDP-Präsidiumssitzung am 13./14.9.1968 in München entscheidend gewesen sei. Dort hatte es geheißen, Schröder sei wegen seiner konservativen Gesinnung „nicht zeitgemäß" und ziehe zudem sicherlich Stimmen der NPD auf sich.

28 Der Spiegel, 7.10.1968, S. 27. 
befand sich noch immer in einer Umbruchphase, die im April 1967 mit einem neuen deutschland- und ostpolitischen Programm eingeleitet worden war ${ }^{29}$. Erst im Januar 1968 hatte Scheel den Vorsitz der Partei übernommen, was den Neuanfang symbolisierte. Kaum zehn Monate waren seitdem verstrichen. Die Person Schröders drohte, die Partei in Anhänger des neuen und des alten Kurses zu spalten.

Die SPD brauchte aber jede Stimme der FDP, um ihren Kandidaten durchzubekommen. Zur absoluten Mehrheit benötigte sie im ersten und zweiten Wahlgang 519 Stimmen der Wahlversammlung. 450 besaß sie selbst, von den insgesamt 84 Liberalen mußten also mindestens 69 für Heinemann stimmen. Aus der Sicht Scheels war daher nichts wichtiger als zu verhindern, daß die Union Schröder gegen Heinemann aufstellte. Wenn man davon ausging, daß der nationalkonservative FDP-Flügel den Christdemokraten wählte, dann konnte es am Ende nicht zum Sieg Heinemanns reichen.

Daß Schröder tatsächlich die entscheidenden Stimmen der FDP abnehmen konnte, wurde beim Wahlausgang am 5. März 1969 durch das äußerst knappe Ergebnis deutlich. Heinemann erhielt zunächst 514, Schröder 501 Stimmen. Beim zweiten Wahlgang verlor der SPD-Kandidat drei Stimmen, Schröder gewann sechs hinzu. Erst der dritte Gang brachte die Entscheidung, denkbar knapp mit 512 zu 506 Stimmen gewann Heinemann. Scheel vermutete, daß im ersten Wahlgang Schröder immerhin schon sechs Stimmen von den Liberalen erhalten hatte. Im zweiten Wahlgang waren es dann nach vorsichtiger Schätzung bereits bis zu zehn FDP-Wahlmänner, die den Unionskandidaten unterstützt hat$\operatorname{ten}^{30}$. Es klingt daher auch sehr unwahrscheinlich, daß Kiesinger die Argumentation Scheels tatsächlich für plausibel hielt und darin nicht den Versuch vermutete, ihn von einer Unterstützung Schröders abzubringen. Wenn der Kanzler aber der Überzeugung war, daß Schröder die größten Chancen besaß, dann bleibt die Frage, warum sich Kiesinger während des Selektionsprozesses in der Union schließlich für Weizsäcker einsetzte. Darauf gibt es nur eine Antwort: Kiesinger wünschte, daß der SPD-Kandidat die Bundespräsidentenwahl gewinnen möge!

Diese auf den ersten Blick wagemutige These stützt sich auf die Aussage Hecks, daß Kiesinger unter allen Umständen die Große Koalition erhalten wollte und daher glaubte, bei einem Sieg des SPD-Kandidaten ließe sich das leichter bewerkstelligen. Heck sagte in einem Gespräch im Jahre 1983 wörtlich: „Kiesinger wollte wie Wehner eine zweite Legislaturperiode der Großen Koalition. Das schien ihm mit Heinemann besser zu klappen." 31 Überspitzt formuliert, bedeutet das: Kiesinger setzte sich für den aussichtsloseren Kandidaten in der Union ein und hoffte im stillen, die Sozialdemokraten würden ihren nominierten Mann durchsetzen; um der Fortsetzung der Koalition willen war er bereit, das Bundespräsidentenamt der SPD zu „opfern“. Mit Heinemann, so könnte Kiesinger kalkuliert haben, wäre die SPD für die Enttäuschung entschädigt, die sie mit dem Scheitern des gemeinsamen Projektes erlitten hatte, Leber zum Nachfolger Lübkes zu wählen.

Man wird diese politische Absicht, die Kiesinger nie bestätigt hat und vermutlich auch nie zugegeben hätte, nur verstehen können, wenn man sich in seine Lage versetzt und dabei auf die Bedeutung seines Verhältnisses zu Wehner achtet. Vieles blieb zwischen beiden unausgesprochen. Beispielsweise haben Wehner und Kiesinger nie über ihre Pläne

29 Vgl. Baring, Machtwechsel, S. $223 \mathrm{ff}$.

30 Vgl. ebenda, S. 120.

${ }^{31}$ Heck, Gespräch mit Journalisten (Dreher), 6.12.1983, S. 1 f.; siehe auch Der Spiegel, 28.10.1968, S. 24. 
am Ende der Koalition gesprochen oder gar ausgemacht, sich für eine Neuauflage der Großen Koalition einzusetzen. Kiesinger hat von Wehner angenommen, dieser wolle die Fortsetzung - aber sicher war er dessen nie ${ }^{32}$. Beschämend mußte es auf den CDU-Vorsitzenden wirken, in der Frage der Bundespräsidentenwahl nicht mehr Herr seiner Partei zu sein - wie er Wehner offen eingestehen mußte. Es bedeutete eine Erniedrigung für ihn, vor dem sozialdemokratischen Parteiführer zugeben zu müssen, daß er die Zügel aus der Hand gegeben hatte. Auf die Rolle des Demütigen verstand sich der Kanzler im Gegensatz zu Wehner nicht. Er stellte die Dinge dar, wie er sie sah - dann wurde die Sache auch im privaten Gespräch nicht mehr erwähnt. Wehner akzeptierte das, beklagte sich aber, wie Ahlers dann Kiesinger mitteilte, im Kreise der anderen SPD-Führer über den Kanzler.

Dem CDU-Vorsitzenden lag also daran, in der Frage der Präsidentennachfolge seinen Koalitionspartner zu versöhnen. Auch wenn der Gedanke, einen gemeinsamen Kandidaten für das Amt aufzustellen, sich nicht mehr verwirklichen ließ, blieb doch die Möglichkeit, daß die SPD ihren Mann auch ohne die Hilfe der Union durchbekam. Die Annahme, daß sich die Wahl Heinemanns mit seinen Interessen vereinbaren ließ, wird noch von der Tatsache gestützt, daß er sich ausschließlich um die SPD bemühte und den Kontakt zur FDP-Spitze nach dem Urteil der Liberalen, aber auch dem seiner Berater geradezu sträflich vernachlässigte. Scheel betonte später, daß sich Kiesinger als Kanzler nie um die FDP gekümmert habe. Das war auch der Eindruck Hecks. Während der Großen Koalition kam es nur zu einem einzigen Gespräch zwischen den beiden Parteivorsitzenden, im Frühjahr 1969. Und es handelte sich um kein erfolgreiches Zusammentreffen: „Es war kein gutes Gespräch, die Atmosphäre war verkrampft. Kiesinger war anzumerken, daß er es nur aus Routine führte. “33 Dazu gehörte auch, daß Kiesinger noch zur selben Zeit gegenüber dem entsetzten Scheufelen von der Einführung des Mehrheitswahlrechts sprach. Scheufelen, der in Stuttgart die Verbindung zur FDP hielt, war über die Äußerung des Kanzlers so erbost, daß er verlangte: „Vergraulen Sie uns die FDP nicht! “34 Kiesinger nahm das übel auf, und bis nach der Bundestagswahl 1969 redeten beide kein Wort miteinander.

Kiesingers Eintreten für Weizsäcker und damit seine Entscheidung gegen Schröder mochte zusätzlich noch dadurch beeinflußt worden sein, daß mit Schröder, falls er gewählt würde, ein Gegner des Regierungsbündnisses von SPD und CDU/CSU in die Villa Hammerschmidt einziehen würde. Dem Kanzler behagte die Vorstellung nicht, daß das Wort seines einzigen wirklichen Widersachers als Bundespräsident ein besonderes $\mathrm{Ge}$ wicht in der Öffentlichkeit besitzen würde. Lübkes Abneigung gegen die FDP hatte der

32 Vgl. AdKASt, Kiesinger I - 226, E/IV.1, A 355, Kiesinger an Dichgans vom 9.1.1980, S. 4; dort vor allem die Bemerkung: „Wehner wäre wohl (!) zu einer Fortsetzung der Großen Koalition bereit gewesen."

${ }^{33}$ Heck, Gespräch mit Journalisten (Dreher), 6.12.1983, S. 3; „Ich bin hinterher noch mit in Scheels Wohnung gegangen und habe versucht, es aufzulockern." Baring (Machtwechsel, S. $71 \mathrm{ff}$.) setzt sich sehr ausführlich mit der Frage auseinander, warum die FDP 1969 mit der SPD eine Koalition gründete. Er arbeitet mehrere Gemeinsamkeiten beider Parteien heraus: erstens die Opposition gegen das Mehrheitswahlrecht; zweitens die innenpolitischen Reformbestrebungen und der geschickte Umgang mit der kritischen Jugend; drittens die neue Ost- und Deutschlandpolitik. Hinzu kamen die Spannungen in der Großen Koalition zwischen den großen Parteien, etwa in der Frage der Aufwertung der DM, die in Richtung einer sozialliberalen Koalition wirkten, sowie die Notwendigkeit der FDP, durch eine Zusammenarbeit mit der SPD den unabhängigen Charakter der Partei unter Beweis zu stellen.

${ }^{34}$ Scheufelen, Gespräch mit dem Verfasser, 27.11.1987. 
christlich-liberalen Regierung Erhard langfristig geschadet. Da Kiesinger die Fortsetzung der Großen Koalition anstrebte, wollte er vermeiden, daß Schröder mit den Mitteln die Große Koalition bekämpfen konnte, die ihm als Bundespräsident zur Verfügung standen.

Kiesinger liebte es, im Rückblick seine Motivation zu verschleiern - übrigens ähnlich wie sein Vorbild Bismarck in seinen Gedanken und Erinnerungen es bei ungleich bedeutenderen Themen tat ${ }^{35}$. Aber in dieser Frage ist leicht zu verstehen, warum Kiesinger seine wahren Ziele verborgen hielt. Als CDU-Vorsitzender konnte er natürlich nicht den Kandidaten der anderen Partei unterstützen. Wenn er sich daher zu diesem Thema äußerte - was selten geschah, dann scheinbar ganz unverfänglich. Dennoch erscheint seine Äußerung vom November 1968 auf die Frage eines Journalisten verräterisch, ob er beide, Schröder und Heinemann, für „präsidiabel“ halte. Darauf antwortete Kiesinger: „Ich halte beide für präsidiabel. Das heißt natürlich nicht, daß ich Herrn Heinemann Herrn Schröder vorziehen würde. " 36 Obwohl der Journalist nicht nach Präferenz fragte - Kiesingers Unterstützung des CDU-Kandidaten setzte er wohl voraus -, verstand der Kanzler die Frage vermutlich so. Seine Antwort erweckte den Eindruck, als ob er sich verteidige oder gar entschuldige. Indem er behauptete, er ziehe „natürlich“ Herrn Heinemann nicht Herrn Schröder vor, hatte er genau das damit schon angedeutet.

\section{Die geschwächte Position des Kanzlers in der eigenen Partei}

Aber Kiesinger schätzte die Position seines Kandidaten in der Union tatsächlich völlig falsch ein. Schon am 14. November 1968, einen Tag vor der Entscheidung im Wahlmännergremium der CDU/CSU, schien ein Sieg Weizsäckers ausgeschlossen. Wie bei der Kanzlerwahl im November 1966 besaß die CSU auch diesmal das entscheidende Votum. Sie legte sich auf Schröder fest. Vermutlich sahen die Bayern eine günstige Gelegenheit, Schröder auf ehrenvolle Weise aus der Parteipolitik zu drängen und damit eine künftige Rivalität zwischen Schröder und Strauß um das Amt des Bundeskanzlers auszuschließen. Kiesinger war von dieser Entwicklung überrascht worden. Anstatt jetzt mit aller Kraft die Wahl Weizsäckers durchzusetzen, entschloß er sich zu einem zweideutigen Kurs. Am Vorabend der Nominierung informierte er Schröder über sein Votum für Weizsäcker, gab aber gleichzeitig zu verstehen, daß er sich nicht sträuben werde, falls die Partei anders entscheide ${ }^{37}$.

Sein halbherziges, zögerliches Eintreten für Weizsäcker erwies sich als Fehler. Er hätte entweder energisch für seinen Favoriten in den eigenen Reihen werben oder gleich den noch amtierenden Verteidigungsminister unterstützen sollen. Hier zeigte sich eine Schwäche Kiesingers in aller Deutlichkeit: Er sah nicht die Notwendigkeit, die Partei auf die Unterstützung seines Kandidaten zu verpflichten. Nur durch entschiedenes Handeln hätte er seine Autorität und Führung sichern können, so aber verlor er an Ansehen. Dies erkannte Kiesinger zu spät. Als sich die Wahlmännerversammlung von CDU/CSU mit 65 Stimmen für Schröder entschieden hatte und nur zwanzig Stimmen auf Weizsäcker gefallen waren, versuchte Kiesinger den Eindruck zu vermeiden, als ob es überhaupt eine Kampfabstimmung zwischen zwei Kandidaten gegeben hatte. Vor dem unter Ausschluß der Öffentlichkeit tagenden Gremium gab er kurz nach der Wahl eine Ehrenerklärung

\footnotetext{
35 Vgl. bei Gall (Bismarck, S. 423 ff.) die Beschreibung des Hergangs um die Emser Depesche und den Kriegseintritt gegen Frankreich.

36 Stuttgarter Zeitung, 26.11.1968.

37 Vgl. Süddeutsche Zeitung, 16.11.1968.
} 
für Schröder ab. Er forderte dazu auf, daß sich die Weizsäcker-Gruppe hinter Schröder stellen solle, um die Einmütigkeit der Union zu demonstrieren. So geschah es. Danach trat Kiesinger vor die Presse und versuchte, das Ergebnis als „einmütige Empfehlung“ der Union hinzustellen. Er weigerte sich, das Zahlenverhältnis der Abstimmung bekanntzugeben. Aber einzelne Mitglieder des Gremiums ließen die Journalisten darüber nicht im unklaren ${ }^{38}$.

Der Sieg Schröders wurde dann - zu Recht - als Niederlage Kiesingers gewertet. Bereits vor der Wahl hatte Dreher geschrieben, Kiesinger habe sich in Sachen Präsidentenwahl in eine fatale Zwickmühle manövriert: „Wird der Kandidat, Minister Schröder, gewählt, muß sich der Bundeskanzler den Vorwurf seiner Partei gefallen lassen, er habe zunächst offenbar aufs falsche Pferd gesetzt; falls Schröder unterliegt, wird es dagegen heißen, Kiesinger sei ihm zu spät entgegengetreten." ${ }^{39}$ Kiesinger selbst hat ein Fehlverhalten später eingeräumt. Er hätte sich stärker für die Kandidatur von Weizsäcker einsetzen müssen. "Wenn ich mir selbst heute einen Vorwurf mache, dann allenfalls den, daß ich damals der Fraktion nicht mit meinem Rücktritt drohte“, meinte er ${ }^{40}$. Ähnlich schätzte das auch der Koalitionspartner ein. Schonungslos erklärte Ahlers in einem Brief an Kiesinger vom 30. Dezember 1968, daß die Nominierung Schröders eine ernste Niederlage für den CDU-Vorsitzenden bedeute und Auswirkungen auf die Fortsetzung der Großen Koalition haben werde. In vertraulichem Ton, den Ahlers als mittlerweile engster Vermittler zwischen Kanzler und der SPD anschlug, schrieb der Pressesprecher: „Wir können nicht an der Tatsache vorbeisehen, daß die Autorität des Bundeskanzlers in der jüngsten Zeit eine gewisse Schwächung erfahren hat, vor allem in der CDU/CSU-Bundestagsfraktion. Die labilen und die diffizilen parlamentarischen Verhältnisse, die oftmals genausowenig symptomatisch für die wahre Stimmung in der Bevölkerung sind, wie das, was die sogenannte veröffentlichte Meinung schreibt, bringen es mit sich, daß jeder politische Mißerfolg eines Führenden, insbesondere des Kanzlers, unterirdische Wirkungen zeitigt, die erst langsam sichtbar werden." Als ein solches negatives Ereignis für den Kanzler müsse rückblickend die Nominierung des Bundesverteidigungsministers zum Präsidentschaftskandidaten gesehen werden. Kaum jemand im Bundestag habe das Engagement für Weizsäcker verstanden und er, Kiesinger, habe sich deshalb in den Augen der meisten Abgeordneten eine „unnötige Niederlage“ eingehandelt. Außerdem glaube er selbst auch, daß bestimmte Vorgänge auf dem Parteitag hiermit bereits in Zusammenhang stünden. Angesichts dieser Stimmung sei es dann sicher auch falsch gewesen, von der Fraktion eine „Ehrenerklärung“ zu verlangen, deren Sinn die Abgeordneten auch nicht begriffen hätten.

Ungeschminkt führte Ahlers in dem Schreiben seine Kritik fort. Ein zweiter Punkt der Sorge betreffe die unerledigte Tagesordnung, krasser ausgedrückt, die „sogenannte Entscheidungsschwäche des Bundeskanzlers"41. Es liege auf der Hand, daß die angedeuteten Schwierigkeiten am schnellsten behoben werden könnten, wenn die Bundesregierung unter Kiesingers Führung in den ersten drei Monaten des neuen Jahres zu den noch anstehenden großen Streitfragen eine klare Position beziehen bzw. entsprechende Beschlüsse fassen würde.

Der Regierungssprecher brauchte den Kanzler nicht darauf aufmerksam zu machen, daß seine Niederlage in der Frage des Unionskandidaten für das Amt des Bundespräsi-

38 Vgl. Meyers, Gespräch mit dem Verfasser, 25.10.1989; siehe auch Der Spiegel, 18.11.1968, S. 28.

39 Süddeutsche Zeitung, 20.11.1968.

40 AdKASt, Kiesinger I - 226, E/IV.1, A 355, Kiesinger an Dichgans vom 9.1.1980, S. 6.

41 AdKASt, Kiesinger I - 226, D/IV.6, A 001, Ahlers an Kiesinger vom 30.12.1968. 
denten auch Kiesingers Ziel gefährden konnte, die Große Koalition über 1969 hinaus fortzusetzen. Auf dem Berliner CDU-Parteitag im November 1968 hatte er deutlich zu spüren bekommen, daß die Partei sich nicht länger uneingeschränkt in die Koalitionsdisziplin mit den Sozialdemokraten einspannen lassen wollte.

\section{Die Tendenz in der Union gegen eine Fortsetzung der Großen Koalition- Kiesingers Spielraum wird kleiner}

Das bestehende Bündnis verlor in der größten Partei immer stärker an Unterstützung. Auf dem Parteitag der CDU vom 4. bis 7. November 1968 in der Berliner Kongreßhalle waren die Mitglieder auf Kampf gegen die Sozialdemokraten gestimmt. Sie zischten daher ihren Vorsitzenden aus, als er in seiner Einleitungsrede erklärte, daß „das Wahlergebnis uns fortgesetzt zu einer Verlängerung der Großen Koalition zwingen könnte“. Kiesinger wartete an dieser Stelle die Reaktion des Publikums ab, wie das Protokoll zeigt, und ging dann auf den Unmut ein: „Das kann so sein. Das könnte 1969 beginnen, könnte sich 1973 fortsetzen, (Zuruf: Schrecklich!) und, meine Damen und Herren, mit 1973 müßte die absolute Grenze erreicht sein. (Zischen) - Ich habe gesagt: die absolute Grenze. Oder wollen Sie bis 1977 weitermachen? (Heiterkeit). “42

Die Stelle ist typisch für Kiesingers Unsicherheit in der Parteipolitik. Anstatt von vornherein deutlich für die Fortsetzung der Großen Koalition zu plädieren, tastete er sich vor dem versammelten CDU-Parteitag vorsichtig an das Thema heran, um dann seine Aussage abzuschwächen, als er den Widerstand spürte. Die Erklärung erwies sich als ungeschickt, die Union könne zu einer Fortsetzung der Koalition "gezwungen“ werden. Damit provozierte er negative Reaktionen. Konnte man denn erwarten, daß sich die größte Partei der Bundesrepublik freiwillig zu einer Koalition zwingen ließe? Seiner Geistesgegenwart verdankte er es, daß er einen drohenden, noch deutlicheren Ausdruck des Unmuts seiner Zuhörer über das bestehende Regierungsbündnis an dieser Stelle durch eine humorvolle Bemerkung verhinderte.

Während Kiesinger einen Schwächeanfall hatte, an Grippe erkrankte und die folgenden Parteitagsdiskussionen von seinem Bett im Dahlemer Hause des Bundesbeauftragten Carl Krautwig am Radio verfolgte, formierte sich unter den prominenteren Führern der Partei eine Opposition gegen die Entscheidung, sich auf die Große Koalition über 1969 hinaus festzulegen. Der Vertriebenenminister und Vorsitzende der CDU in Schleswig-Holstein Hassel verlangte, daß der Koalitionsentscheid erst nach der Wahl getroffen werde. Barzel forderte: „Schluß mit den Koalitionszwängen!“ Auch der rheinlandpfälzische Ministerpräsident Kohl meinte: „Wir müssen in der Schlußerklärung deutlich machen, daß wir ungebunden in die nächste Wahl gehen, mit dem klaren Ziel, eine regierungsfähige Mehrheit zu gewinnen." 43

Je näher der Wahltermin des Herbstes 1969 rückte, desto geringer war das Verständnis, das die Union dem Koalitionspartner entgegenbrachte. Mitte Juli 1968 schrieb Hassel als Landesparteivorsitzender an seine Kollegen: „Ich darf auch Sie herzlich bitten, die momentane günstige Stimmung gegenüber der CDU/CSU in den folgenden

42 Kiesinger, Reden und Interviews 1968, Rede vom 4.11.1968, S. 361.

43 16. Bundesparteitag der Christlich Demokratischen Union Deutschlands, S. 121; Kohl brachte den Antrag ein, man möge in die Schlußerklärung aufnehmen, daß „wir ungebunden und frei nach allen Seiten, und zwar nicht nur verbal, sondern tatsächlich frei in die nächste Bundestagswahl gehen mit dem klaren Ziel, diese Wahl mit einer regierungsfähigen Mehrheit für die CDU/ CSU zu gewinnen“; siehe Barzels Zustimmung, ebenda, S. 147; vgl. Der Spiegel, 11.11.1968, S. 27. 
Monaten zu nutzen. “44 Der Ausgang der Bundestagswahlen 1969 werde ganz wesentlich auch davon abhängen, ob man die Stammwähler in diesem Bereich halten und neue hinzugewinnen könne. Die Wahlen in Baden-Württemberg Ende April hätten gezeigt, daß die SPD unter den Vertriebenen und Flüchtlingen überwiegend zugunsten der NPD verloren habe. Diese Protestwähler könne die CDU/CSU herüberziehen, wenn man sich um diese Personenkreise kümmere. Immerhin handele es sich um mehr als zehn Millionen Stimmberechtigte.

Das neue Selbstbewußtsein der Partei und seine geschwächte Position nach der Niederlage Weizsäckers zwangen Kiesinger, sich jetzt noch vorsichtiger zu bewegen. Der Spielraum, insbesondere in der Deutschland- und Ostpolitik, wurde jetzt noch kleiner. Denn das latent vorhandene Mißtrauen bei der Union gegen eine vermutete sozialdemokratische Bereitschaft, über die Regierungslinie deutlich hinauszugehen, trat offen zu Tage. Kiesinger hat später im Zusammenhang mit dem Berliner Parteitag auf dieses Dilemma hingewiesen: "Je mehr sich die Wahlperiode des 5. Bundestages ihrem Ende zuneigte, desto geringer wurde bei beiden Koalitionspartnern die Bereitschaft, die Koalition fortzusetzen, auch wenn beide Seiten bemüht waren, nicht vorzeitig die ,Ehe auf Zeit' zu kündigen", heißt es in einer Erklärung aus dem Jahre 198045. Es sei eben von Jahr zu Jahr schwerer geworden, auf die Dauer ein gemeinsames politisches Programm durchzuführen. Für Kiesinger bedeutete dies in der Ostpolitik jetzt: konsequente Abkehr von den Plänen Brandts und Bahrs bei gleichzeitiger Aufrechterhaltung der eigenen ostpolitischen Zielsetzung.

\section{Der „Fall Babr"}

Kaum war der Parteitag überstanden und auch die Frage der Bundespräsidentennachfolge in der Union geklärt, als Ulbricht die SPD erneut in eine unangenehme Lage brachte und damit die Koalition belastete. Auf dem fünften Parteitag der Polnischen Vereinigten Arbeiterpartei (PVAP) behauptete er am 12. November 1968: „Die sozialdemokratische Führung hatte unserer Parteiführung zugesagt, auf dem Wege der Verständigung über Teilfragen die Anerkennung der Deutschen Demokratischen Republik durch die westdeutsche Bundesrepublik herbeizuführen. " 46 Sie habe jedoch ihr Wort gebrochen. Obwohl man ihr zum Beispiel mit Passierscheinen entgegengekommen sei, habe sie den großen Verrat, den Übergang auf die Politik der CDU, der herrschenden Partei des westdeutschen Monopolkapitals, vorbereitet.

Die Christdemokraten schenkten Ulbrichts Worten Glauben. „Wenn das eine der Figuren in Ost-Berlin gesagt hätte“, zitierte die Süddeutsche Zeitung die Aussage eines Kabinettsmitgliedes, „könnte man denken, es handle sich um Agitprop-Produkte; aber wenn Ulbricht das sagt, hat er was im Ärmel." 47 In der CDU/CSU wurde schon lange über die angeblich dubiose Politik Brandts und seines Beraters Bahr gesprochen, besonders im Berliner Landesverband. Dort vermutete man, daß sich der frühere Regierende Bürgermeister inzwischen der Kontrolle der Öffentlichkeit, vielleicht sogar der des Kanzlers, entzogen habe. Im August 1968 teilte Heck Kiesinger in einem längeren Bericht die Einschätzung der Berliner Parteiführung mit: „Man ist überzeugt, daß die Sozialdemo-

\footnotetext{
${ }^{44}$ AdKASt, Kiesinger I - 226, D/IV.6, A 004, Hassel an die Landesvorsitzenden der CDU vom 17.7.1968, S. $1 \mathrm{f}$.

45 AdKASt, Kiesinger I - 226, E/IV.1, A 355, Kiesinger an Dichgans vom 9.1.1980, S. 4.

46 DzD, 1968, S. 1472.

47 Süddeutsche Zeitung, 27.11.1968.
} 
kraten, insonderheit der Außenminister und sein Berater Bahr bereit sind, gegenüber der Sowjetunion und gegenüber dem Zonenregime im allgemeinen, aber insbesondere, was die Präsenz der Bundesrepublik in Berlin betrifft, eine Konzession nach der anderen zu machen, weil sie sich der Hoffnung bzw. der Täuschung hingäben, auf diese Weise doch noch mit den Russen bzw. mit den Herren aus Pankow ins Gespräch zu kommen. [...] Herr Brandt habe über ein Jahr um den Austausch von Gewaltverzichtserklärungen weiterverhandelt, obwohl die Sowjetunion der Bundesrepublik in einer Note schriftlich zur Kenntnis gebracht habe, daß eine solche Gewaltverzichtserklärung natürlich die Rechte und Pflichten der Sowjetunion, die sich aus Art. 53 bzw. 107 der UN-Charta ergäben, nicht berühren würde. Daß der Außenminister diese Tatsache der Regierung, dem Parlament und der Öffentlichkeit verheimlicht hat, wird dahingehend ausgedeutet, daß er seine eigene Politik mache. Ich bin gefragt worden, ob der Bundeskanzler darüber orientiert sei. Ich habe diese Frage nicht beantworten können."

Natürlich war der Kanzler unterrichtet und billigte ausdrücklich die Verhandlungen um den Gewaltverzicht. Außerdem unterlief den Berliner CDU-Mitgliedern ein zeitlicher Fehler: Die Verhandlungen liefen bereits seit Beginn der Großen Koalition, also länger als eineinhalb Jahre. Zudem waren im November 1967 nur neun Monate vergangen, seitdem die Sowjetunion erstmals auf die Feindstaaten-Klausel Bezug genommen hatte. Der Vorwurf trifft also nicht zu, Brandt habe „über ein Jahr" verhandelt, obwohl er von dem Vorbehalt der UN-Charta-Klauseln gewußt habe. Aber an dieser Stelle geht es nur darum, zu zeigen, wie stark in der Union das Mißtrauen gegen Brandt gewachsen war. Dazu zählten auch die angeblich vielfältigen Kontakte, die die Sozialdemokraten mit den Kommunisten unterhielten. Von der Existenz solcher Gespräche waren die Christdemokraten überzeugt ${ }^{48}$. In Berlin sei mit Sicherheit bekannt, richtete Heck aus, daß seit etwa 14 Tagen Kontakt zwischen einem Abgesandten von Herrn Stoph und Senator König $^{49}$ bestehe mit etwa folgendem Hintergrund: Stoph habe erklären lassen, man warte nun beim Thema Postforderung allenfalls noch bis Januar zu, aber dann sei man mit der Geduld am Ende. Man sei empört darüber gewesen, daß die geforderten 120 Millionen DM nicht bezahlt worden seien, und halte die Stellungnahme des Bundespostministers für völlig unzureichend. Allenfalls könne man sich vorstellen, daß für die vergangenen zwei Jahre ein Betrag von mindestens 35 Millionen gezahlt würde ${ }^{50}$. Er, Heck, habe auf einem zweiten Weg erfahren können, daß diese Gespräche zwischen einem Abgesandten von Stoph und Senator König in der Tat stattgefunden hätten. Außerdem sei ihm mitgeteilt worden, daß Staatssekretär [Klaus Dieter] Arndt, der in Berlin seinen Wohnsitz habe, fortlaufend mit Abgesandten aus Pankow konferiere.

Ulbrichts Bemerkung, die SPD habe mit der SED die Anerkennung der DDR in Etappen beschlossen, konnte also nicht einfach als Propaganda abgewiesen werden. Auch die Erklärung, die Wehner vorbrachte, klang wenig überzeugend: Ulbricht wolle mit seinen Behauptungen „Spuren verwischen“, hieß es in einer Erklärung vom 12. No-

48 Vgl. Der Spiegel, 29. April 1991, S. 17. Wie sich herausgestellt hat, gab es auch enge Kontakte zwischen Politikern aus der Berliner FDP und dem Ministerium für Staatssicherheit. Der frühere Bundestagsabgeordnete William Borm, ein vehementer Verfechter der Ostpolitik, soll nach Erkenntnissen des Justizministeriums sogar „Zuträger und Einflußagent der DDR" gewesen sein.

${ }^{49}$ Karl König (1910-1979) bekleidete das Amt des Berliner Wirtschaftssenators von 1965 bis 1975.

50 AdKASt, Kiesinger I - 226, D/IV.6, A 004, Heck an Kiesinger vom 18.8.1968, S. 2 f.; Bundespostminister Dollinger hatte in einem Brief an seinen Kollegen einen Ausgleich allein für das Jahr 1967 von ca. 16 Mio. DM angeboten; vgl. TzD, Dollinger an den Ost-Berliner Postminister Schulze vom 8.8.1968, S. $38 \mathrm{ff}$. 
vember ${ }^{51}$. Die Christdemokraten trauten dem Planungschef im Auswärtigen Amt, dem Sonderbotschafter Bahr, heimliche Kontakte zur SED und Absprachen durchweg zu. Der Abgeordnete Werner Marx ließ Kiesinger wissen, er verfüge „seit etwa acht Wochen" über Informationen, aus denen hervorgehe, daß vor und nach dem Auftreten von Bahr vor der Evangelischen Akademie Tutzing 1963 "Geheimgespräche mit der SEDFührung" stattgefunden hätten. Offensichtlich sei sogar die Formel „Wandel durch Annäherung" eine auf solche Weise vorbereitete Formulierung gewesen. Diese Information sei offensichtlich auch Journalisten bekannt und werde gegenwärtig recherchier ${ }^{52}$. Tatsächlich behauptete der Bayern-Kurier, das Hausblatt der CSU, wenige Tage später, Geheimdienstmaterial aus dem Westen gebe Anlaß zu Fragen, ob und wann Bahr im Zentralkomitee der SED in Ost-Berlin Gespräche geführt habe. Am 24. November berichtete die Welt am Sonntag, der Bundesnachrichtendienst verfüge über ein Tonband, auf dem ein Gespräch Bahrs mit Mitgliedern des Zentralkomitees der SED aufgezeichnet worden sei.

Aber die Meldungen bestätigten sich nicht. Es existierte kein Tonband, zumindest nicht bei den westlichen Geheimdiensten. Der BND hatte lediglich einen, wie Brandt in der SPD-Fraktionssitzung vom 25. November 1968 fand, „dubiosen“ Bericht im Auftrag des Bundeskanzleramtes zusammengestellt. Auch die Behauptung, Bahr sei mit Mitgliedern des ZK zusammengetroffen, stimmte angeblich nicht mit dem tatsächlichen Sachverhalt überein. Bahr versicherte Brandt in einer Unterredung, daß es zwar eine Begegnung mit Ulbricht, mit Grotewohl und mit dem späteren ersten DDR-Staatspräsidenten Wilhelm Pieck gegeben habe. Aber das sei 1945 bzw. 1946 gewesen. Damals habe er als Journalist für die Nene Zeitung gearbeitet. Bahr versicherte: Mit einem ZK-Mitglied der SED habe er seither nicht mehr gesprochen ${ }^{53}$. Vor diesem Hintergrund erstattete der SPD-Vorsitzende seiner Fraktion Bericht: „Er habe den Bundeskanzler gebeten, den Zeitungsmeldungen nachzugehen. Nach seinem derzeitigen Erkenntnisstand auf Grund der Informationen von drei Geheimdiensten existiere kein solches Tonband, da Bahr seines Wissens nicht in Ost-Berlin gewesen sei. Er könne jedoch nicht ausschließen, daß es im Osten solches Material gebe und halte es deshalb für besonders klärungsbedürftig, wer dem Bayern-Kurier die entsprechenden Informationen gegeben habe. " ${ }^{54}$

Interessanterweise äußerte Brandt hier einen Vorbehalt. Wenn der „Osten“ Material besitzen konnte, dann sprach doch etwas dafür, daß Gespräche stattgefunden hatten. Diese Möglichkeit leugnete Bahr übrigens nicht. Er wandte sich nur gegen die Behauptung, daß er mit ZK-Mitgliedern gesprochen habe und daß er jemals "drüben gewesen“ sei. Bahr fügte aber gegenüber der Süddeutschen Zeitung hinzu: SED-Funktionäre kämen gerne nach West-Berlin, „sie drängen sogar bis an den Rhein vor" 55 . Obwohl sich die Behauptungen der konservativen Blätter nicht beweisen ließen, blieb an der Person Bahrs das Image des Geheimnisvollen, aber auch Unheimlichen haften. Dazu trug Bahr übrigens selbst bei, indem er weiterhin Kontakte vor allem mit sowjetischen Diplomaten

51 DzD, 1968, S. 1474.

52 AdKASt, Kiesinger I - 226, D/IV.6, A 002, Marx an Barzel vom 15.11.1968.

53 Vgl. Der Spiegel, 2.12.1968, S. 32.

$54 \mathrm{AdsD}$, Protokolle interner Sitzungen der Führungsgremien, SPD-Fraktionssitzung vom 25.11.1968, S. 1 .

55 Süddeutsche Zeitung, 27.11.1968; vgl. Berg, Vorbeugende Unterwerfung, S. 169, sowie Bahr, Gespräch mit dem Verfasser, 4.7.1988. Tatsächlich empfing Bahr in den frühen sechziger Jahren in Berlin Besuch von Berg, dem Gesandten Stophs. Aber es handelte sich hierbei um den einzigen Kontakt zu SED-Funktionären, beteuerte Bahr. 
pflegte. Häufig beobachteten Journalisten, wie Botschaftsangehörige und Kollegen von sowjetischen Medien im Auswärtigen Amt empfangen wurden. Außer Gesprächspartnern in der DDR, so schrieb Dreher beispielsweise, habe Bahr auch seine „Hausrussen" 56 . Dem Kanzleramt war diese Tatsache allerdings verborgen geblieben. Im Januar 1969 wurde Kiesinger durch ein Telegramm des Bonner Botschafters in Moskau auf ein Gespräch aufmerksam, von dem nicht einmal der Staatssekretär des Auswärtigen Amtes, Georg Ferdinand Duckwitz, etwas wußte. Botschafter Helmut Allardt berichtet Kiesinger am 5. Januar 1969, daß Semjonow ihn auf eine deutsch-sowjetische Unterredung in der sowjetischen Botschaft in Rolandseck angesprochen habe ${ }^{57}$.

Wer da mit wem über was eine Unterredung geführt hatte, muß hier offenbleiben. Sicher ist, daß das Treffen im Zusammenhang mit dem "Fall Bahr" stand. Denn als Carstens seine Untersuchung der Verdächtigungen abschloß und am 3. Februar 1969 eine Pressenotiz herausgab - mit der Aussage, die Vorwürfe über Ostkontakte Bahrs seien nunmehr geklärt und ausgeräumt -, lautete der letzte Satz: „Der Bundeskanzler soll künftig über alle wichtigen Kontakte des Auswärtigen Amtes mit osteuropäischen Ländern informiert werden." Damit war für Kiesinger die Sache erledigt, allerdings nicht für Brandt. Erneut kritisierte dieser die Rolle des BND, der - wie schon bei den Gesprächen der Sozialdemokraten mit den italienischen Kommunisten - ausschließlich das Kanzleramt informiert und dessen Dossier offenbar als Quelle der Anschuldigungen durch die Presse gedient hatte. Brandt schrieb am 4. Februar 1969, an einer nicht auskurierten Rippenfellentzündung leidend, $z w a r$ in versöhnlichem aber bestimmtem Ton an Kiesinger: „Ich weiß, daß Sie in diesen Wochen viel Sorgen gehabt haben; leider hätte ich Ihnen davon auch dann nur wenig abnehmen können, wenn ich in Bonn gewesen wäre. Es wird sehr darauf ankommen, daß wir uns die unbestreitbaren Erfolge der Regierungsarbeit nicht vermiesen lassen und daß wir in den nächsten Monaten noch große Anstrengungen machen, um die sachliche Bilanz abzurunden. Es ist unvermeidlich, daß sich Erscheinungen des Vorwahlkampfes bemerkbar machen werden. Ich werde in meiner Partei weiterhin dafür eintreten, daß eine unnötige und vorzeitige Belastung der sachlichen Arbeit vermieden wird. “58

Dann ging Brandt zum heiklen Punkt über. Staatssekretär Carstens habe ihm den Bericht gebracht, den er am 15. Dezember über die Quellen der gegen Bahr gerichteten Vorwürfe erhalten hatte. Am Vortag sei dazu eine Pressemitteilung herausgegeben worden. Er gehe nun davon aus, daß geklärt werde, „wie BND-Berichte in die Hände Unbefugter" geraten konnten. Und Brandt fuhr fort: „Davon abgesehen ist es mir unerklärlich, wie eine - übrigens dubiose - BND-Aufzeichnung zum Zwecke eines Vortrags im Bundeskanzleramt gefertigt werden konnte und vermutlich angefordert worden war, ohne daß mir davon Kenntnis gegeben wurde. Wenn jetzt noch von interessierter Seite eine bestimmte Sprechregelung versucht wird (FAZ vom heutigen Tag: ,Kiesinger unzufrieden über Bahr'), werde ich nicht darum herumkommen, meinerseits darzulegen oder darlegen zu lassen, womit ich in diesem Zusammenhang unzufrieden bin. ${ }^{\text {59 }}$ Brandt

56 Süddeutsche Zeitung, 27.11.1968; Bahr (Gespräch mit dem Verfasser, 4.7.1988) erklärt, mit sowjetischen Journalisten seien Treffen "gang und gäbe" gewesen.

57 Vgl. AdKASt, Kiesinger I - 226, D/IV.6, A 001, Kiesinger an Brandt vom 14.1.1969; dort wird auf das Fernschreiben Allardts, Nr. 26 vom 5.1.1969, Bezug genommen.

58 AdKASt, Kiesinger I - 226, D/IV.6, A 001, Brandt an Kiesinger vom 4.2.1969.

59 Ebenda, S. 2 f.; vgl. den erwähnten Artikel der Frankfurter Allgemeinen Zeitung, 4.2.1969. Dort wurde notiert: „Diese letzte Feststellung [, daß der Bundeskanzler laufend informiert werden müsse,] besagt, wie in Bonn erklärt wird, daß der Bundeskanzler zweifellos unzufrieden darüber war, daß er bisher über Bahrs Kontakte nicht unterrichtet gewesen war." 
drohte also damit, öffentlich die Vermutung anzustellen, der Bundesnachrichtendienst observiere im Auftrag der Unionsminister oder gar des Bundeskanzlers den Koalitionspartner. Das Ende der Koalition deutete sich im Frühjahr 1969 schon an, nicht nur mit solchen Drohungen und Unmutsäußerungen der Spitzenrepräsentanten beider Parteien.

\section{Die SPD füblt sich im Stich gelassen}

Während sich die Union stärker gegenüber der SPD zu profilieren suchte, fühlten sich die Sozialdemokraten vom Koalitionspartner im Stich gelassen. Ahlers hatte dem Kanzler schon im Juni 1968 berichtet, daß bei den SPD-Abgeordneten nach der Verabschiedung der Notstandsgesetze Ratlosigkeit herrsche. Sie hätten das Gefühl, daß sie jetzt von der CDU/CSU nicht länger benötigt würden. Die Parlamentarier hofften darauf, der Kanzler werde ein Signal setzen, damit noch andere, gemeinsame Projekte durchgeführt werden könnten. Es werde oft etwa der Wunsch geäußert, er möge seinen Einfluß geltend machen, um einen Koalitionskompromiß in der Verkehrsplanung, beim sogenannten Leber-Plan, zu finden und durchzusetzen ${ }^{60}$.

Auch an der Spitze beider Parteien herrschte schon lange Ratlosigkeit. Nach den anstrengenden Frühsommermonaten 1968 schienen die gemeinsamen Kräfte zunächst aufgebraucht. Die beiden Fraktionsführer Barzel und Schmidt hatten mit Engagement und Zähigkeit gemeinsam das Stabilitätsgesetz zur Förderung des Wachstums der Wirtschaft ${ }^{61}$ und die Notstandsgesetze im Bundestag durchgebracht. Danach, im Juni 1968, fühlten sie sich eines gemeinsamen Ziels beraubt und waren darüber verärgert, daß die Regierung offenbar keine neuen Aufgaben anzupacken beabsichtigte, auch den Kontakt zu ihnen, immerhin den parlamentarischen Führern, offensichtlich vernachlässigte. Barzel und Schmidt seien unmutig darüber, so Ahlers, daß sie über die Absichten der Bundesregierung nicht genügend unterrichtet würden und außerdem wichtige Informationen nicht erhielten, die sie für ihre Arbeit und ihre eigene Urteilsbildung brauchten. Der Höhepunkt des Unmuts habe sich aber ergeben, als die beiden Herren von dem Besuch des Außenministers bei Botschafter Abrassimow erfuhren ${ }^{62}$.

Irritationen und Mißverständnisse nahmen auch im Kabinett mehr und mehr zu. Längst unterhielt sich Kiesinger nicht mehr mit Brandt, unterrichteten sich die Parteivorsitzenden nicht mehr über ihre Reden im voraus, wie es Brandt etwa noch vor dem Parteitag in Nürnberg getan hatte. Die Ostpolitik war durch die sowjetische Invasion in Prag festgefahren. Kiesinger verhinderte jeden weiteren Schritt auf die Sowjetunion zu mit dem Hinweis, daß nach der Intervention die deutsche Seite keine Konzessionen machen dürfe. Brandt fühlte sich häufig durch Kiesinger persönlich angegriffen. Ahlers wirkte mehr und mehr als Persönlichkeit des Ausgleichs. So mußte er beispielsweise die Verärgerung des Außenministers ausräumen, als der Kanzler im Oktober 1968 in einer Regierungserklärung zur Stagnation in der Frage des britischen EG-Beitritts scheinbar kritisierend äußerte, man habe sich zuviel und zu vieles auf einmal vorgenommen. Verschiedene Vorhaben seien miteinander verkettet worden: die Beitrittsfrage, die innere Entwicklung des Gemeinsamen Marktes, das Problem der Fusion der Gemeinschaften, selbst die Zusammenarbeit auf Gebieten, die mit dem Markt gar nichts zu tun hätten ${ }^{63}$. Brandt bezog diese

60 Vgl. AdKASt, Kiesinger I - 226, D/IV.6, A 001, Ahlers an Kiesinger vom 20.6.1968.

61 Vgl. Baring, Machtwechsel, S. 136; es sei die größte Leistung der Großen Koalition, sagte Wehner im Juni 1969.

62 Vgl. AdKASt, Kiesinger I - 226, D/IV.6, A 001, Ahlers an Kiesinger vom 20.6.1968.

${ }^{63}$ Vgl. VdDB, 5. Wahlperiode, 188. Sitzung vom 16.10.1968, S. 10163. 
Kritik auf sich und verstand die Äußerung als Rückzug aus der gemeinsam vereinbarten Unterstützung des englischen Beitrittswunsches. Nach eigener Schilderung glaubte allerdings Ahlers, Brandt beruhigt zu haben. Es sei ihm gelungen, in einem Gespräch mit Brandt die Verärgerung zu beseitigen, die sich wegen der Europa-Passage in Kiesingers Regierungserklärung ergeben hätte. Er habe Brandt klargemacht, daß sich die Bemerkung nicht auf ihn, sondern in erster Linie auf bestimmte Abgeordnete aller drei Bundestagsparteien bezogen hätte. Nach seiner Kenntnis der Dinge zögen Kiesinger und Brandt in dieser europäischen Frage an einem Strang ${ }^{64}$.

Ein anderes Symptom der Krise war die wachsende Unzulänglichkeit des Kreßbronner Kreises. Der Erfolg der Runde hatte auf der Tatsache beruht, daß sich hier nur die Spitzen der beiden Parteien trafen, um sich über das künftige Vorgehen zu verständigen. Durch die kleine Anzahl der Mitglieder arbeitete der Kreis effektiver als jedes andere Gremium der Koalition. Ursprünglich waren neben Kiesinger und Wehner nur die Partei- und Fraktionsvorsitzenden Brandt, Strauß, Barzel und Schmidt sowie der Generalsekretär der CDU, Heck, zugelassen. Allmählich wuchs indessen der Kreis. Nach und nach wurden die Staatssekretäre des Bundeskanzleramtes und einzelner Ministerien hinzugezogen. Im Laufe des Jahres 1968 gesellte sich auch noch Bundestagspräsident Gerstenmaier hinzu. Da die schnelle und zuverlässige, weil diskrete Absprache dadurch immer weniger gewährleistet war, verlor der Kreis an Wirkung. Schmidt machte seinem Unmut über diese Entwicklung im Dezember 1968 Luft: „Er verbraucht nicht nur zuviel Zeit, er tendiert auch mehr und mehr dazu, ein unverbindlicher Kabinettsausschuß zu werden. Ich kann die stets wechselnde Besetzung nicht vorteilhaft finden, ebensowenig die nicht verabredete Hinzuziehung des Bundestagspräsidenten. Ich ärgere mich darüber, daß das Presseamt ohne meine Zustimmung die Tagesordnung bekannt gibt und noch mehr ärgere ich mich über das ständig wachsende Maß an Bekanntgabe angeblicher Ergebnisse und an Indiskretionen aus dem Kreßbronner Kreis, die zum Teil noch dazu verfälscht gepflanzt werden. " 65

Schmidt schlug vor, der Kreßbronner Kreis solle auf seine ursprüngliche, sehr knappe Besetzung zurückgeführt werden, damit die Diskretion gewahrt bleibe; die Anwesenheit mehrerer Staatssekretäre und eines ehemaligen Bundesministers erscheine ihm nicht nützlich. Der Kreis sei inzwischen so groß geworden, daß ein freimütiger persönlicher Gedankenaustausch derjenigen, die nun einmal nach innen und nach außen die Hauptverantwortung trügen, erheblich beeinträchtigt sei. Die Folge dieser Kritik war allerdings nicht eine Reduzierung der Teilnehmerzahl. Vielmehr ließ Kiesinger das Treffen in den letzten Monaten der Koalition gar nicht mehr ansetzen. Anfang Mai 1969 war es wiederum der Fraktionsvorsitzende der SPD, der nunmehr anmahnte, daß „es überhaupt keine Zusammenkünfte mehr im ,Kreßbronner Kreis' gäbe“"66.

\footnotetext{
64 Vgl. AdKASt, Kiesinger I - 226, D/IV.6, A 001, Ahlers an Kiesinger vom 30.10.1968, S. 2.

${ }^{65}$ AdKASt, Kiesinger I - 226, D/IV.6, A 007, Schmidt an Kiesinger vom 20.12.1968, S. 2 f.

66 AdKASt, Kiesinger I - 226, D/IV.6, A 007, Schmidt an Kiesinger vom 6.5.1969.
} 


\section{Der Anfang vom Ende:}

\section{Kiesinger verläßt die Grundlage des Bündnisses mit Wehner - Die Chance des Durchbruchs in der Ostpolitik im Frühjahr 1969}

Im Frühjahr 1969 befand sich Kiesinger gegenüber seiner eigenen Fraktion in der Defensive. Diese Entwicklung war, wie beschrieben, zum Teil von der SPD verschuldet worden. Die KPI-Kontakte der Sozialdemokraten drängten Kiesinger aus seiner unabhängigen Position zwischen den Fraktionen auf die Linie der Unionsfraktion. Das zögerliche Auftreten in der Frage der Lübke-Nachfolge trug zu seiner Schwächung bei. Hatte Kiesinger schon vorher - und zwar aus eigenem Antrieb und eigener Überzeugung - den Koalitionspartner in der Ost- und Deutschlandpolitik gebremst und jede weitere Initiative zunächst unterbunden, so bestärkte das wachsende Mißtrauen der Union gegenüber der SPD ihn zusätzlich darin, dem Koalitionspartner rigoros jeden Spielraum zu nehmen und die Kontrolle des Auswärtigen Amtes durch das Kanzleramt zu verschärfen. Die Umsetzung dieses Vorhabens hatte sich in der Bahr-Affäre bereits angedeutet. Es konnte dabei nicht ausbleiben, daß trotz des Kanzlerwunsches, die Koalition nach den Wahlen im Herbst 1969 fortzusetzen, sein Verhältnis zu Wehner belastet wurde. Kiesinger geriet in die Gefahr, durch die Ablehnung der ostpolitischen Konzeption der SPD auch die Zukunft der Koalition aufs Spiel zu setzen. Tatsächlich kam es im März 1969 zu einem Bruch zwischen ihm und Wehner über die Ziele ihrer Deutschlandpolitik. Die Basis ihres Bündnisses wurde dadurch zerstört, und er trug entscheidend dazu bei, daß die Koalition nach der Wahl von 1969 keine Fortsetzung mehr fand.

\section{Erstes Anzeichen für eine Verschlechterung des Verbältnisses}

Trotz der Enttäuschung über das Scheitern des Plans, einen gemeinsamen Präsidentschaftskandidaten aufzustellen, blieb das Verhältnis zwischen den beiden Gründungsvätern der Großen Koalition zunächst unbelastet. Wehner machte nicht Kiesinger für diese Fehlentwicklung verantwortlich. Anfang Dezember 1968 erhielt der Bundeskanzler einen persönlich gehaltenen Brief. „Sehr verehrter Herr Bundeskanzler! Erlauben Sie mir, bitte, Ihnen an diesem Tag ganz einfach ein Zeichen meiner Hochachtung zu geben“, hieß es da. Und noch deutlicher wirkten die Worte: „Die Geschäfte scheinen oft stärker zu sein als wir. Dennoch sollen Sie wissen, daß ich mit der gleichen Überzeugung an Ihrer Seite stehe wie am ersten Tag. Es wäre mir zwar lieber, es gäbe manchmal Gelegenheit, mehr als ein Wort zu sagen, aber wichtiger ist, nicht zu zerfallen mit dem, was nicht des Augenblicks wegen getan worden ist." 67

Auf den ersten Blick scheint das Schreiben ein Zeichen des Wohlwollens und der engen Verbundenheit zu sein. Aber beim genaueren Lesen wirkt die Aussage des Briefes nicht so eindeutig. Der letzte Absatz läßt darauf schließen, daß Wehner in jener Zeit den Wunsch unterdrückte, zu einzelnen Vorgängen in der Regierung seine abweichende Meinung darzulegen. Er verzichtete darauf, im Blick auf das, was „nicht des Augenblicks wegen getan“" wurde - also um der Erhaltung des Regierungsbündnisses willen. Meinungsverschiedenheiten in kleineren Dingen sollten das große gemeinsame Ziel nicht gefährden. Dieser Brief ist wichtig, weil er zeigt, daß die Grundlagen noch intakt waren. Aber schon bald würden auch die großen Ziele in Frage gestellt werden.

67 AdKASt, Kiesinger I - 226, D/IV.6, Wehner an Kiesinger vom 1.12.1968. 
Tatsächlich hatte sich seit der Zerschlagung des Prager Frühlings zwischen beiden Männern eine tiefe Diskrepanz in der Einschätzung künftiger Chancen für die Ost- und Deutschlandpolitik ergeben. Ein kurzer Blick auf die Erklärungen von Kiesinger und Wehner während der Debatte am 16. und 18. Oktober 1968 vor dem Bundestag verdeutlicht das. Die Intervention hatte den Kanzler darin bestärkt, gegenüber Moskau mit großer Vorsicht und unter Vermeidung irgendwelcher zusätzlicher „Angebote“ von deutscher Seite aufzutreten. Nach den Ereignissen in Prag, meinte Kiesinger, könne die Sowjetunion jederzeit auch eine friedliche Annäherung zwischen West- und Osteuropa als eine Gefährdung und Bedrohung ihrer hegemonialen Sphäre auffassen. „Diese neue, zwar schon in früheren Jahren gelegentlich anklingende, aber jetzt in voller Schärfe formulierte Doktrin zwingt uns wie alle Völker der übrigen, insbesondere der westlichen Welt zu einer Überprüfung unserer bisherigen Politik.“68

Wehner urteilte ganz anders. Er klagte zwar über die Brutalität, mit der die eurasische Supermacht der tschechischen Reformbewegung ein Ende gesetzt hatte. Aber anders als Kiesinger schien ihm das Ereignis eine Bestätigung zu sein, auf dem eingeschlagenen Kurs der Entspannung fortzufahren. Gerade jetzt müsse sich die Bundesregierung um die Sowjetunion, die Osteuropäer und die DDR bemühen. Er verpackte diese Botschaft allerdings in scharfe Attacken gegen die Sowjets. Es entstand bei den Zuhörern der Union der Eindruck, als ob der Minister mit dem Kanzler und dessen Einschätzung übereinstimmte. Wehner warnte beispielsweise: Man dürfe den Vorgang in der ČSSR nicht als „Verkehrsunfall“ betrachten oder als „Kavaliersdelikt“, das man einfach übergehen könne ${ }^{69}$. Der Unterschied zur Einschätzung Kiesingers wurde erst deutlich, als Wehner erklärte, man habe mit solchen Reaktionen der Sowjetunion rechnen müssen. „Wer sich, wenn er fährt, nicht darüber im unklaren sein kann, daß er sich vor einer offensichtlich sehr schwierigen Wegstrecke befindet, die er aber zu bewältigen suchen muß und auch will, der läßt doch wohl mindestens seine Reifen gründlich prüfen und notfalls auswechseln - und vielleicht auch sonst noch einiges an seinem Wagen -, um sicher zu sein, soweit das menschenmöglich ist, daß sie die Belastung aushalten und die Strapazen bestehen können. Sich so zu verhalten, das heißt doch nicht ,Ich gebe auf - oder?"70

Während Kiesinger zum Abwarten riet, zeigte sich Wehner auch in jener Zeit dazu bereit, die Fahrt nach Osten wieder aufzunehmen. Ihre unterschiedlichen Auffassungen darüber, wie aktiv die Bundesregierung unmittelbar nach dem Prager Einmarsch sein dürfe oder müsse, stießen im Februar 1969 frontal aufeinander. Unerwartet eröffnete sich die Möglichkeit zu Verhandlungen mit der SED.

\section{Kiesinger und die Bundesversammlung in Berlin}

Am 5. März 1969 sollte der Bundespräsident gewählt werden. Als Ort der Wahl hatte der Bundestagspräsident, wie immer seit 1954, Berlin vorgesehen. Die Regierung war allerdings unsicher, ob sie Gerstenmaier raten sollte, darauf zu bestehen. Besonders der Bundeskanzler war der Meinung, man solle den Osten nicht unnötig provozieren. Mit dieser Haltung stellte er sich gegen die eigene Fraktion, vermochte sich aber wieder einmal nicht durchzusetzen. Das mußte der Bundesvorsitzende der CDU schon im Juni 1968 erfahren, als er aus dem gleichen Grund die Entscheidung in Frage stellte, den 16. Bundespar-

${ }^{68} \mathrm{VdDB}, 5$. Wahlperiode, 188. Sitzung vom 16.10.1968, S. 10060.

${ }^{69}$ Debré hatte am 29.8.1968 vor dem Außenpolitischen Ausschuß der Nationalversammlung vom "Verkehrsunfall auf der Straße der Entspannung“ gesprochen; L'année politique, S. 272.

$70 \mathrm{VdDB}, 5$. Wahlperiode, 190. Sitzung vom 18.10.1968, S. $10301 \mathrm{f}$. 
teitag der CDU nach Berlin einzuberufen. Angesichts der DDR-Schikanen auf den Transitstraßen zögerte Kiesinger, den Beschluß durchzuführen. Das müsse sehr genau überlegt werden, bemerkte er öffentlich ${ }^{71}$. Doch der massive Protest der anderen CDU-Führer ließ ihn wankend werden. Von einer möglichen Verlegung alarmiert, schrieb etwa der Berliner Abgeordnete Gradl, ein Bundesvorstandsmitglied: „Ich bitte Sie herzlich, sehr verehrter Herr Bundeskanzler, in dieser Sache keinen Zweifel aufkommen zu lassen. Unter der Oberfläche der Zuversicht und Gelassenheit ist die Stimmung in der Führungsschicht Berlins ohnehin besorgt. Ein Zeichen dafür: Der Hauptgeschäftsführer der Berliner Industrie- und Handelskammer, unser Parteifreund Dr. Skrodzki, sagte mir neulich in ganz anderem Zusammenhang, wenn die Bundesversammlung diesmal [...] in Bonn stattfinden sollte, dann zweifle die Berliner Wirtschaft nicht mehr, wohin die Reise gehe."72

Eine harte, entschlossene Haltung bot sich vor allem auch deswegen an, weil die drei Alliierten, die die Hoheit über West-Berlin ausübten, zögerten, der CDU zu ihrem Parteitag eine eindeutige Empfehlung zu geben. Als der Generalsekretär bei den drei westlichen Siegermächten sondierte, wie die Regierungen auf den Bundesparteitag in der Stadt reagieren würden, erhielt er unterschiedliche Auskünfte. Seydoux, der offensichtlich zuvor die Meinung seiner Regierung eingeholt hatte, habe klar erkennen lassen, daß es der französischen Regierung lieber wäre, wenn man mit dem Parteitag nicht nach Berlin gehen würde, erklärte Heck in einem Schreiben dem CDU-Vorsitzenden. Auch offiziell befragt, würde die französische Regierung voraussichtlich eine solche Auskunft erteilen. Es sei aber ebenso klar zu erkennen, daß die französische Regierung von sich aus nicht gegen die Abhaltung des Parteitags in Berlin intervenieren werde.

Dagegen habe man ihn darüber informiert, daß die amerikanische Botschaft ihrer Regierung eindeutig abgeraten habe, wegen des Berliner Parteitags zu intervenieren. Die Botschaft sei offensichtlich der Meinung, daß es falsch wäre, irgendeine Präsenz in Berlin, die bisher gepflogen worden sei, aufzugeben. Von der britischen Botschaft habe er keinen maßgebenden Herren erreichen können ${ }^{73}$.

Der CDU-Parteitag fand trotz französischer Vorbehalte in Berlin statt, und die Sowjetunion verhielt sich ruhig. Die Veranstaltung wurde lediglich durch den Lärm einiger Jagdflugzeuge gestört, die über Berlin die Schallmauer durchbrachen. Aber daran hatten sich inzwischen die Bonner Parlamentarier - und auch die Berliner - gewöhnt. Trotzdem sollte es für Kiesinger damit sein Bewenden haben. Der Kanzler erklärte Bundestagspräsident Gerstenmaier, der allein die Entscheidungsbefugnis über den Ort der Bundesversammlung besaß, man solle aus der Einberufung nach Berlin keine Prestigefrage machen. Kiesinger schlug vor, man könne die Wahlversammlung als Jubiläumsveranstaltung mit dem Hinweis auf die Wahl des ersten Bundespräsidenten Heuss einberufen, die zwanzig Jahre zuvor in Bonn stattgefunden hatte ${ }^{74}$. Auch Scheel stimmte in einem Gespräch mit dem Kanzler, das noch vor dem CDU-Parteitag stattfand, dem Vorhaben zu. Man müsse allerdings den Eindruck vermeiden, als ob ein störungsfreier CDU-Parteitag durch die Verlegung der Bundesversammlung erkauft werden solle ${ }^{75}$.

71 Vgl. Der Spiegel, 10.6.1968, S. 20.

72 AdKASt, Kiesinger I - 226, D/IV.6, A 004, Heck an Kiesinger vom 30.5.1968.

73 Vgl. AdKASt, Kiesinger I - 226, D/IV.6, A 004, Heck an Kiesinger vom 18.8.1968, S. 4.

74 Vgl. Der Spiegel, 25.11.1968, S. 41.

75 Vgl. AdKASt, Kiesinger I - 226, D/IV.6, A 001, Ahlers an Kiesinger vom 30.10.1968, S. 3; Ahlers machte deutlich: „In Sachen Zeit und Ort der Bundesversammlung findet heute in Berlin ein Gespräch statt, zu dem der Bundestagspräsident die Partei- und Fraktions-Vorsitzenden eingeladen hat. Die gegenwärtige Tendenz in Bezug auf den Ort ist eindeutig auf Berlin gerichtet.“ 
Am entschiedensten für Berlin trat der ehemalige Regierende Bürgermeister Brandt ein. Und als Gerstenmaier Anfang Dezember 1968 Brandt und auch Wehner zusammen mit zehn Abgeordneten des außenpolitischen wie gesamtdeutschen Bundestagsausschusses zu sich einlud, erklärten neun der Anwesenden, sie seien für Berlin als Wahlort ${ }^{76}$. Zusammen mit der Zustimmung der Alliierten genügte das dem Bundestagspräsidenten. Am 18. Dezember 1968 gab er bekannt, daß er sich für Berlin als Ort der Bundesversammlung zur Wahl des Bundespräsidenten entschieden habe.

\section{Reaktion aus Moskau}

Die Sowjetunion reagierte auf die Ankündigung mit einer ablehnenden Stellungnahme. In Moskau wurde dem deutschen Botschafter ein Papier überreicht, das zwar das Wort „Protest“ vermied, aber zugleich deutlich machte, die Anwesenheit von 22 NPD-Abgeordneten bei der Wahl in Berlin werde als Provokation aufgefaßt. Im Zentralorgan Prawda hieß es dazu wörtlich: „Gerstenmaier weiß sehr gut, was er tut, wenn er kaltblütig die Durchführung dieser Versammlung plant, an der Neo-Nazi[s] teilnehmen werden und die gerade im Reichstagsgebäude stattfinden soll, wo die faschistische Bestie schließlich getötet wurde. “77

Am 10. Januar 1969 wurde Brandt direkt vom sowjetischen Botschafter über die Haltung Moskaus informiert. Die Sowjets kritisierten die Entscheidung, aber verzichteten darauf, irgendwelche Vergeltungsmaßnahmen anzudrohen. Offenbar wollte der Kreml nicht gleich am Anfang die gerade eingezogene amerikanische Nixon-Administration verärgern. Das schloß man in Bonn aus dem insgesamt unerwartet milden sowjetischen Protest gegen die Bundesversammlung. Andererseits vermutete die Bundesregierung - diesen Gedanken hatte Kiesinger in das Zentrum seiner Argumentation gegen den Wahlort Berlin gestellt -, der Sowjetunion könne unter Umständen daran gelegen sein, daß die Wahlversammlung in Berlin stattfinde. Denn damit sehe sie den von ihr behaupteten „revanchistischen Charakter“ der Bonner Politik eindeutig bewiesen.

Nach der Begegnung mit Zarapkin schien Außenminister Brandt, der sich bisher dieser Sichtweise verschlossen hatte, dem Argument des Kanzlers zuzustimmen. Ahlers berichtete Mitte Januar 1969 in einem Vermerk für den Bundeskanzler: „Der Außenminister ist jetzt auch der Meinung, daß die Entscheidung, nach Berlin zu gehen, vielleicht doch nicht ganz richtig gewesen sei. Er stimmt auch Ihrer Interpretation zu, daß Moskau, dessen Position nach dem ruhigen Ablauf des CDU-Parteitages in dieser Sache stark ist, ein Interesse daran hat, wenn wir die Bundesversammlung in Berlin tagen lassen. "78

Ahlers hielt in dem Vermerk fest, er habe den Außenminister gefragt, ob dieser eine Möglichkeit sähe, doch nicht nach Berlin zu gehen. Brandt habe dies nicht völlig ausgeschlossen. Er, Ahlers, glaube darüber hinaus, daß die Bemühungen, in der Frage der Interventionsklausel von Moskau etwas zu erreichen, wenig erfolgversprechend sein würden, wenn es wegen Berlin zu einer Kontroverse komme. Andererseits wäre es denkbar,

Lediglich der US-Sicherheitsberater Kissinger hatte offenbar dazu geraten, den Ort nicht vorschnell festzulegen. Die neue amerikanische Administration wolle sich erst eine Meinung bilden. Die Zustimmung der USA muß dann aber erfolgt sein; vgl. Münchner Merkur, 17.12.1968, sowie Der Spiegel, 16.12.1968, S. 29.

76 Vgl. Der Spiegel, 9.12.1968, S. 24.

77 DzD, 1968, Bericht über die Note der Regierung der UdSSR an die Regierungen Frankreichs, Großbritanniens und der Vereinigten Staaten vom 23.12.1968, S. 1623; vgl. Basler Nachrichten, 22.12.1968.

${ }^{78}$ AdKASt, Kiesinger I - 226, D/IV.6, A 001, Vermerk Ahlers an Kiesinger vom 15.1.1969, S. 1 f.; dort auch die folgenden Zitate. 
diese Bemühungen zu unterstützen, wenn Berlin als Tagungsort fallengelassen würde. „Es fragt sich also, ob dies überhaupt noch zu machen ist. Die erste Voraussetzung dafür wäre meines Erachtens eine Kompensation für die West-Berliner. Diese könnte in einer Wiederaufnahme der Passierscheinregelung liegen. Sollten die Russen bereit sein, dies in Ost-Berlin durchzudrücken, so könnte auch Bürgermeister Schütz kaum noch Einwände erheben. Die zweite Voraussetzung wäre eine irgendwie geartete positive Reaktion Moskaus auf einen solchen Schritt unsererseits. Die dritte wäre ein Einverständnis Washingtons.“ Ahlers betonte zum Schluß: „Unter diesen Bedingungen würde ich eine Verlegung der Bundesversammlung von Berlin nach Bonn gegenüber der deutschen Öffentlichkeit für vertretbar halten."

In diesem Vermerk wurde erstmals angedeutet, daß sich die Bundesregierung die Verlegung des Wahlortes abhandeln lassen könne. Interessant ist auch, daß der Regierungssprecher bereits zu einem Zeitpunkt ein Passierscheinangebot für eine ausreichende Gegenleistung hielt, als noch niemand anders an einen solchen Vorschlag gedacht hatte. Erst einen Monat später wurde dieser Vorschlag der Bundesregierung von seiten der DDR tatsächlich offeriert. Doch Mitte Januar 1969 geriet die Frage des Versammlungsortes zunächst in den Hintergrund der aktuellen Politik in Bonn. Sie wurde von der Diskussion um die Vorwürfe gegen Gerstenmaier, seinem anschließenden Rücktritt und der Wahl seines Nachfolgers im Amt des Bundestagspräsidenten überlagert.

\section{Die Offensive der $D D R$}

Die DDR-Propaganda hatte nach dem Einmarsch der Truppen des Warschauer Pakts in die ČSSR die Bundesregierung scharf angegriffen und diese für die militärische Invasion verantwortlich gemacht. Gleichzeitig wetterte sie gegen die angeblich „revanchistische Anspruchshaltung “ in bezug auf West-Berlin. Unter allen Umständen sollte verhindert werden, daß die Wahlversammlung in Berlin stattfand. Bestärkt hatte die Kommunisten, $\mathrm{daß}$ sie in ihrem Kampf gegen die Bundesrepublik und in ihrem rastlosen Bemühen um die Anerkennung in den vorangegangenen Monaten Erfolge erzielt hatten. So hatte die Bundesregierung völlig unvorbereitet die Entscheidung des Internationalen Olympischen Komitees im Oktober 1968 getroffen, künftig nicht nur eine zweite deutsche Mannschaft, wie erstmals bei den Winterspielen in Grenoble, sondern ab sofort auch die Nationalfahne und die Hymne der DDR zuzulassen. Wenige Wochen vor der Entscheidung hatte Brandt Kiesinger gegenüber noch behauptet: „Es dürfte, gerade nach der Besetzung der ČSSR, unschwer möglich sein, Beschlüsse des IOC in diesem Jahr zu vermeiden. "79

Aber darin täuschte sich der Außenminister. Die Entscheidung des Olympischen Komitees wirkte auf die Bundesregierung noch fataler dadurch, daß die nächsten Sommerspiele 1972 in München stattfinden sollten. Bei den zu erwartenden Goldmedaillen von Sportlern aus der DDR würde ausgerechnet in der Bundesrepublik erstmals die Hymne „Auferstanden aus Ruinen“ offiziell ertönen, während gleichzeitig die schwarzrot-goldene Flagge mit Hammer und Zirkel - dem „Architektenzeichen“, wie Wehner das Emblem spöttisch nannte - gehißt werden würde. Das war ein Triumph für Ulbricht und seine Genossen. Aber um München als Olympia-Austragungsort zu sichern, akzeptierte die Bundesregierung diese unangenehme Aussicht ${ }^{80}$.

79 AdKASt, Kiesinger I - 226, D/IV.6, A 001, Brandt an Kiesinger vom 16.9.1968. Kiesinger antwortete (AdKASt, Kiesinger I - 226, D/IV.6, A 001, Kiesinger an Brandt vom 3.10.1968): „Ich glaube, wir sollten das Ergebnis des IOC-Kongresses abwarten und dann über das weitere Vorgehen entscheiden."

80 Vgl. Baring, Machtwechsel, S. 239. 
In gewisser Weise war aus der Sicht Ost-Berlins auch die Kampagne gegen Lübke erfolgreich gewesen. Der Bundespräsident hatte im Oktober 1968 seinen vorzeitigen Rücktritt erklärt. Ein Erfolg, der allerdings ein unangenehmes Problem nach sich zog: der Versammlungsort für die Wahl seines Nachfolgers mußte bestimmt werden. Vermutlich war die Entscheidung des Bundestagspräsidenten für Berlin Anlaß für eine DDR-Kampagne gegen Gerstenmaier. Die DDR ließ eine Schmähschrift im Westen veröffentlichen, in der fälschlicherweise behauptet wurde, Gerstenmaier habe in der Zeit des Nationalismus für den Sicherheitsdienst gearbeitet. Nur Gerstenmaiers tadelloses Renommee als Angehöriger des Widerstands im Kreisauer Kreis und seine Beteiligung beim gescheiterten Putschversuch am 20. Juli 1944 verhinderten, daß der Inhalt des Pamphlets in der bundesdeutschen Presse aufgegriffen wurde ${ }^{81}$. Dagegen löste ein Artikel, der am 11. Januar 1969 in der linksliberalen Frankfurter Rundschau erschien, eine öffentliche Diskussion um Wiedergutmachungsleistungen aus, die der Bundestagspräsident in Anspruch genommen hatte. Im Jahre 1965 hatte Gerstenmaier über seinen Anwalt offiziell beantragt, seine rechtliche Lage nach dem „Gesetz zur Regelung der Wiedergutmachung nationalsozialistischen Unrechts für Angehörige des öffentlichen Dienstes“ festzustellen. Er wollte sich auf diesem Wege vor verleumderischen Behauptungen schützen. Gleichzeitig mit dem gewünschten Bescheid erhielt der Präsident Bezüge von 280000 DM als Wiedergutmachung für den von den Nazis verursachten Ausfall von Professoreneinkünften zugesprochen. Der Schwabe Gerstenmaier beging den Fehler, das Geld anzunehmen und zu behalten, anstatt es einer Stiftung oder Hilfsorganisation zu spenden. Man nahm ihm übel, daß er sich als zweithöchster Repräsentant der Bundesrepublik auf diese Weise bereichert hatte.

Für Gerstenmaiers Rücktritt vom Amt des Bundestagspräsidenten war aber nicht die Tatsache entscheidend, daß er das Geld angenommen und privat verwendet hatte. Nach dem Gesetz war er zur Annahme verpflichtet. Zum Verhängnis wurde ihm dagegen seine Reaktion auf die öffentliche Diskussion. Er klagte darüber, er sei gezwungen gewesen, seine Integrität unter dem Nationalsozialismus durch dieses Verfahren bestätigen zu lassen. Er ließ sich zu Äußerungen hinreißen wie „Nazi müßte man gewesen sein“ oder „Solange Sie nicht den Schein vorlegen in diesem Staat des Berechtigungswesens, sind Sie der Angeschmierte ${ }^{\text {"82 }}$. Er bedauere tief, jemals anders reagiert zu haben als mit schweigender Verachtung, schrieb Gerstenmaier ${ }^{83}$. Aber diese Einsicht kam viele Jahre zu spät. Nach seinen unklugen, stillosen Einlassungen waren die Bundestagsparteien nicht länger bereit, ihn als Präsidenten zu halten. Am 23. Januar 1969 erklärte er seinen Rücktritt.

Die Neubesetzung des Amtes eröffnete unerwartet die Chance, noch einmal die Frage des Orts der Bundesversammlung zu überdenken. Der neue Bundestagspräsident, vermerkte Ahlers, sei nicht an die Entscheidung seines Vorgängers gebunden. Selbst der Berliner Senat rückte etwas von seiner bisherigen Position ab. Auf einer Arbeitstagung des überparteilichen Kuratoriums Unteilbares Deutschland erklärte der Regierende Bür-

81 Vgl. Gerstenmaier (Streit und Friede, S. 588), der dazu schreibt: „Das Pamphlet der Pankower Kommunisten,Vom SD-Agenten P38/546 zum Bundestagspräsidenten' zog seinen Saft aus den Archiven des ehemaligen Reichskirchenministeriums, des alten Auswärtigen Amtes und vielleicht auch aus Beständen der Gestapo. Das Ganze war ein schwindelhaftes Mixtum compositum, aufgehängt an einer dreisten Fälschung: einer Karteikarte, die nichts enthielt als meinen Namen, meine Anschrift und eine Nummer. Nach der Ansicht sachverständiger Leute stammte sie vermutlich aus einer Kartei der bei Aus- und Einreisen besonders zu kontrollierenden Leute, der Telefonüberwachung oder dergleichen."

82 Süddeutsche Zeitung, 21.1.1969.

83 Vgl. Gerstenmaier (Streit und Friede, S. 590): „Ich hielt nicht an mich. Das war mein Fehler.“ 
germeister Schütz Anfang Februar 1969, West-Berlin bestehe durchaus nicht dogmatisch auf jeder einzelnen Bindung zur Bundesrepublik. „Es könnte sein, daß manche[s] sich als unnütz erweist. Dann müssen andere [Garantien], wenn irgendmöglich an ihre Stelle treten." ${ }^{44}$ Schütz dachte dabei in erster Linie an die Einbeziehung West-Berlins in den deutsch-sowjetischen Handelsvertrag oder in ein Luftfahrtabkommen. Über das abnehmende Interesse in der Stadt an der Einberufung der Wahlmännerversammlung nach Berlin schrieb der Bundesbevollmächtigte und frühere Staatssekretär im Ministerium für gesamtdeutsche Fragen, Krautwig, besorgt an den Staatssekretär im Bundeskanzleramt, Carstens: „Der Berliner Senat zeigte in den letzten Wochen eine zunehmende Bereitschaft, auf die Abhaltung der Bundesversammlung in Berlin zu verzichten. Noch vor wenigen Monaten erklärte der Regierende Bürgermeister, daß Berlin unter gar keinen Umständen verzichten könne." 85 Auch aus der Wirtschaft sei in den letzten Monaten immer häufiger die Frage in bezug auf die Bundespräsidentenwahl in Berlin gekommen, ob das sein müsse?

In dieser Lage beging die SED einen Fehler. Die DDR sperrte am 10. Februar 1969 für die Mitglieder und Mitarbeiter der Bundesversammlung die Transitstrecke ${ }^{86}$. Damit hatte sie der Bundesregierung die Möglichkeit genommen, ohne Gesichtsverlust die Wahl nach Bonn zu verlegen. Nach diesem Affront blieb nichts anderes übrig, als am Wahlort Berlin festzuhalten. Der neue Bundestagspräsident, Hassel, erklärte demgemäß nach Rücksprache mit dem Bundeskanzler, dem Außenminister, den Fraktionsvorsitzenden sowie dem Regierenden Bürgermeister, es bestehe kein Anlaß, die Bundesversammlung an einen anderen Ort zu verlegen. In der SPD-Fraktionssitzung vom 11. Februar erklärte Brandt: „Es war immer die Auffassung der sozialdemokratischen Partei und Fraktion, $\mathrm{da} ß$ wir auch im Zusammenhang mit dem Abhalten der Bundesversammlung keine Verschärfung im Verhältnis zwischen der BRD und der UdSSR wollen. Wir haben uns auch nie zu Fürsprechern von Prestigepolitik gemacht." Das ändere aber nichts daran, daß die Ost-Berliner Maßnahmen als „rechtswidrig, anmaßend und entspannungsfeindlich“ gekennzeichnet werden müßten. Die Ereignisse der letzten Tage hätten es auch als hoffnungslos erscheinen lassen, durch „eine Politik, wie sie von einigen vorgeschlagen wurde, durch Geben und Nehmen über einen Abschnitt des Stillhaltens hinweg die Lage entspannen zu helfen ${ }^{\alpha 87}$. Das sei so gut wie hoffnungslos geworden. In dieser Auffassung trafen sich jetzt beide Parteiführungen der Koalition.

\section{Die SED bietet Passierscheine an}

Die Sowjetunion hatte ab dem 30. Dezember 1968 eine ständige Kampagne gegen die Bundesversammlung in Berlin geführt. Sie verurteilte die Berlinpolitik der Bundesregierung als „entspannungshemmend“". Allerdings verstummten die Angriffe Ende Januar 1969 für eine Woche, als sich mit der Ablösung von Gerstenmaier die Möglichkeit ergab, daß der neue Bundestagspräsident eine Verlegung des Ortes anordnete. Ab dem 6. Februar, einen Tag nach der Wahl von Hassel zum Nachfolger Gerstenmaiers, setzte

${ }^{84}$ Hannoversche Allgemeine, 5.2.1969.

${ }^{85}$ AdKASt, Kiesinger I - 226, D/IV.6, A 005, Krautwig an Carstens vom 14.2.1969, S. 3.

$86 \mathrm{Vgl}$. Note vom 7.2.1969 in Neues Deutschland, 7.2.1969. Zuvor hatte die DDR in einer Note an die Bundesregierung erklärt: „Bonn müsse die volle Verantwortung für die Folgen tragen, die sich aus Maßnahmen ergeben könnten, die die Deutsche Demokratische Republik zu treffen gezwungen sein werde.“

${ }^{87}$ AdsD, SPD-Fraktionssitzung vom 11.2.1969, S. 5; vgl. Baring, Machtwechsel, S. 237. 
die Kampagne erneut ein, offensichtlich mit dem Ziel, den neuen Bundestagspräsidenten zu beeindrucken und zur Absage Berlins zu verleiten. Die Sowjets klagten die Bundesrepublik einer "rechtswidrigen Einmischung“ in der Stadt an und behaupteten, da West-Berlin auf dem Territorium der DDR liege, sollte die DDR-Regierung über die Einhaltung interalliierter Entnazifizierungs-, Entmilitarisierungs- und Demokratisierungsbeschlüsse von 1945 bis 1947 gemäß der sowjetischen Auslegung wachen ${ }^{88}$. Die sowjetische Propaganda begleitete eine Note der DDR vom 6. Februar an die Bundesregierung, in der Ost-Berlin Bonn einen "groben Bruch des Völkerrechts“ vorwarf und Gegenmaßnahmen für den Fall ankündigte, daß die Wahlversammlung stattfinden sollte ${ }^{89}$. Zwei Tage später machte die DDR ihre Drohung wahr und erließ die schon erwähnte Anordnung eines Transitbenutzungsverbots für die Teilnehmer an der Wahlversammlung. Vermutlich bewirkte der prompte, entschiedene und scharfe Protest der drei Westmächte, daß die Sowjetunion ihrem Verbündeten sehr schnell Zügel anlegte und sich auch selbst in der Kommentierung der Berliner Wahlversammlung zurückhielt. Zusätzlich zum Protest der drei westlichen Botschafter in der Bundesrepublik ${ }^{90}$ bekräftigte der britische Premierminister Harold Wilson am 14. Februar in West-Berlin das britische Engagement und die Sicherheit der Stadt; Präsident Nixon kündigte demonstrativ einen Besuch an; die amerikanische Administration machte den Sowjets zudem klar, daß es in den Fragen der Rüstungsbegrenzung zu keinem Ergebnis kommen werde, falls sich in und um Berlin die Spannungen erhöhten.

Vermutlich hatte Moskau die Haltung der Westmächte falsch eingeschätzt, wie Wettig meint ${ }^{91}$. Die Sowjets seien durch die demonstrative Kooperationsbereitschaft des Westens in dem Glauben bestärkt worden, die negativen Auswirkungen der Prager Invasion seien überwunden. So wurden auf einer Konferenz der französisch-sowjetischen Kommission für wirtschaftliche Zusammenarbeit in Paris einige wichtige Vereinbarungen getroffen. Auch das Interesse der neuen amerikanischen Administration am Dialog über Rüstungskontrolle und Präsident Nixons Erklärung, er werde die Ratifikation des Atomsperrvertrages vorantreiben, trugen dazu bei. Vor diesem Hintergrund, so Wettig, habe Moskau die Entschiedenheit der Alliierten in der Wahlversammlungsfrage beurteilt. In Bonn wurde zudem der sowjetische Botschafter in Ost-Berlin, Abrassimow, vorstellig und protestierte bei den Botschaftern der drei alliierten Mächte gegen das Vorhaben der Bundesrepublik. Die Tatsache, daß Washington, Paris und London den Protest nicht gleich mündlich zurückwiesen, habe Moskau ebenso von der halbherzigen Einstellung der Westmächte überzeugt, wie das in Bonn kursierende Gerücht, eine „befreundete Macht“ habe dem Bundestagspräsidenten abgeraten, die Versammlung nach Berlin einzuberufen.

88 Vgl. Wettig, Die Berlin-Krise 1969, S. 687.

89 Vgl. EA 24 (1969), Folge 5, S. Z 43. Moskau unterstützte die Argumentation der DDR-Führung, indem die Sowjets die Besatzungsrechte der Westmächte in Frage stellten. Diese hätten, als sie 1948 den Viermächte-Status „zerstört" hätten, das Recht auf Präsenz in West-Berlin eingebüßt, behauptete etwa Radio Moskau am 11.2.; vgl. Wettig, Die Berlin-Krise, S. 687.

90 Vgl. EA 24 (1969), Folge 8, S. D 192; dort heißt es: „Die deutsche Entscheidung, die diesjährige Bundesversammlung in Berlin abzuhalten, wurde nach gebührender Konsultation mit den drei Mächten im Rahmen von deren Verantwortung für Berlin getroffen. Die drei Regierungen sind infolgedessen der Ansicht, daß es für die ostdeutsche Bekanntmachung vom 8.2. keine Rechtfertigung gibt. Diese Bekanntmachung ist im übrigen unvereinbar mit der Tatsache, daß die Sowjetunion, nicht Ostdeutschland, für den freien und ungehinderten Zugang von Personen und Gütern nach Berlin verantwortlich ist."

91 Vgl. Wettig, Die Berlin-Krise 1969, S. 686. 
Diese Darstellung Wettigs berücksichtigt allerdings nicht, daß die Sowjetunion während ihrer Kampagne gleichzeitig auch versöhnliche Botschaften an Bonn sandte. Radio Moskau hatte beispielsweise Anfang Februar 1969 im Zusammenhang mit der geplanten Bundesversammlung erklärt, die Sowjetunion sei nicht an „gefährlichen Leidenschaften und internationalen Krisen “ interessiert ${ }^{92}$. Es gab außerdem Anzeichen, daß Moskau bei einer Entscheidung Bonns für die Verlegung des Wahlortes auch in anderen strittigen Fragen mit sich reden lassen wollte. Als der Regierende Bürgermeister Schütz am 31. Januar mit Abrassimow zusammentraf, soll dieser die Möglichkeit eines Passierscheinangebots durch die DDR angedeutet haben ${ }^{93}$.

Und noch ein anderes Ereignis zeigt die trotz heftiger verbaler Proteste insgesamt erstaunlich zurückhaltende sowjetische Haltung gegenüber der Bundesregierung: Am 8. Februar unterbreiteten die Sowjets in einer Note zum Atomsperrvertrag einige Lösungsvorschläge, die die Vorbehalte Kiesingers und der Union ausräumen helfen sollten. Ahlers nannte sie sogar ein „Stück Unterschriftshilfe“. Die sowjetische Regierung versicherte dort, daß der friedlichen Nutzung der Kernenergie keine Hindernisse in den Weg gelegt würden. Selbst für das Problem der beiden von Moskau in den Dialog eingeführten Feindstaatenklauseln wies man einen Ausweg: Die Resolution 255 der UNGeneralversammlung gelte auch für die Bundesrepublik, wurde ausdrücklich herausgestellt. In der Resolution, die die Vereinten Nationen im Zusammenhang mit dem Nichtweitergabevertrag verabschiedet hatten, war festgelegt worden, daß keine Nuklearmacht gegenüber einem nichtnuklearen Staat Druck ausüben oder Gewalt anwenden dürfe. Mit diesem Hinweis sollten die deutschen Befürchtungen ausgeräumt werden, oder zumindest hatte man dies gehofft ${ }^{94}$. Am 13. Februar protestierte Botschafter Zarapkin in einem Gespräch mit Kiesinger zwar erneut gegen die Wahl in Berlin, aber er erklärte auch, bei einem Verzicht wäre die Sowjetunion bereit, der Bundesrepublik „in anderen Bereichen hilfreich" zu sein ${ }^{95}$. Vier Tage später war aus Washington zu hören, daß der dortige Botschafter Anatoli Dobrynin mitgeteilt habe, Moskau sei zu einer „Geste der Entspannung " bereit, erwarte allerdings seinerseits, daß die Bundesrepublik durch die Wahl in Berlin das Ost-West-Klima nicht verschärfe ${ }^{96}$. Aber niemand wußte genau, welche „Hilfe“ die Sowjetunion im Sinne hatte. Die ganze Woche über wartete der Kanzler vergeblich auf das angekündigte Zeichen.

92 Frankfurter Allgemeine Zeitung, 14.2.1969. Immerhin sei, worauf Wettig (Die Berlin-Krise 1969, S. 687) hinweist, in der sowjetischen Propaganda "noch eine gewisse Vorsicht erkennbar" gewesen, „sich bei den Drohungen weder hinsichtlich der zu unternehmenden Aktionen noch hinsichtlich der eigenen Handlungsbindung allzu genau festzulegen“.

93 Vgl. Dreher, Süddeutsche Zeitung, 24.2.1969. Nach Ansicht des Spiegel (3.3.1969, S. 26) machte Moskau dagegen keine solche Andeutung.

${ }^{94} \mathrm{Vgl}$. Neue Zürcher Zeitung, 10.2.1969.

95 Wettig, Die Berlin-Krise 1969, S. 688 f. Der neue Kurs der Sowjetunion zeigte sich in den Äußerungen der Medien zu West-Berlin. Die These, Bonn habe keinerlei Machtbefugnis in der Stadt, verschwand. Die Besatzungsrechte der Westmächte wurden nicht mehr in Zweifel gezogen. Am 20.2. appellierte Moskau an Bonn, man solle auf die vorgesehene Aktion aus Einsicht und gutem Willen verzichten. Von Drohung und Erpressung war jetzt keine Rede mehr.

96 Vgl. Kissinger (Memoiren, S. 196), der dort berichtet, Dobrynin habe versprochen, die Sowjetunion werde für Beruhigung der Lage sorgen. Der chinesische Premierminister Tschou En-lai habe ihm später sogar erklärt, der Grenzzwischenfall am Ussuri im März 1969 sei von den Sowjets bewußt provoziert worden, um von Berlin abzulenken. Die westdeutschen Parlamentarier hatten daher ungestört nach Berlin reisen können. Baring (Machtwechsel, S. 235) meint, China habe die Rolle eines Beschleunigers gespielt und die Gesprächsbereitschaft der Sowjetunion noch verstärkt. 
In der Zwischenzeit traf Ulbricht mit dem Generalsekretär der KPdSU, Breschnew, in der Sowjetunion zusammen. Man vermutete in Bonn, der Staatsratsvorsitzende sei dabei zu einem Passierscheinangebot für die West-Berliner überredet worden ${ }^{97}$. Am Freitagabend, dem 21. Februar, wurde in West-Berlin ein Brief des ersten Sekretärs der SED übergeben, der an den Vorsitzenden der SPD, Brandt, adressiert war. Die DDR-Führung hatte vermutlich diese Form gewählt, um ihre „Drei-Staaten-Theorie“ nicht zu untergraben. Denn bisher akzeptierte sie nur den Berliner Senat als Verhandlungspartner für die Passierscheinabkommen. In dem Schreiben hieß es: „Uns wurde bekannt, daß in der SPD die Frage erörtert wird, in der Regierung die Frage der Verlegung der Bundesversammlung in eine westdeutsche Stadt aufzuwerfen. Wenn die sozialdemokratischen Minister einen solchen Beschluß der Bundesregierung und eine Entscheidung des Bundestagspräsidenten herbeiführen könnten, würde das eine Minderung der Spannungen bedeuten. $\mathrm{Da}$ West-Berlin eine selbständige politische Einheit ist, könnte der Senat von West-Berlin in diesem Fall an die Regierung der Deutschen Demokratischen Republik betreffs der Gewährung der Möglichkeit des Besuchs der Hauptstadt der Deutschen Demokratischen Republik für West-Berliner Bürger zu Ostern 1969 herantreten. Nach unserer Information ist die Regierung der Deutschen Demokratischen Republik bereit, diesen Vorschlag positiv zu prüfen. “98

Da Brandt sich im Ausland aufhielt, nahm der stellvertretende Vorsitzende Wehner das Schriftstück in Empfang und sandte es am folgenden Tag, dem 22. Februar, einem Samstagmorgen, an den Kanzler mit den begleitenden Worten: „Ich bin der Meinung, $\mathrm{da} ß$ Sie über diesen Vorgang unterrichtet sein müssen, wenn Sie Ihre Bemühungen fortsetzen, Schaden zu verhüten und die Verständigungspolitik der Bundesregierung auch gegenüber der Regierung der UdSSR deutlich zu machen." 99 Darauf hatte der Kanzler nur gewartet. Tagelang hatte Kiesinger überlegt, ob er den sowjetischen Botschafter zu sich bestellen sollte, um endlich zu erfahren, an welche „entspannungsfreundliche Geste“ Moskau dachte ${ }^{100}$. Jetzt war es soweit. Mit dem Brief Ulbrichts in der Hand ließ er

${ }^{97}$ Vgl. Süddeutsche Zeitung, 24.2.1969; Wettig (Die Sowjetunion, S. 58 f.) vermutet, daß Ulbricht bei seiner Unterredung mit Breschnew am 17.2. bereits auf das Angebot angesprochen worden sei. Auch während der Unterhaltung zwischen dem sowjetischen Ministerpräsidenten Kossygin am 20.2. mit DDR-Botschafter Bittner soll die Aktion Gegenstand des Meinungsaustausches gewesen sein.

98 DA 3 (1969), S. 307; siehe auch EA 24 (1969), Folge 8, S. D 193.

99 Zitiert nach Die Welt, 25.2.1969; siehe auch AdKASt, Kiesinger I - 226, D/IV.6, Wehner an Kiesinger vom 25.2.1969; dort befindet sich der handschriftliche Entwurf einer Antwort an Ulbricht, den Wehner für Brandt verfaßt hatte. Er ist ohne Datum versehen, muß allerdings am 25.2. geschrieben worden sein, da der Brief von Schütz an Stoph vom gleichen Tag erwähnt ist. Der Brief ist dann auch tatsächlich wortwörtlich an Ulbricht abgegangen; vgl. DA 3 (1969), S. 308 f. Er lautet: „An den Ersten Sekretär des ZK der SED W. Ulbricht. Ihr Schreiben vom 21. dieses Monats, das ich nach Rückkehr von einer Auslandsreise bestätige, hat das Präsidium der SPD zur Kenntnis genommen. Über die Bundesversammlung und ihren Tagungsort kann es zwischen der SPD und Ihnen keine Erörterung geben. Wegen der Bedeutung, die wir jedem Beitrag zur Verständigung beimessen, haben wir den sachlichen Kern des Schreibens in die in Gang befindlichen Erörterungen und Gespräche eingebracht, die unsere Regierung führt. Soweit es sich um spezielle Berliner Probleme, insbesondere die Benachteiligung der Einwohner WestBerlins handelt, hat sich der Regierende Bürgermeister von Berlin mit dem Ihnen sicher bekannten Schreiben vom heutigen Tage an den Vorsitzenden des Ministerrats der DDR gewandt. Bei seinen Bemühungen hat Bürgermeister Schütz unsere volle Unterstützung. gez. Willy Brandt, Vorsitzender der SPD.“

100 Vgl. Wettig, Die Sowjetunion, S. 58. Für seine Vermutung, Kiesinger habe am 19.2. bei der sowjetischen Botschaft in Rolandseck sondieren lassen, ob Moskau bereit wäre, den Verzicht auf die Abhaltung der Wahlversammlung in Berlin mit Passierscheinen für West-Berliner zu hono- 
an diesem Morgen Zarapkin rufen. Aber zunächst ohne Erfolg. Kiesinger bat daher den Botschafter das erste und einzige Mal schriftlich zu sich. „In Anbetracht neuer Informationen aus Ost-Berlin lege ich Wert darauf, Sie baldmöglichst zu sehen. Bitte nehmen Sie wegen eines Termin[es] mit meinem Büro Verbindung auf“, hieß es in der Mitteilung101.

Das Treffen kam an diesem Tag erst gegen 15 Uhr zustande. In Bonn erklärte man sich das stundenlange Fernbleiben des Botschafters damit, daß Zarapkin noch keine Instruktionen aus Moskau erhalten hatte. Offenbar noch immer unvorbereitet traf der $\mathrm{Di}$ plomat im Palais Schaumburg ein. Auf die Frage Kiesingers, ob er von dem Brief Ulbrichts wisse, den er ihm in Kopie vorlege, mußte Zarapkin verneinen. Damit war die kurze Unterredung beendet. Der Botschafter versprach, sich bald wieder zu melden.

Tatsächlich bat Zarapkin noch am Abend um einen Termin beim Bundeskanzler. Aber diesmal waren die Rollen vertauscht. Kiesinger hatte seinen Wochenendurlaub in Bebenhausen um einen Tag hinausgeschoben, um den Botschafter zu empfangen. Auf die Heimfahrt wollte der Kanzler jetzt nicht länger verzichten. Seinen Mitarbeitern erklärte der Kanzler daher am Samstagabend, Zarapkin solle am nächsten Tag nach Stuttgart kommen. Er wolle dort mit ihm sprechen ${ }^{102}$. Kiesinger genoß die ungewohnte Situation: Bisher hatte er sich werbend um Moskau bemühen müssen, ohne erkenntliche Reaktion. Meistens beschimpften ihn die Sowjets, prangerten die angeblich revanchistischen Ziele der Bundesregierung an. Jetzt war die Situation umgekehrt: Die Kommunisten kümmerten sich um ihn, den bürgerlich konservativen Politiker. Und noch ein Aspekt spielte eine Rolle: Die Supermacht bat um ein Gespräch mit dem Kanzler der außenpolitisch viel weniger bedeutsamen Bundesrepublik.

Am Sonntagnachmittag flog Zarapkin in Begleitung Diehls und des Staatssekretärs im Auswärtigen Amt, Duckwitz, im Hubschrauber nach Stuttgart. Sie trafen den Kanzler im Gästehaus von Scheufelen. Man habe zunächst einige Gläser baden-württembergischen Weines getrunken und das Thema gar nicht berührt, sondern über „dieses und jenes" geredet, berichtete Diehl später. Dann habe Kiesinger beiläufig festgestellt, es bestehe da offenbar ein Mißverständnis zwischen Moskau und Bonn. Die Bundesversammlung werde selbstverständlich in Berlin stattfinden, aber die Sowjetregierung solle sich keine Sorgen machen, es handele sich um keinen unfreundlichen Akt, da er sich nicht gegen die Sowjetunion richte. Zarapkin habe zunächst schweigend zugehört, aber schließlich mit einem heftigen Ausbruch reagiert: Die Bundesrepublik wolle den unabhängigen Status Berlins nicht akzeptieren. Man müsse die Wahl als Provokation auffassen. Doch Kiesinger wiegelte ab und betonte den friedlichen Charakter seiner Regierungspolitik, die auf Versöhnung mit Moskau ausgerichtet sei. Anschließend wandte sich das Gespräch einer praktischen Lösung des Problems $z^{103}$. Kiesinger stellte klar, die Sowjetunion müsse einen „überzeugenden Beitrag" leisten, wenn die Bundesregierung die Zustimmung zur Verlegung des Wahlortes geben solle. Darauf erwiderte der Botschaf-

rieren, findet sich kein Hinweis im Material. Da Kiesinger aber eine dauerhafte Regelung an strebte, scheint das Angebot den Sowjets so nicht unterbreitet worden zu sein. Im Brief von Ulbricht war die Diskussion in der SPD um eine Verlegung des Wahlortes angesprochen worden. Ahlers hatte als erster den Vorschlag aufgebracht. Es spricht also einiges dafür, daß vom Auswärtigen Amt aus vorsorglich Sondierungen unternommen wurden.

101 AdKASt, Kiesinger I - 226, D/V.5, A 310, Kiesinger an Zarapkin vom 22.2.1969.

102 Vgl. Diehl (Gespräch mit dem Verfasser, 29.11.1989): „Er hätte ihn auch in Bonn empfangen können. Aber Kiesinger meinte, nein, er solle schon mal nach Stuttgart kommen."

103 Ebenda; Kiesinger habe die Sache geschickt gehandhabt, meint Diehl. 
ter, Verhandlungen zwischen der DDR und dem Berliner Senat fänden bereits statt. Aber das stimmte nicht mit den Tatsachen überein. Der Kanzler ließ den Regierenden Bürgermeister anrufen und bat darum, die Behauptung zu bestätigen. Schütz verneinte, es gäbe keine Verhandlungen über eine Passierscheinregelung. Der Botschafter war falsch informiert worden. Daraufhin einigten sich Zarapkin und Kiesinger auf die Erklärung, es seien Verhandlungen angekündigt ${ }^{104}$. Aber der Kanzler machte deutlich, daß es mit der einmaligen Ausgabe von Passierscheinen nicht getan sei. Bonn erwarte von Ost-Berlin eine überzeugendere Geste. Der Kanzler dachte etwa an eine langfristige Besuchsregelung für die West-Berliner, die seit dem Mauerbau, von ganz wenigen Gelegenheiten in den sechziger Jahren abgesehen, auch von Ost-Berlin abgeschnitten waren. Damit war die Unterhaltung beendet.

Von dem Treffen in Stuttgart ließ Kiesinger eine Fotografie verbreiten, die ihn mit dem Botschafter beim gegenseitigen Zuprosten zeigt ${ }^{105}$. Das Bild sollte dokumentieren, wie entspannt und vertraut der Kanzler mit dem Diplomaten Moskaus umging. Der Kanzler zeigte sich auch vom Verlauf des Treffens befriedigt. Gleich im Anschluß hielt er eine Pressekonferenz ab. Dort erklärte er den Journalisten, die Frage sei nun, ob Moskau OstBerlin dazu drängen werde, mehr nur als ein Passierscheinabkommen im Tausch für die Verlegung des Wahlortes anzubieten.

Kiesinger war davon überzeugt, daß die Sowjets seiner Forderung nachgeben würden. Er erinnerte an den Besuch von Bundeskanzler Adenauer 1955 in Moskau, den er als Vorsitzender des außenpolitischen Bundestagsausschusses begleitet hatte. Damals hatte Adenauer der Aufnahme diplomatischer Beziehungen zur Sowjetunion zugestimmt. Im Gegenzug verpflichtete sich Moskau, die noch zurückgehaltenen Kriegsgefangenen nach Deutschland zurückzuschicken. Kiesinger machte auf Parallelen zwischen 1955 und 1969 aufmerksam: Beide Male schienen die Verhandlungen festgefahren zu sein, beide Male war der Lösung ein Nervenkrieg vorausgegangen. 1955 hätten die Sowjets erst in letzter Minute die deutschen Forderungen akzeptiert. Er hoffe, daß es ähnlich wie damals auch jetzt zu einem solch guten Ende komme.

Und der Bundeskanzler wurde noch redseliger. So müsse man mit Russen umgehen, meinte er zu den Journalisten. Man habe ihm angesehen, berichtet ein Augenzeuge, daß er glaubte, jetzt sei der Durchbruch im Verhältnis zur Sowjetunion gelungen ${ }^{106}$. Wie stark der Kanzler von diesem Gefühl beherrscht gewesen sein mußte, zeigt ein Briefentwurf an einen Freund aus Studentenzeiten, den Augsburger Chefarzt Ottmar Emminger. Der Entwurf wurde am 14. März, also neun Tage nach der Bundespräsidentenwahl, diktiert. „Du wirst sicherlich die Presseberichte über meine Gespräche mit Botschafter Zarapkin und meine Bemühungen verfolgt haben, eine vernünftige Verständigung mit der Sowjetunion zu erzielen“, hieß es da. „Wir waren bereit, über den Ort für die Abhaltung der Bundesversammlung neu zu diskutieren, wenn sich die andere Seite hätte entschließen können, ihrerseits ein Zeichen der Verständigungsbereitschaft zu geben. Das hätte zum Beispiel dadurch geschehen können, daß die Lebensbedingungen der Menschen in Berlin überzeugend verbessert worden wären. "An Verständigungsbereitschaft habe es jedenfalls auf deutscher Seite nicht gefehlt, und man habe ja auch zunächst die Hoffnung haben können, daß die andere Seite zu einem annehmbaren Kompromiß bereit sei. Diese Hoffnung habe sich dann jedoch leider zerschlagen. Er sei davon überzeugt, daß seine Gespräche

104 Vgl. Süddeutsche Zeitung, 24.2.1969.

105 Vgl. Der Spiegel, 3.3.1969, S. 23.

106 Vgl. Dreher, Gespräch mit dem Verfasser, 5.7.1988. 
mit Botschafter Zarapkin aber wesentlich dazu beigetragen hätten, die mancherorts befürchtete große Krise abzuwenden. Inzwischen habe die Bundesversammlung relativ ungestört stattgefunden. Die Bundesregierung werde selbstverständlich auch weiterhin nach Möglichkeiten einer praktischen Verständigung mit der Sowjetunion suchen ${ }^{107}$.

Kiesinger war trotz allem mit sich und der Welt zufrieden. Nach einer langen Kette von Enttäuschungen in den vorangegangenen Monaten schien sich der bedeutendste Erfolg seiner Ostpolitik einzustellen. Erstmals wandten sich die Sowjets nicht an den Außenminister, sondern direkt an ihn. Und auch das war ein Novum: Moskau bot einen Handel an, den Preis bestimmte der Kanzler. So hatte sich Kiesinger die Entwicklung von Anfang an gewünscht. Zudem brauchte er dringend einen Erfolg, der sich innenpolitisch nutzen ließ. Er wollte seine Kanzlerschaft und damit die Große Koalition über 1969 hinaus fortsetzen, aber die CDU/CSU schien ihm darin nicht folgen zu wollen. Die Parteibasis, so erfuhr er etwa von Kohl, sei unzufrieden, verlange einen starken Parteiführer. Der rheinland-pfälzische Landesvorsitzende hatte Kiesinger am 12. Februar 1969 folgenden Lagebericht gesandt: „Vor allen wichtigen Wahlen gab es immer eine Art Hysterie der Akteure. Dies ist nicht unnatürlich und an sich nicht besorgniserregend. Diesem, Normalzustand' mischt sich indes augenblicklich ein deutlicher Unterton des Mißbehagens bei, der auch nicht vor Ihrer Person haltmacht. Der allgemeine Vorwurf ist, daß der Bundesvorsitzende eine zu große Distanz zur eigenen Partei habe. "108 Die Behauptung, der Kanzler lasse Führungswillen vermissen, werde eilfertig kolportiert und bleibe nicht ohne Wirkung. Der Ruf nach dem starken Mann ertöne nicht nur in Kreisen der Wirtschaft, wo er besonders gepflegt werde, sondern auch in der eigenen Partei.

Vor diesem Hintergrund suchte Kiesinger das Stuttgarter Ereignis parteipolitisch zu nutzen. Am Tag nach dem Treffen mit Zarapkin, dem 24. Februar, gab er vor dem Fraktionsvorstand seiner Partei eine klare Richtung an: Mit Passierscheinverhandlungen für Ostern 1969 werde er sich nicht zufriedengeben, er strebe längerfristige Regelungen an. Und um seine Unnachgiebigkeit zu unterstreichen, fügte er hinzu: „Weder durch Druck noch durch Drohungen lasse ich mich einschüchtern. Sie können versichert sein, daß ich absolut hart bleiben werde. " 109 Zunächst geschah aber nichts weiter. Aus dem Osten kam kein Echo. Erst als Schütz am 25. Februar die Initiative ergriff und Ost-Berlin mitteilte, der Senat sei zu Verhandlungen bereit, erhielt er umgehend Antwort. Die Ost-Berliner Nachrichtenagentur $A D N$ verbreitete, die Regierung der DDR habe sich dem Berliner Senat gegenüber bereit erklärt, West-Berliner Bürgern die Möglichkeit von Verwandtenbesuchen in der Hauptstadt der DDR zu Ostern 1969 zu gewähren, vorausgesetzt, die westdeutsche Bundesversammlung werde die Wahl des westdeutschen Bundespräsidenten nicht in West-Berlin durchführen. Das habe der Vorsitzende des Ministerrats in einem Brief an den Regierenden Bürgermeister mitgeteilt ${ }^{110}$.

Eine erste öffentliche Reaktion auf Kiesingers Forderung fand sich in einer Mitteilung des DDR-Presseamtes vom 26. Februar. Dort hieß es, konservative Kreise in West-

107 AdKASt, Kiesinger I - 226, D/IV.6, A 003, Kiesinger an Emminger vom 14.3.1969, Vermerk: „Es wurde keine Antwort des Herrn BK abgesandt“, S. 1 f. Der Entwurf war eine Antwort auf den Brief Emmingers vom 15.2. Dieser hatte kritisiert, daß die Bundesregierung an Berlin als Tagungsort festhalte; vgl. AdKASt, Kiesinger I - 226, D/IV.6, Emminger an Kiesinger vom 15.2.1969.

108 AdKASt, Kiesinger I - 226, D/IV.6, A 005, Kohl an Kiesinger vom 12.2.1969, S. 1 f.

109 Der Spiegel, 3.3.1969, S. 25.

110 Vgl. Die Welt, 26.2.1969; vgl. auch DA 3 (1969), Mitteilung des DDR-Presseamtes über Stophs Brief an Schütz, S. 308. 
deutschland versuchten, „unzumutbare Forderungen an die Deutsche Demokratische Republik“ zu stellen. Doch der Kanzler ließ sich nicht beirren. Ohne ein Angebot mit längerfristiger Perspektive werde die Wahl in Berlin stattfinden, bekräftigte er noch einmal Wehner gegenüber. Wehner bot an, seinen Kontaktmann, den Ost-Berliner Anwalt Wolfgang Vogel, in dieser Sache als Vermittler einzusetzen. Vogel war schon für den Gesamtdeutschen Minister Mende der Verbindungsmann zur Regierung der DDR in der heiklen Frage des Häftlingsfreikaufes gewesen. In der Zeit der Großen Koalition setzte er diese Tätigkeit fort; Vogel war mit Wehner schon einige Male geheim zusammengetroffen ${ }^{111}$. Der Minister nutzte jetzt den Kontakt, um die Vorstellungen der Bundesregierung noch einmal zu verdeutlichen. Er schrieb:

„Sehr geehrter Herr Vogel! Bitte, entschuldigen Sie, daß ich Ihnen brieflich mitzuteilen versuche, was ich im Nachgang zu meiner telefonischen Bemerkung vom 13. Februar gern zur Kenntnis Ihrer Seite bringen möchte, nachdem Sie mir vor vierzehn Tagen gesagt hatten, Sie sollten mir etwas mitteilen und danach gefragt hatten, ob ich etwas dazu zu sagen hätte. Ich bitte Sie herzlich, meinen Brief lediglich als eine Fortsetzung meiner damals auf Ihre Frage gegebenen Antwort zu verstehen, das heißt, ihn nicht als einen Brief aufzufassen, durch den ich Ihre anwaltlichen Aufgaben und Pflichten mit etwas belasten möchte, das außerhalb Ihrer Pflichten liegt. Ich hoffe, daß Sie selbst und Ihr Auftraggeber unter diesen Umständen mein Schreiben nicht als unangemessen auffassen.

Vor vierzehn Tagen hatte ich Ihnen auf die Frage, die Sie an die Mitteilungen über Maßnahmen aus Anlaß der Einberufung der Bundesversammlung zum 5. März nach Berlin geknüpft hatten, geantwortet, daß ich unter den Verantwortlichen in Bonn keinen getroffen hätte, der aus Lust an einer Art von Herausforderung oder Provokation am Tagungsort Berlin festhielte. Aber es ergäbe sich eine Art von $Z$ wangsläufigkeit aus der Steigerung der Auseinandersetzung über das Recht oder die Rechtmäßigkeit in dieser Frage.

Heute möchte ich hinzufügen: Die Bundesversammlung muß nicht in Berlin tagen. Sie kann an einem anderen Ort stattfinden. Damit das noch ermöglicht werden kann, müssen aber alle am Streit um die Rechtmäßigkeit der Tagung beteiligten Seiten dazu beitragen, die Auseinandersetzung vom Ballast der Prestigebedürfnisse zu befreien, so berechtigt auch jeder Seite ihr eigener Anspruch erscheinen mag.

Die Bundesregierung hat der Regierung der UdSSR zu verstehen gegeben, daß sie einen entsprechenden Beitrag zu leisten gewillt ist. Die Regierungen der Vereinigten Staaten Amerikas, Großbritanniens und Frankreichs, die mit der Regierung der UdSSR eine besondere Verantwortung in Berlin tragen, haben zu verstehen gegeben, daß sie die Bemühungen der Bundesregierung billigen.

In Berlin selbst sind am 26. Februar Beauftragte des Senats und des Vorsitzenden des Ministerrats der DDR zusammengetreten, um nach einem vorausgegangenen Schriftwechsel über spezielle Berliner Probleme, insbesondere die Möglichkeiten zur Aufhebung der Benachteiligung der Einwohner West-Berlins im Verkehr mit dem anderen Teil Deutschlands, zu verhandeln.

Ich vermag mich des Eindrucks nicht zu erwehren, daß die begrüßenswerten Ansätze zu solchen Verhandlungen in Berlin belastet werden, wenn sie unter dem Druck der Vorbedingungen einer Verlegung des Tagungsortes der Bundesversammlung stehen, für die der Senat nicht zuständig ist. Wenn es trotz der unterschiedlichen Auffassungen über die Rechtmäßigkeit der Veranstaltung der Bundesversammlung in Berlin möglich gemacht werden soll, die Spannungen zu mindern, so geht das nur um den Preis gleichzeitig von jeder beteiligten Seite zu leistender Beiträge, deren Summe eine Situation ergibt, die von allen als der Beginn von Handlungen, die der Verständigung dienen, gewertet werden kann.

Wenn die Bundesregierung zu verstehen gegeben hat, daß ein überzeugender Beitrag in Richtung größerer Freizügigkeit in Berlin sie veranlassen würde, den Tagungsort der Bundesversammlung zu verlegen, so bedeutet das, daß jede der beteiligten Seiten im Vertrauen darauf, daß die anderen entsprechend handeln, ihren Schritt tut. Das ist weder das Verlangen nach Vorleistungen noch ein Junktim, sondern es ist der Beginn von Handlungen jeder Seite, die der Verständigung dienen.

Würde zum Beispiel die Regierung der DDR auf der Grundlage ihrer eigenen Gesetze für die Einwohner West-Berlins die Besuchs- und Reisemöglichkeiten entsprechend den Regelungen ord-

111 Vgl. Mende, Wende, S. 140; Kreutzer, Gespräch mit dem Verfasser, 22.8.1988; siehe auch Schacht, Ulrich/Schwilk, Heimo, Gezielte Agitation und Propaganda, in: Die Welt, 9.1.1994. 
nen, die für Westdeutsche gelten, das heißt, daß der West-Berliner Personalausweis Besuchsreisen von West-Berlinern ermöglicht, wäre das ein überzeugender Schritt.

Ich bitte um Entschuldigung dafür, daß ich ein Beispiel angeführt habe. Meine Sache ist es nicht, Ihrer Seite Vorschläge zu machen; ich möchte nur verdeutlichen helfen, was meine Seite meint, wenn sie von überzeugenden Schritten spricht.

Deshalb versage ich es mir auch, eine Reihe weiterer Möglichkeiten anzuführen. Aber ich darf wohl damit schließen, daß ich zu bedenken bitte, wie sehr es die Lage verbessern würde, wenn es entsprechend dem Angebot des Bundeskanzlers im Brief vom 28. September 1967 an den Vorsitzenden des Ministerrats der DDR und entsprechend der Vollmacht, die die Volkskammer am 9. August 1968 dem Ministerrat der DDR erteilt hat - schon zur Fühlungnahme von Bevollmächtigten beider Seiten gekommen wäre.

Erlauben Sie mir, bitte, auch am Schluß meines Schreibens Sie um Verzeihung dafür zu bitten, daß ich Sie, verehrter Herr Vogel, damit belade, dieses Schreiben weiter zu geben; ich hätte mir die Freiheit nicht genommen, wenn ich nicht meinte, auf Grund der besonderen Mitteilung, die Sie mir vor vierzehn Tagen zu machen hatten, meiner damaligen Antwort diesen Nachtrag hinzufügen zu dürfen. In vorzüglicher Hochachtung, Ihr ergebener Herbert Wehner. "112

Kaum ein Brief Wehners demonstriert so deutlich wie dieser, was Grass mit seiner Beobachtung meinte, Wehner lege seine Sätze wie Irrgärten an ${ }^{113}$. Das betrifft vor allem die heiklen Stellen seines Textes. Positionen, die nicht im Widerspruch zu denen der DDRRegierung standen, hat Wehner einfach und kurz dargestellt. Das gilt etwa für die Botschaft, die Bundesversammlung müsse nicht in Berlin, sondern könne auch an einem anderen Ort tagen. In komplizierte Satzkonstruktionen verpackte er dagegen Forderungen und Interpretationen der Bundesregierung. Sie sind in vielen kleinen, zwischen präzisen und allgemein gehaltenen Nebensätzen untergebracht. Das alles hat nur einen Zweck: Wehner will nicht aufdringlich, nicht unfreundlich erscheinen, den Adressaten nicht verschrecken. Man sieht das deutlich, wenn er die Vorbedingung der DDR für PassierscheinVerhandlungen kritisiert. Wenn Spannungen vermindert werden sollten, so heißt es da, dann gehe das nur „um den Preis gleichzeitig von jeder beteiligten Seite zu leistenden Beiträge", deren Summe - und hier wird Wehner wieder allgemein - eine Situation ergebe, „die von allen als der Beginn von Handlungen, die der Verständigung dienen, gewertet werden kann“. Indem Wehner die Verantwortlichkeit scheinbar auf die beiden beteiligten Seiten gleichermaßen verteilt, hofft er, der für die DDR-Führung bestimmten Nachricht des Briefes etwas von ihrer Schärfe zu nehmen. Denn das war der Zweck des Briefes: Bevor es zu Verhandlungen kommen konnte, mußte Ost-Berlin seine Vorbedingung - die Verlegung des Ortes der Bundesversammlung - zurücknehmen. Ulbricht hatte ja seinerseits deutlich gemacht, daß erst zu dem Zeitpunkt verhandelt werden konnte, wenn die Bundesregierung die Verlegung bereits angeordnet hatte. Unter dieser Voraussetzung war jedoch von vornherein die Aufnahme von Verhandlungen aussichtslos - abgesehen von den langfristigen Verbesserungen im Reiseverkehr für West-Berliner, die Kiesinger seinerseits als Bedingung für den Rückzug der Bundesversammlung aus Berlin genannt hatte. Damit schien die Lage hoffnungslos verfahren zu sein, noch bevor Wehner seinen Brief absandte.

Tatsächlich zahlten sich seine Bemühungen nicht aus. Statt eines erhofften großzügigen Angebots erhielt die Bonner Regierung am nächsten Tag einen Hinweis ganz ande-

112 AdKASt, Kiesinger I - 226, D/IV.6, Wehner an Vogel vom 27.2.1969. Auf einem beiliegenden Zettel hat Wehner handschriftlich vermerkt: „Sehr verehrter Herr Bundeskanzler! Zu Ihrer Information sende ich Ihnen diese Kopie eines Schreibens, über das ich am 26. II. kurz mit Ihnen gesprochen hatte. Ihr ergebener Herbert Wehner."

113 Vgl. Grass, Tagebuch einer Schnecke, S. 70; siehe auch Baring, Machtwechsel, S. 614. 
rer Art: Die Sowjetunion behauptete am 28. Februar, in West-Berlin würden Rüstungsgüter hergestellt. Das sei ein eindeutiger Verstoß gegen das Potsdamer Abkommen. In einer Note an die DDR-Regierung forderte sie dazu auf, die notwendigen Maßnahmen zu ergreifen, die dieser „illegalen militaristischen Tätigkeit“ ein Ende setzen würden ${ }^{114}$. Daraufhin sperrte die DDR die Transitstrecke in den folgenden Tagen jeweils für mehrere Stunden. Der Druck auf die Bundesregierung verstärkte sich, als Moskau am 2. März erklärte, für den Lufttransport der Mitglieder der Bundesversammlung nach Berlin könne sie keine Sicherheitsgarantie geben ${ }^{115}$.

Mit dem Umschalten der Sowjets auf die harte Linie ${ }^{116}$ war endgültig die Aussicht auf eine Verständigung zunichte gemacht ${ }^{117}$. Gestützt auf Erklärungen der Verbündeten, beharrte Bonn jetzt auf dem Wahlort Berlin. Noch einmal traf sich Kiesinger mit Zarapkin, aber man ging ohne ein greifbares Ergebnis wieder auseinander. Vor den Fernsehkameras erklärte der Kanzler am 1. März, die andere Seite sei nicht bereit, einen überzeugenden Verständigungsbeitrag zu leisten. Die Bundesversammlung werde daher in Berlin stattfinden, und man werde den Nervenkrieg eben durchstehen müssen ${ }^{118}$. Am 5. März wurde Heinemann schließlich - trotz aller Pressionen und Propaganda ${ }^{119}$ - in Berlin zum Bundespräsidenten gewählt. Die Veranstaltung verlief wider Erwarten ohne größere Störungen. Lediglich der Lärm einiger sowjetischer Düsenflugzeuge erinnerte an die unangenehmen Begleitumstände im Vorfeld der Wahl.

\section{Das Zerwürfnis zwischen Kiesinger und Webner}

Während sich Kiesinger und die Union in den letzten Wochen vor der Bundespräsidentenwahl vor allem mit der Frage des Wahlortes beschäftigt hatten, galt das Interesse der Sozialdemokraten vorrangig dem Sieg ihres Präsidentschaftskandidaten. Es war den Sozialdemokraten sogar willkommen, daß sich der Koalitionspartner ganz auf das Ortsproblem zu konzentrieren schien. Ein Mitglied des Kreßbronner Kreises vertraute einem Journalisten an, die SPD halte absichtlich das Thema "Wahlort" in der Diskussion,

114 EA 24 (1969), Folge 8, S. D 196 f. Das Kriegsgüterthema war schon einmal, am 19.2., von Radio Moskau angesprochen worden, wurde danach aber nicht mehr aufgegriffen; vgl. Wettig, Die Berlin-Krise, S. 692.

115 Vgl. DA 3 (1969), S. 313.

116 Vgl. Wettig, Die Berlin-Krise 1969, S. 690 f. Die Sowjetunion hatte selbst in der Zeit der Verhandlungen über eine Verlegung des Tagungsortes ihre Propaganda nicht eingestellt. Sie begleitete die diplomatischen Bemühungen mit sanften Drohungen. Am 22.2. wurden die Deutschen darauf hingewiesen, daß UdSSR und DDR die „Bedingungen“ West-Berlins verändern könnten. Die sowjetischen Kommentatoren hoben die "Gefährlichkeit" der geplanten Bundesversammlung hervor. Es wurde versucht, den Eindruck einer ständig wachsenden Bewegung in der Bundesrepublik gegen die Versammlung zu erwecken. Hinzu kam, daß am 20.2. Manöver angekündigt wurden, die an den Zugangswegen nach West-Berlin stattfinden sollten.

117 Wettig (Die Berlin-Krise, S. 692) meint, vor allem die Verärgerung der Sowjets über die Ablehnung des Passierscheinangebots durch den Bundeskanzler habe zu zum Teil wütenden Angriffen geführt. Das Angebot habe den Sowjets Selbstüberwindung gekostet, und Bonn habe in ihren Augen ,arrogant aufgetrumpft“.

118 Vgl. EA 24 (1969), Folge 8, S. D 198.

119 Vgl. DA 3 (1969), S. 316; die Sowjetunion war vorsichtig genug, keine weiteren Maßnahmen anzukündigen. Am 5.3. erklärte Radio Moskau: Ausgehend von der Rechtslage würde die Einbeziehung West-Berlins in die DDR die beste Lösung der West-Berlin-Frage sein. Aber man dürfe nicht vergessen, daß die drei Westmächte bisher nicht den Wunsch bekundet hätten, auf ihre Rechte betreffend West-Berlin zu verzichten. Vgl. auch ebenda, S. 307-316, die wichtigsten Äußerungen von seiten DDR und UdSSR vom 27.2. bis 5.3.1969. 
um die CDU/CSU von der Frage abzulenken, wer denn die Wahl gewinnen werde120. Unter allen Umständen wollte die SPD diesmal ihren Kandidaten durchbringen. Für Wehner besaß dieses Ziel jenen Stellenwert, den die Bildung der Großen Koalition im Herbst 1966 besessen hatte. Er sandte Kiesinger Zeitungsausschnitte, aus denen hervorging, daß die Person Heinemanns von Unionspolitikern verleumdet worden war. Beispielsweise erhielt der Kanzler die Ausführungen des Bundestagsabgeordneten Heinrich Aigner in einer Veranstaltung der Jungen Union. Aigner hatte dort, wie das Amberger Volksblatt berichtete, dem Justizminister angekreidet, daß dieser „in der Notzeit nicht zu unserem Staat gestanden" und erst nach 1945 die deutsche Staatsbürgerschaft wieder beantragt habe. „Ich brauche Ihnen wohl nichts hinzuzufügen“, schloß Wehner das Schreiben ${ }^{121}$.

Mißtrauisch beobachteten die Sozialdemokraten die Wahlvorbereitungen der Union. Im Februar 1969 galt eine Sorge der Möglichkeit, daß Schröder mit den Stimmen der rechtsradikalen NPD-Wahlmänner siegen konnte. Dagegen leitete die SPD vorsorglich eine öffentliche Kampagne ein. Schröder galt als stockkonservativer Politiker. Wehner und andere befürchteten, daß ein Bundespräsident Schröder eine erneute Belastung für die Bundesrepublik im In- und Ausland darstellen könne. Die NPD dürfe nicht den Ausschlag geben, verkündete Schmidt am 15. Februar 1969, und die Parole wirkte ${ }^{122}$. Wehner ärgerte besonders, daß Kiesinger alles laufen ließ. Er warf dem CDU-Vorsitzenden vor, nicht von Anfang an mit Entschiedenheit für einen gemeinsamen Kandidaten in seiner Partei geworben zu haben. Noch Monate später erklärte Wehner zornig: „Er [Kiesinger] hat ja manche Fehler gemacht, ein paar Tage darauf den Fehler, der uns alle um ein Haar in eine fürchterliche Situation gebracht hätte: einen Bundespräsidenten mit Hilfe der NPD wählen zu lassen." 123

In dieser Situation tat Wehner, was zu tun übrig blieb. Da der Wahlausgang von der FDP abhing, gab er Scheel und Weyer, dem Landesvorsitzenden von Nordrhein-Westfalen, das entscheidende Argument für die Unterstützung des SPD-Kandidaten an die Hand: die Absage an eine Wahlrechtsänderung. Falls die FPD Heinemann wähle, sei das Thema vom Tisch, erklärte er. Das sicherte die Zustimmung der Liberalen zur Wahl Heinemanns. Bei der letzten Vorbesprechung der FDP-Wahlmänner auf der Dachterrasse des Berliner Hotels Europäischer Hof erklärte Weyer: Wenn Heinemann am nächsten Tag gewählt werde, werde die Wahlrechtsreform nicht mehr aufgegriffen. Zu dieser Mitteilung sei er von Ministerpräsident Heinz Kühn und von Wehner ausdrücklich autorisiert worden ${ }^{124}$. Ein Argument von gleichem oder gar stärkerem Gewicht konnten die Befürworter Schröders nicht vorweisen. Bei einer Probeabstimmung hatten zuvor noch 23 Wahlmänner für Schröder gestimmt, was zur Wahl des Unionskandidaten gereicht hätte. Bei einer erneuten Abstimmung bekam er nur noch fünf Stimmen. Am Ende reichte es für Heinemann, dank der FDP. Wehner hatte sich durchgesetzt.

120 Dreher, Gespräch mit dem Verfasser, 5.7.1988.

121 AdKASt, Kiesinger I - 226, D/IV.6, Wehner an Kiesinger vom 12.11.1968, S. 1 f. Die Auflistung von verbalen „Entgleisungen“ der anderen Seite überließ Wehner sonst dem Vorsitzenden oder dem Fraktionsvorsitzenden; vgl. etwa Briefe Brandts vom 9.6.1967 oder 14.3.1968; Heck und besonders Strauß schickten ihrerseits Listen und Zeitungsausschnitte über Verunglimpfungen der Unionsführer durch Sozialdemokraten.

122 Vgl. Welt am Sonntag, 16.2.1969.

123 Terjung (Hrsg.), Der Onkel, Wehner am 26.1.1970, S. 186.

124 Vgl. Mende, Wende, S. 296, sowie Baring, Machtwechsel, S. 113 ff.; Hildebrand (Erhard, S. 391 f.) deutet diesen Zusammenhang lediglich an. 
Weniger Erfolg war ihm allerdings beschieden, als er Kiesinger drei Tage vor der Berliner Präsidentenwahl von der Notwendigkeit überzeugen wollte, das Angebot aus OstBerlin anzunehmen. Am Abend des 2. März waren im Palais Schaumburg die beiden Gründungsväter der Koalition zusammengekommen ${ }^{125}$. Der Minister suchte den Kanzler davon zu überzeugen, daß dieser jetzt unbedingt selbst die Initiative übernehmen müsse. Damals habe es "nicht nur eine Chance“, sondern „die Notwendigkeit" gegeben, an den letzten Brief Kiesingers für den DDR-Ministerratsvorsitzenden Stoph anzuknüpfen, betonte Wehner im Rückblick ${ }^{126}$. Um überhaupt einmal von den großen Forderungen wegzukommen, „dem Anerkennungswunsch der SED und den Hoffnungen auf die Wiedervereinigung bei uns“, sollten beide deutschen Seiten „zunächst einmal“ ein Gespräch beginnen, sich „an einen Tisch“ setzen. In dem oben zitierten Brief an den Ost-Berliner Anwalt Vogel hatte der Minister erklärt, die Lage werde sich sehr verbessern, wenn es zu Kontakten zwischen Bevollmächtigten der jeweiligen Regierung kommen könnte ${ }^{127}$. Der Bundeskanzler hatte dies ja auf sein Drängen hin im September 1967 angeboten, und auch Ulbricht stellte im August 1968 Gespräche in Aussicht. Wehner wollte zunächst die offenen, kleinen Fragen besprechen. Er dachte an die Zahlungsforderung der DDR für die Post, die wirtschaftlichen Beziehungen, eben die Probleme des Modus vivendi zwischen beiden Staaten. Alle anderen Fragen sollten zunächst noch warten. Wichtig sei jetzt allein die Herstellung direkter Kontakte ${ }^{128}$.

Während der Minister den Kanzler zur Aufnahme von Verhandlungen mit dem DDRRegime drängte, hatte er in einem Zeitungsartikel der SED-Führung die Schuld daran gegeben, daß keine Verhandlungsgespräche stattgefunden hatten. Die DDR hätte die Bundespräsidentenwahl in Berlin verhindern können. Der Ministerrat hätte jederzeit im Rahmen seiner eigenen Gesetzgebung anordnen können, daß „zum Beispiel die Benachteiligung der Einwohner West-Berlins bei Besuchen und Reisen in den anderen Teil der Stadt oder Deutschlands aufgehoben würde“. Es sei ihm nicht unbekannt gewesen, deutete hier Wehner seinen Vermittlungsversuch über Vogel an, daß „auch das als ein Zeichen verstanden worden wäre" 129 .

Tatsächlich vertrat Wehner hier aber eine Politik, die er selbst nicht guthieß. Nach außen stellte er sich hinter den Entschluß des Kanzlers. Im privaten Gespräch jedoch drang der Minister energisch auf Kiesingers Einverständnis für die Aufnahme von Verhandlungen. Kiesinger erinnerte sich später daran, daß Wehner mit besonderem Nachdruck gesprochen habe ${ }^{130}$. Dabei sei es diesem gar nicht um die Zugeständnisse gegangen, betonte Kiesinger im Rückblick. Wehner habe vielmehr die Verlegung der Bundesversammlung aus Berlin schon als Beginn einer Einigungspolitik verstanden. Der Minister habe ihm an vielen Abenden seine Konzeption nahezulegen versucht. Unter dem Stichwort der „demokratischen Lösung " der nationalen Frage habe Wehner den sozialdemokratischen Versuch verstanden, die SED für ein liberales politisches System in der DDR zu interessieren. Ein solcher Prozeß werde eine Annäherung zwischen beiden deutschen Staaten erleichtern, könne aber nur gelingen, wenn die Sowjetunion diesem Prozeß ihre Zustim-

125 Vgl. Schmoeckel, Zeittafel; nur dieser Abend kommt laut Terminkalender für das Gespräch in Frage. Brandt und Duckwitz waren zunächst auch anwesend.

126 Terjung (Hrsg.), Der Onkel, S. 186; dort auch die folgenden Zitate.

127 Vgl. AdKASt, Kiesinger I - 226, D/IV.6, Wehner an Vogel vom 27.2.1969, S. 2.

128 Vgl. Die Welt, 27.3.1969.

129 Bulletin, 4.3.1969.

130 Vgl. AdKASt, Kiesinger I - 226, A 322, Gespräch mit Löwe, 31.1.1978, S. 60. 
mung nicht verweigere. Und allein aus der Erwägung heraus, Moskau nicht zu verärgern, habe der Minister für gesamtdeutsche Fragen auf die Verlegung der Bundespräsidentenwahl von Berlin nach Bonn gedrängt, behauptete Kiesinger im Jahre 1978131.

Zum ersten Mal setzte hier jedoch Kiesinger seine Deutschlandpolitik gegen Wehner durch. Bisher hatte der Kanzler in den wichtigen Fragen immer nachgegeben, wenn sein Minister ihn drängte. Das war geschehen, als Wehner im Frühjahr 1967 den Briefwechsel Kiesingers mit Stoph initiierte und als er in der zweiten Antwort des Kanzlers im September desselben Jahres unbedingt einen Bevollmächtigten der Bundesregierung forderte. Noch im März 1968 hatte Kiesinger in seiner Regierungserklärung die DDR in das vorgeschlagene Gewaltverzichtsabkommen ausdrücklich mit einbezogen. Auch dies ging auf Wehner zurück.

Aber im März 1969 war der Kanzler entschlossen, sich nicht länger in der Deutschlandpolitik von seinem Koalitionspartner beirren zu lassen. Die Aufmerksamkeit, mit der die Bundesregierung bisher Ost-Berlin bedacht hatte, sollte nun endlich allein auf Moskau konzentriert werden. Kiesinger hatte im Grunde nie etwas mit den Vertretern der SED zu tun haben wollen und erwartete von ihnen keine Hilfe in der Ostpolitik. Schon im Oktober 1967 bekannte er sich dazu, die DDR isolieren zu wollen ${ }^{132}$. Da die SED-Führung sich gegen das Verhandlungsangebot Bonns sperrte, fiel es nicht schwer, den Kommunisten eine entspannungsfeindliche Haltung zu unterstellen. Kiesinger wollte Ulbricht als unverbesserlichen Kalten Krieger ins ostpolitische Abseits stellen. Im Frühjahr 1969 glaubte er, daß Moskau bereit zu sein schien, den direkten Kontakt zum Bundeskanzler zu suchen. Der Draht nach Ost-Berlin war aus dieser Sicht unbedeutend und überflüssig geworden.

Damit zerstörte Kiesinger die gemeinsame politische Basis mit Wehner. Er nahm dem Vernunftbündnis den Grund, auf dem die Große Koalition aufgebaut war. Kiesinger habe ihm an diesem Abend, dem 2. März 1969, sein wahres Gesicht gezeigt, meinte der SPDPolitiker später. Der Kanzler habe ihm immer den Eindruck vermittelt, auch ihm gehe es in erster Linie um den Kontakt zur DDR-Regierung. Aber das sei wohl falsch gewesen, meinte ein ernüchterter Wehner ${ }^{133}$. Seine tiefe Enttäuschung darüber brachte Wehner allerdings erst ein dreiviertel Jahr später, im Januar 1970, in einem Interview zum Ausdruck. Kiesinger habe mit dem, was er in den Jahren zuvor erklärt habe, seine wahre Haltung „verdeckt“ und „zeitweilig auch verschleiert“, meinte er dort. Je näher der Wahlkampf herangerückt sei, desto krasser sei die wirkliche Auffassung des Kanzlers in den Vordergrund getreten: Es habe gar keinen Sinn, mit „denen“ - der DDR-Führung - zu reden. Im Grunde genommen sei das nach Meinung Kiesingers „nur dialektischer Zeitvertreib“ gewesen. Und auf die Frage, welche Bedeutung dieses Gespräch im März 1969 gehabt habe, antwortete Wehner kurz: „Damals war das eine Möglichkeit, an der wir uns zerstritten haben. Das war die Frage einer Nacht."

Der Einschnitt im Verhältnis zwischen Wehner und Kiesinger war größer als nur die Meinungsverschiedenheit in einem Punkt. In einer Nacht war das Verhältnis irreparabel zerbrochen. Wehner empfand die Begründung, die Kiesinger ihm gab, als endgültige Absage an seine Zielsetzung. Die Politik der Isolierung [der DDR] wäre keine Politik, die vor den Menschen, vor der Geschichte Bestand hätte“, meinte Wehner mit Blick auf die Argumente, die Kiesinger vorgebracht hatte. Der Minister für gesamtdeutsche Fra-

131 Ebenda, S. 46 und 60.

132 Vgl. AdKASt, Kiesinger I - 226, D/II.1, A 008, Gespräch mit Wirsing, 5.10.1967, S. 5.

133 Vgl. Terjung (Hrsg.), Der Onkel, Wehner am 26.1.1970, S. 186; dort auch die folgenden Zitate. 
gen hielt weiter an dem fest, was er schon im Januar 1967 erklärt hatte: Falls sich die DDR liberalisiere und sich etwa dem Modell Jugoslawien angleiche, „dann könnte sich sogar die Frage einer völkerrechtlichen Anerkennung in einem neuen Licht stellen" 134 .

Von diesem Zeitpunkt an, so berichtet Neusel, habe Wehner begonnen, vor anderen schlecht über Kiesinger zu reden. So sei ihm „hintenherum“ zugetragen worden, daß Wehner in einem Gremium der SPD sich „erstmals abschätzig über den Kanzler“ geäußert habe ${ }^{135}$. Auch Kiesinger hat den Meinungsunterschied zu Wehner in der Frage der Wahlortverlegung als Entzweiung empfunden. Damals sei es zu einem „gewissen Bruch“ zwischen ihm und Wehner gekommen, meinte er in einem Gespräch 1978. Aber noch im nachhinein rechtfertigte er seine damalige Weigerung, den Vorstellungen des Ministers zu folgen. Wehner habe „um lächerlicher Zugeständnisse willen“ von Berlin als Wahlort abrücken wollen ${ }^{136}$.

Die nun unversöhnlich gegenüberstehenden Auffassungen der beiden hatten Konsequenzen für Kiesingers Wunsch, das Bündnis über 1969 hinaus fortzusetzen. Es zeigte sich, daß die Gemeinsamkeiten offensichtlich im Frühjahr 1969 aufgebraucht waren. Von jetzt an galt die Devise in beiden Lagern, die Koalition zwar unter allen Umständen bis zu den Bundestagswahlen im September fortzuführen. Es sollten allerdings keinerlei Zugeständnisse gemacht werden, die über die gezogenen Grenzen hinausgingen. Nur noch der minimalste Konsens wurde gesucht. Auch wenn Kiesinger die Fortsetzung der Koalition anstrebte, wozu er sich übrigens öffentlich erst gegen Ende des Wahlkampfes bekannte, mußte ihm nun bewußt werden, daß die Chancen für eine Erneuerung des Bündnisses mit der SPD gering waren.

Und wie sah es bei Wehner aus? Es ist kein Zufall, daß sich der stellvertretende SPDVorsitzende nach dem 5. März 1969 voller Hochachtung und sogar mit Wärme über Scheel äußerte. Die Wahl Heinemanns zum Präsidenten sei eine große Tat Scheels gewesen, etwas, was er nie vergessen werde. Ein „vorfrühlingshafter Hauch" von gemeinsamen sozialliberalem Aufbruch, schreibt Baring, habe in der Luft gelegen ${ }^{137}$. Kiesinger, der sich von der Wahl Heinemanns eine Verbesserung des Koalitionsklimas erhofft hatte, mußte erleben, daß der Sieg des Sozialdemokraten im Gegenteil eine Koalition zwischen FDP und SPD wahrscheinlicher machte. Und an dieser Entwicklung hatte auch er seinen Anteil.

\section{Kritik an der Partei- und Machtpolitik Kiesingers}

Im Frühjahr 1969 fiel das gemeinsame Fundament der beiden wichtigsten Politiker der Großen Koalition auseinander. Kiesinger trug auf seine Weise dazu bei. Nie hat er sich sprunghafter und zweideutiger verhalten als in der Koalitionsfrage seit dem Herbst 1968. Von einer konsequent verfolgten Zielsetzung läßt sich nur wenig erkennen. Das ist vermutlich auch auf eine persönliche Schwäche zurückzuführen: seiner Konfliktscheu. Kiesinger ging schwierigen Problemen gern aus dem Weg - in der Außen- wie in der Innenpolitik. Er vermochte nicht, Richtungen in der Partei zu beeinflussen, und es fehlte ihm ein Gespür dafür, wann er sich gegen drohende Niederlagen zu stemmen hatte. Der Kanzler mochte ahnen, daß die Koalition unaufhaltsam und unüberbrückbar auseinanderdriftete, aber er fügte sich in das Schicksal.

134 Ebenda, S. $184 \mathrm{f}$.

135 Neusel, Gespräch mit dem Verfasser, 30.11.1989.

136 AdKASt, Kiesinger I - 226, A 322, Gespräch mit Löwe, 31.1.1978, S. 60.

137 Baring, Machtwechsel, S. 121. 
Für Kiesinger schien das Regieren oftmals einen rein abstrakten Charakter zu haben. Karl-Ulrich Majer, der als Lektor seiner Bücher das Vertrauen des Kanzlers besaß, hat einmal von dem Eindruck berichtet, dieser habe sich mit einer gewissen Neugier im Zentrum der Macht bewegt ${ }^{138}$. Kiesinger wollte das Geheimnis der Macht kennenlernen und enträtseln. Er war darin eher einem Wissenschaftler und Forscher ähnlich, der im Kanzleramt allgemein die Möglichkeiten und Grenzen des Regierungschefs studierte, anstatt selbst die Hebel der Macht für seine Zwecke zu betätigen. Nur so läßt sich vielleicht erklären, warum Kiesinger in dieser Zeit den Eindruck vermittelt, als habe er sich zu einer widersprüchlichen Politik treiben lassen, die auch zum Teil den eigenen Interessen widersprach.

Kiesinger wollte an der Macht bleiben. Aber wie sahen seine Optionen aus? Da er sich mit der FDP nicht verständigte, blieb die Hoffnung auf die absolute Mehrheit der eigenen Partei oder die Fortsetzung der Koalition mit der SPD. Zwar mag im nachhinein der knappe Ausgang der Bundestagswahl - der Union fehlte nur 0,9 Prozent zur absoluten Mehrheit - suggerieren, daß Kiesinger zu Recht allein auf das Ziel der absoluten Mehrheit setzte. Dies hat er auch später so behauptet ${ }^{139}$. Aber konnte sich der Unionsvorsitzende erlauben, nur dieses sehr vage und unsichere Ziel anzusteuern? Das klingt nicht überzeugend. Wahrscheinlicher ist, daß er vor der Fraktion seine Hoffnung auf die Fortsetzung der Koalition verschleierte. Vermutlich hoffte er, daß sich mit der Zeit die Stimmung in der Union gegenüber der SPD zum Positiven wandeln und zudem das Ergebnis so knapp ausfallen würde, daß eine andere als die Neuauflage der bestehenden Koalition erst gar nicht in Frage kam.

Was blieb ihm auch anderes übrig? Er selbst hatte - ungewollt - alles getan, um dem Bündnis die Zukunft zu rauben. Begonnen hatte es mit seinem Versäumnis, CDU/CSU und SPD auf einen gemeinsamen Kandidaten bei der Bundespräsidentenwahl zu verpflichten. Das wog um so schwerer, als der Kanzler seinem Minister und engen Kontaktmann anfänglich offenbar den Eindruck vermittelt hatte, die Union werde einen SPDPräsidentschaftskandidaten unterstützen. Schon im Frühsommer war klar, daß andere CDU-Führer wie Barzel, Heck und Kohl darauf bestanden, einen eigenen Unionskandidaten aufzustellen. Anstatt aber zu diesem Zeitpunkt seine Absicht deutlich zu machen und für einen gemeinsamen Kandidaten in der eigenen Partei zu werben, schloß sich Kiesinger diesem Vorhaben an. Es sieht so aus, als ob er sich selbst eingestehen mußte, in dieser Sache bereits alle Fäden aus der Hand gegeben zu haben. Seitdem konnte der CDU-Vorsitzende nur noch hoffen, daß die SPD ihren Mann am Ende - auch ohne seine Hilfe - durchbekommen werde.

Völlig unverständlich war sein Taktieren bei der Kandidatensuche im eigenen Lager. Offenbar unterstützte er eine Persönlichkeit, die von der SPD nicht als Kampfkandidat verstanden werden konnte. Weizsäcker war klarer Außenseiter in der Fraktion, und Kiesinger beging mit seiner Wahl einen weiteren Fehler. Weil er von dem Vorschlag vermutlich selbst nicht überzeugt war, setzte er sich nicht glaubhaft genug für Weizsäcker ein. Viel zu spät schien er zu realisieren, daß der halbherzige Einsatz zu einer innerparteilichen Niederlage für ihn selbst geworden war. Die Ehrenerklärung für Schröder änderte daran nichts mehr. Damit setzte sich die Kette von Fehleinschätzungen und Fehlentscheidungen fort. Als Folge begab sich Kiesinger noch mehr in die Abhängigkeit seiner Partei. Er büßte Autorität ein, und seine innerparteiliche Position wurde noch schwächer.

138 Vgl. Majer, Gespräch mit dem Verfasser, 16.12.1988.

139 Vgl. AdKASt, Kiesinger I - 226, E/IV.1, A 355, Kiesinger an Dichgans vom 9.1.1980, S. 5. 
Diese Entwicklung hatte Auswirkungen auf den außenpolitischen Entscheidungsprozeß. Kiesinger billigte dem Koalitionspartner künftig kaum noch einen Freiraum zu. Die wachsende Kritik am Kanzler innerhalb seiner Partei ließ ihn sich auch in höherem Maße auf seine Stärke, die Außenpolitik, besinnen und nach einem eigenen Weg der Ostpolitik suchen. Daher war vor allem sein parteipolitisches Ungeschick daran schuld, wenn der Wille zu gemeinsamer Politik zwischen den Koalitionsparteien im Laufe des Jahres 1969 aufgezehrt war.

Um dem Bündnis mit der SPD eine neue Zukunft zu geben, hätte er das Angebot vom Februar für eine Passierscheinausgabe an Ostern besser angenommen. Vielleicht wäre noch einmal eine gemeinsame Vision der Ostpolitik entstanden; vielleicht hätte sich auch die Sowjetunion besonnen, verstärkt den Kontakt zur Großen Koalition gesucht und so die schwierige Situation aufgelockert. Denn schließlich - das war ja des Kanzlers Überzeugung - lag der Schlüssel für die Fortsetzung der Ostpolitik in Moskau. Aber wollten nicht gerade die Sowjets die unterschiedlichen ostpolitischen Positionen der Koalitionsparteien gegeneinander ausspielen, weil sie sich davon einen Vorteil versprachen? Kiesinger war von dieser sowjetischen Taktik überzeugt.

\section{Hat Moskau sich ausschließlich auf die Zusammenarbeit mit der SPD eingerichtet?}

Zunächst schien es im März 1969 so, als ob sich Kiesingers Hoffnung erfüllen sollte und die Gespräche um die Verlegung der Bundesversammlung aus Berlin wirklich den Anfang eines neuen, weitgehenden Dialogs zwischen Moskau und Bonn bildeten. Nur knapp zwei Wochen nach der Berliner Bundesversammlung wandten sich die Führer der Warschauer Pakt-Staaten mit einem Appell an die Öffentlichkeit, der als Ausgangspunkt einer neuen Haltung der Sowjetunion gegenüber der Bundesrepublik gedeutet wurde ${ }^{140}$. Man klagte die Bundesregierung nicht länger als „revanchistisch“ oder „militaristisch“ an. Zwar wurden weiter Forderungen erhoben: nach wie vor sollte die Oder-Neiße-Grenze sowie die Existenz der DDR anerkannt werden. Darüber hinaus erwarteten die Staatschefs den Verzicht auf den Alleinvertretungsanspruch und auf die Verfügungsgewalt über Kernwaffen. Auch auf den besonderen Status West-Berlins wurde hingewiesen. Im Unterschied zu bisherigen Stellungnahmen machte der Warschauer Pakt aber die Erfüllung dieser Forderungen nicht zu Vorbedingungen von Verhandlungen oder sogar von der Aufnahme von diplomatischen Beziehungen. Diese neue Linie wurde den Deutschen in den folgenden Monaten bei informellen Gesprächen oft bedeutet, was die Bundesregierung allerdings nicht gleich von der Ernsthaftigkeit dieser neuen Haltung überzeugte ${ }^{141}$. Gleichzeitig wiesen symbolische Ereignisse auf ein stärkeres sowjetisches Interesse an engeren Beziehungen zur Bundesrepublik. Im Mai 1969 besuchten der Erste Parteisekretär Breschnew und Ministerpräsident Kossygin erstmals ausführlich den westdeutschen Stand auf der Moskauer Industrieausstellung. Auch eine Demonstration vor der sowjetischen Botschaft in Bonn anläßlich des Jahrestages des Einmarsches in die ČSSR, bei der Fensterscheiben eingeworfen und die Wände mit Farb-

140 Vgl. EA 24 (1969), Folge 7, S. D 151 ff.; Bender (Neue Ostpolitik, S. 156) schreibt, die Sowjetunion habe damit ihre Verhandlungsbereitschaft bekundet. Baring (Machtwechsel, S. 236) meint, Moskau habe Ruhe haben wollen, und daher habe es den Appell "maßvoll“ formuliert; siehe auch Hildebrand, Erhard, S. 335.

141 Vgl. Garton Ash, Im Namen Europas, S. 90; Wettig (Die Sowjetunion, S. 197, Fn 177) führt einige solcher Hinweise auf. Darunter einen Trinkspruch des sowjetischen Botschafters Abrassimov vom 12.6.1969, der in Neues Deutschland wiedergegeben wurde. 
beuteln verschmiert wurden, spielte die Sowjetunion entgegen früherer Gewohnheiten herunter ${ }^{142}$.

Das waren kleine Zeichen eines Wandels der sowjetischen Haltung gegenüber der Bundesrepublik. Was hatte den Wandel bewirkt? Die Historiographie ${ }^{143}$ ist sich sehr schnell darüber einig geworden, daß diese veränderte Haltung nach der Berliner Bundespräsidentenwahl vom Schußwechsel am Ussuri Anfang März 1969 zwischen sowjetischen und chinesischen Grenztruppen ausgelöst wurde ${ }^{144}$. Löwenthal hat schon 1967 behauptet, Moskau suche einen politischen Durchbruch in Europa zu erreichen, um den Rücken für die sich abzeichnenden künftigen Auseinandersetzungen mit der Volksrepublik China freizubekommen ${ }^{145}$. Einen Zusammenhang zwischen den Ereignissen an Spree und am Ussuri stellten die Sowjets selbst her. Sie behaupteten, die Westdeutschen und die Chinesen hätten sich zusammengetan, um dem sozialistischen Lager in den Rücken zu fallen. Die sowjetische Regierung fühlte sich derart bedrängt, daß sie nicht nur in Peking energisch protestierte, sondern auch Wert darauf legte, die sowjetische Rolle bei dem Grenzzwischenfall unaufgefordert durch ihre Botschafter bei den Westmächten und auch bei der Bundesregierung erläutern zu lassen ${ }^{146}$. Der sino-sowjetische Gegensatz war also ein wichtiger Grund für die Suche nach Kontakten mit Bonn. Klaus Mehnert hat daneben auch auf den wirtschaftlichen Bereich hingewiesen. Die Enttäuschung über die wirtschaftliche Entwicklung der Sowjetunion mochte den Wunsch nach engerer Zusammenarbeit mit der leistungsfähigsten und modernsten Wirtschaft in Europa bestärkt haben ${ }^{147}$.

Welche Ereignisse auch immer den Wandel der sowjetischen Deutschlandpolitik initiiert haben, er bedeutete für Kiesinger zunächst eine große Genugtuung. Denn Moskau mußte mit dieser Entscheidung gleichzeitig die Unterstützung für Ulbrichts aggressive Deutschlandpolitik aufgeben. Der Kanzler las angenehm erstaunt die vertraulichen Berichte über den Hergang auf der Budapester Konferenz. Ulbricht hatte - so war

142 Vgl. Allardt, Moskauer Tagebuch, S. 180 ff.; siehe auch Schmoeckel/Kaiser, Vergessene Regierung, S. 181; zu den anderen Hinweisen zählen noch das Angebot über ein Handelsabkommen und die Wiederaufnahme von Verhandlungen über ein Luftfahrtabkommen.

$143 \mathrm{Vgl}$. Wassmund, Suprematie.

144 Vgl. Griffith (Ostpolitik, S. 166), der erklärt, Moskau habe auf Entspannung gesetzt, um im Westen für den Ussuri-Krise „einen Ausgleich zu schaffen“. Nach Whetten (Germany's Ostpolitik, S. 98) fühlte sich die Sowjetunion erneut umzingelt und suchte nach Auswegen; vgl. auch Mehnert, Der Moskauer Vertrag, S. 814, und Baring, Machtwechsel, S. 235.

145 Vgl. Löwenthal, Der Einfluß Chinas, S. 345 f.

146 Wettig (Die Berlin-Krise 1969, S. 696) meint, diese These habe ein doppeltes Ziel verfolgt, einerseits die Chinesen als Feinde des Sozialismus zu entlarven, andererseits das sowjetische Nachgeben in der Berlin-Frage durch eine Art Dolchstoßlegende zu begründen; siehe auch Schulz, Die sowjetische Deutschlandpolitik, S. 280.

147 Vgl. Mehnert, Der Moskauer Vertrag, S. 815 f. Mit jährlichen Zuwachsraten von 5,5 \% im Planjahrfünft 1966-1969 lag die Sowjetunion unter dem mancher kapitalistischer Staaten. Gleichzeitig stiegen die Militärausgaben, was zu einer Auseinandersetzung über die Prioritäten -Schweroder Konsumgüterindustrie - führte. Zusätzlich soll auch das Motiv eine Rolle gespielt haben, durch eine freundlichere Haltung gegenüber Bonn die engen Bindungen zwischen den USA und der Bundesrepublik zu lockern. Auch Fritsch-Bournazel (Die Sowjetunion und die deutsche Teilung) verweist auf den wirtschaftlichen Aspekt. Die Erkenntnis habe sich durchgesetzt, um eine Beschleunigung des Modernisierungsprozesses zu bewirken, sei die zusätzliche Hilfe durch langfristige, intensive wirtschaftlich-wissenschaftliche technische Kooperationsabkommen mit der westlichen Welt unerläßlich; siehe dazu auch Wassmund, Kontinuität im Wandel, S. 103 f.; Garton Ash, Im Namen Europas, S. 89; Heller/Nekrich, Utopia in Power, S. 629-41. 
die allgemeine Ansicht informierter Journalisten - eine große Niederlage erlitten. Jetzt bewahrheitete sich, was Kiesinger schon im Januar 1967 anläßlich der Aufnahme diplomatischer Beziehungen zu Rumänien geäußert hatte: daß der Kampf des SED-Regimes gegen die Ostpolitik der Bundesregierung auf die DDR selbst zurückfallen werde. Aus den Aufzeichnung eines Augenzeugen ging beispielsweise hervor: „In Ost-Berlin wird die Budapester Konferenz als größte Niederlage Ulbrichts seit 20 Jahren empfunden. [...] Als wenige Tage vor der Konferenz der Entwurf des Appells von der Sowjetunion den anderen Paktstaaten zugestellt wurde, soll in Ost-Berliner Regierungskreisen erhebliche Verwirrung geherrscht haben. Keiner der von Ulbricht vorgebrachten Formulierungswünsche war im Entwurf enthalten. Weder von der diplomatischen Anerkennung der DDR [war] die Rede noch von der selbständigen Einheit West-Berlins. Ebenso fehlt die gewünschte Formulierung, daß Berlin die Hauptstadt der DDR sei, wie die Feststellung, daß die Bundesrepublik als Staat der Revanchepolitik der Störenfried Europas sei."

In Budapest habe sich Ulbricht - bis auf geringe Unterstützung Polens in der OderNeiße-Frage - den übrigen Paktstaaten allein gegenüber gesehen, fährt der Bericht fort. Selbst als er zuletzt nur noch auf der Forderung bestanden hatte, in den Appell solle die Formulierung der "diplomatischen Anerkennung der DDR “ aufgenommen werden, hätten nicht nur die ČSSR, Ungarn und Rumänien widersprochen, sondern auch die Sowjetunion. Über die Formulierung der „Existenz der DDR“ habe man nicht hinausgehen wollen. „In sehr harten zweiseitigen Gesprächen soll die Sowjetunion Ulbricht klargemacht haben“, heißt es wörtlich in dem Bericht, „daß ihr die Zustimmung der übrigen Paktstaaten wichtiger sei, als die Durchsetzung seiner Forderungen, die im übrigen nach Meinung aller anderen Paktstaaten eine beabsichtigte Sicherheitskonferenz von vornherein zum Scheitern verurteilt hätte. “148

Trotz des Budapester Appells kam es in der Zeit der Großen Koalition nicht mehr zu einer Verständigung und Annäherung zwischen Bonn und Moskau. Zwar gab es, wie schon erwähnt, wiederholt kleine Hinweise, daß die Sowjets keine Vorbedingungen für einen Dialog stellten; aber der Bundeskanzler zweifelte daran, ob der Kreml wirklich die nach wie vor bestehenden und auch im Appell zitierten Ziele ausklammern wolle. Kiesinger wartete offensichtlich auf ein noch deutlicheres Zeichen aus Moskau, das ihm die bedingungslose Gesprächsbereitschaft der Sowjets signalisieren sollte. Später warf er der Sowjetunion vor, ihm kein Vertrauen geschenkt und statt dessen ganz auf eine künftige Zusammenarbeit mit der SPD gesetzt zu haben. Er beklagte sich darüber, daß man ihn habe „hängenlassen“. Mit Verbitterung registrierte Kiesinger, der Kreml habe im August 1969 während der Moskaureise einiger sozialdemokratischer Abgeordneter offenbar die Bereitschaft angedeutet, über die grundsätzlichen Meinungsunterschiede hinwegzusehen und ein Gespräch über weniger kontroverse Themen einzuleiten ${ }^{149}$. Kiesinger bezog sich auf ein Gesprächsprotokoll in der liberalen Wochenschrift Die Zeit. Darin hatte Schmidt erklärt, nach wie vor seien die Russen in der deutschen Frage hart, aber sie seien bereit, ihre Maximalforderungen auszuklammern. Kiesinger fand später, daß dieser Artikel „sehr wichtig" gewesen sei. Merkwürdig sei nur, daß er „immer verschwiegen“ werde. „Er [Schmidt] sagt da drinnen vorsichtig:, Ich weiß natür-

148 AdKASt, Kiesinger I - 226, D/IV.6, A 001, Anlage zu Ahlers an Kiesinger vom 24.6.1969, „Vermerk für Willy Brandt" vom 19.6.1969, S. 2 f.

149 Baring (Machtwechsel, S. 238) schreibt, Kiesinger sei „Feuer und Flamme“ gewesen. In dem Gespräch sei verabredet worden, was er Botschafter Zarapkin immer wieder vorgeschlagen habe. 
lich nicht, ob das endgültig ist, aber meine Gespräche haben mir diesen Eindruck vermittelt.' Und das war meine Politik, damit wollte ich Zeit gewinnen." 150

Für die These einer Bevorzugung der Sozialdemokraten durch die Sowjets spricht die Auseinandersetzung, die sich zwischen den Chefideologen der KPdSU und der SED über die Frage der Gefahr für die sozialistischen Gesellschaften durch die Sozialdemokratie entspann. Michail Andrejewitsch Suslov hatte sich auf einer Konferenz anläßlich des 50. Jahrestages der Kominterngründung am 25. März 1969 gegen die These Stalins der zwanziger und dreißiger Jahre gewandt, wonach die Sozialdemokratie als Hauptfeind zu behandeln sei. Da die KPD die Massen unter Umgehung der Sozialdemokratie angesprochen habe, sei sie in eine gewisse Isolierung und einen sektiererischen Zustand geraten ${ }^{151}$. Ulbricht widersprach auf der gleichen Konferenz vehement. In seiner Rede betonte er den "prinzipiellen Kampf“ gegen die Sozialdemokratie, die er als „bourgeoise Agenturen in der Arbeiterklasse" bezeichnete und für die nationalsozialistische Machtergreifung verantwortlich machte.

Auch künftig hielt die SED an ihrer Kritik gegen die SPD fest. Sie weigerte sich, die Politik der Bundesregierung positiv zu bewerten. Nach wie vor galt ihr Kampf den westdeutschen Revanchisten, nicht den ,revanchistischen Kräften“ in Westdeutschland. Weiterhin verlangte sie die völkerrechtliche Anerkennung der DDR durch die Bundesrepublik. Aber die Ost-Berliner sahen sich durch die große Brudernation genötigt, ihre Ansprüche seit März 1969 etwas zurückzunehmen. Man formulierte jetzt vorsichtiger und betonte nicht länger die Anerkennung der ostdeutschen Forderungen als Vorbedingung, wie im Budapester Appell festgelegt, sondern nannte sie eine „entscheidende objektive Voraussetzung“, die ein „Kernproblem“ der europäischen Sicherheit darstelle. Auch änderte sich intern die Einschätzung der SPD. So wurden die Vorbereitungen der Kampagne gegen Wehner durch die Staatssicherheit eingestellt. Es erschien plötzlich nicht mehr opportun, diesen Politiker zu belasten, der offensichtlich bereit zu sein schien, von festgefahrenen Positionen der Bundesrepublik abzurücken. Darüber hinaus intensivierte die SED ihre Kontakte mit unterschiedlichen Persönlichkeiten aus dem westlichen Teil Deutschlands. Mit insgesamt 420 Funktionären der SPD und des DGB seien im ersten Quartal des Jahres 1969 Gespräche geführt worden, hielt ein Dokument am 30. April 1969 fest, das in den Unterlagen des Staatssicherheitsministeriums der DDR gefunden wurde ${ }^{152}$.

Andererseits sah die SED-Führung in den Auffassungen der Bundesregierung nach wie vor unzumutbare Vorbedingungen für ein politisches Gespräch. Die Sowjetunion erwiderte, die internationale Anerkennung der DDR sei unaufhaltsam, und gab damit zu verstehen, daß es nicht notwendig sei, die Durchsetzung der ostdeutschen Forderungen

150 AdKASt, Kiesinger I -226, A 322, Gespräch mit Löwe, 31.1.1978, S. 47. Im Wortlaut sagt Schmidt (Protokoll einer Kreml-Reise. Ein Zeit-Interview mit Helmut Schmidt, in: Die Zeit, 29.8.1969, S. 3): „Dies war einer unserer entscheidenden Eindrücke: Früher sagten die Sowjets, erst müssen diese fünf Forderungen erfüllt sein, dann kann man über alles andere reden. Nun vermitteln sie den Eindruck, daß sie bereit wären, die Maximalforderungen auszuklammern, ohne freilich ihre grundsätzliche Position etwa in Frage stellen zu lassen. Aber ob das in vier Monaten oder vier Jahren noch so ist, das weiß ich nicht. Ich weiß nicht einmal, ob das heute wirklich so ist. Das kann man erst wissen, wenn man es ausprobiert hat. Man muß das Vehikel Europäisches Sicherheitssystem bemühen, um es auszuprobieren, um es auszuloten."

151 Siehe Wettig, Die Sowjetunion, S. 62, sowie Mehnert, Der Moskauer Vertrag, S. 812 f.

152 Vgl. Reuth, Die Feindtätigkeit Wehners, in: Frankfurter Allgemeine Zeitung, 31.12.1993; sowie Schacht, Schwilk, Gezielte Agitation, in: Die Welt, 9.1.1994. 
zu forcieren ${ }^{153}$. In der gemeinsamen Erklärung vom 14. Juli hieß es, der Abbau seiner traditionellen Positionen liege im Interesse Westdeutschlands. Die Beziehungen zur DDR könnten sich nur „auf der Basis des allgemein anerkannten Völkerrechts als Beziehungen zwischen souveränen Staaten entwickeln"154.

Ob allerdings die sowjetische Regierung tatsächlich im Spätsommer 1969 nur den Sozialdemokraten die Chance der Annäherung einräumte, den Christdemokraten aber nicht, läßt sich mit Bestimmtheit nicht sagen. Zwar äußerte Außenminister Andrej Gromyko im Gespräch mit Schmidt, daß seine Regierung die Vorschläge der SPD in der Außenpolitik verfolge und daß „man manchmal Elemente größerer Elastizität“ bemerkt und positiv aufgenommen habe ${ }^{155}$. Aber als Distanzierung der SPD von der Politik der CDU/CSU sei dies in Moskau nicht verstanden worden. Die sozialdemokratische Grundtendenz entspreche der der anderen Regierungspartei. Folgt man dieser Aussage, dann hat der Kreml eine Unterscheidung zwischen Union und SPD in jener Zeit nicht getroffen. Es ist aber auch möglich, daß Gromyko die Bemerkung mit dem Hintergedanken machte, die Sozialdemokraten sollten sich ermutigt fühlen, noch deutlicher von den Positionen der CDU/CSU abzurücken. Denn bisher habe die sowjetische Seite „noch keine Anzeichen dafür, daß die Regierung der Bundesrepublik Deutschland ernste Absichten“ leiteten. Die Sowjetunion habe die Ernsthaftigkeit ihres Willens zur Entspannung in der Budapester Erklärung vom 17. März 1969 unterstrichen. Gromyko spielte auf die Forderung nach einer „Konferenz über Sicherheit und Zusammenarbeit in Europa“ an. Er schlug vor, daß die Bundesregierung den Gedanken einer Sicherheitskonferenz aufgreifen und unterstützen solle. Wenn die Deutschen sich aktiv an den Vorbereitungen beteiligten, „würde sich das positiv auf der Waagschale für die Bundesrepublik auswirken “156. Auch der sofortige Beitritt zum Nichtweitergabevertrag würde als weiteres Zeichen für den guten Willen der Bundesrepublik gewertet werden. Die deutsche Zustimmung zum Vertrag werde das Verhältnis zu Moskau erheblich bessern.

Aber genau dies ist fraglich. Irgendwann wäre auch nach einem Beitritt die Forderung nach Anerkennung des Status quo von sowjetischer Seite auf den Verhandlungstisch gelegt worden. Zwar hätte die Bundesregierung vielleicht Zeit gewinnen können, wie Kiesinger meinte. Aber hätte sich das zu ihrem Vorteil ausgewirkt? Vermutlich nicht. Denn spätestens dann hätte auch eine christdemokratische Führung bekennen müssen, wie weit sie zu gehen bereit war. Zwar schien Kiesinger willens zu sein, wie er auf einem seiner Waldspaziergänge Ahlers andeutete, vielleicht eines Tages selbst die DDR anzuerkennen. Aber bis dahin - dies machte der Kanzler bei solchen Gelegenheiten auch deutlich - werde noch viel Zeit vergehen.

In der SPD war dagegen die Bereitschaft zur Anerkennung des Status quo sehr viel größer als in der CDU/CSU. Falls der Koalitionspartner SPD - vorausgesetzt, die Große Koalition wäre 1969 fortgesetzt worden - versucht hätte, der Sowjetunion weitgehende Zugeständnisse - mit oder ohne Zustimmung der Union - schon frühzeitig anzubieten, wären die Christdemokraten erneut gezwungen worden, eine defensive, bremsende Rolle zu spie-

153 Vgl. Wettig, Die Sowjetunion, S. $63 \mathrm{f}$.

154 EA 24 (1969), Folge 19, Gemeinsame Erklärung über den Besuch einer Partei- und Regierungsdelegation der DDR in der Sowjetunion vom 14.7.1969, S. D 472.

155 Zitiert nach Lehmann, Öffnung nach Osten, Aufzeichnung des Gesprächs der Delegation der Fraktionsvorsitzenden der SPD-Bundestagsfraktion mit dem sowjetischen Außenminister Gromyko am 21.8.1969, S. 227.

156 Ebenda, S. 228. 
len. Das hätte innerhalb der Bundesregierung zu einem fundamentalen Streit zwischen den Bündnispartnern führen können. Es war also abzusehen: Spätestens dann wäre die Koalition zerbrochen. Im Jahre 1969 stellte sich also nur die Alternative zwischen rasch vereinbarten Regelungen in der Ostpolitik, wie sie die sozialliberale Koalition dann tatsächlich anstrebte, oder einer sehr vorsichtigen Annäherung an die Sowjetunion und die Länder Osteuropas, wie sie eine CDU-Regierung unter Kanzler Kiesinger versucht hätte.

\section{Zwischen Minimalkonsens und Parteiegoismus - Kambodscha und andere Krisenfälle in der letzten Phase der Koalition}

Im Mai 1969 rückte noch einmal die Hallstein-Doktrin in den Mittelpunkt der Auseinandersetzung zwischen den beiden Koalitionsparteien. Am 8. Mai nahm das kleine asiatische Land Kambodscha die Beziehungen zu Ost-Berlin auf. Es folgte darin vermutlich dem Wunsch Moskaus. Prinz Samdech Norodom Sihanouk, der 1953 das Land nicht nur aus der französischen Herrschaft in die Unabhängigkeit geführt hatte, sondern auch seit 1960 als Premierminister die Regierung leitete, mußte sich die Freiheit durch hohe Diplomatie erhalten. Seit Jahrhunderten versuchte Kambodschas östlicher Nachbar Vietnam sich kambodschanisches Land anzueignen. Die Gegend um Saigon war erst Anfang des 19. Jahrhunderts den Kambodschanern weggenommen worden. Frankreich hatte als Kolonialmacht zeitweilig für Ruhe gesorgt. Aber seit der Unabhängigkeit suchte Sihanouk mit dem großen Nachbarn China, aber auch der Sowjetunion, trotz des bestehenden Schismas zwischen den beiden größten kommunistischen Mächten, ein Gegengewicht zu Vietnam aufzubauen.

Die Lage des kleinen, wirtschaftlich schwachen Landes mit einer Bevölkerung von 6,5 Millionen wurde dadurch prekär, daß einerseits die Nordvietnamesen Basen in Kambodscha für ihren Angriff auf Südvietnam anlegten und nutzten, andererseits sich das Verhältnis zu Peking durch die Kulturrevolution erheblich verschlechtert hatte ${ }^{157}$. Mitte der sechziger Jahre hatte Prinz Sihanouk ganz auf die Hilfe Chinas gesetzt und sogar die diplomatischen Beziehungen zu den Vereinigten Staaten abgebrochen, die die beiden gefährlichsten Nachbarn des Landes, Südvietnam und Thailand, wirtschaftlich, politisch und vor allem militärisch unterstützten. Für die Annäherung an China mußte Sihanouk zusätzlich seine Lieblingsidee einer Neutralitätskonferenz in Pnom Penh aufgeben. Aber die Hoffnungen des Prinzen erfüllte Peking nicht. China löste sein Versprechen nicht ein, sich für den Norden Vietnams zu engagieren, während sich der amerikanische Einsatz ab Sommer $1965 \mathrm{im}$ Süden Vietnams erheblich verstärkte. Sihanouk hoffte damals, daß mit chinesischer Unterstützung der Norden ein Gegengewicht zum Süden bilden und Peking gleichzeitig einen mäßigenden Einfluß auf das nordkoreanische Regime ausüben würde. Durch diese Enttäuschung ernüchtert, nahm Sihanouk die Idee der Neutralitätskonferenz wieder auf und suchte sogar neue Kontakte zu den Amerikanern ${ }^{158}$.

157 Vgl. Singh, Die Südasien-Politik, S. 527.

158 Vgl. Braun, Außenpolitik am Scheideweg?, S. 326. Braun verweist darauf, daß es für Prinz Sihanouk keine schlimmere Vorstellung gegeben habe als ein von den USA unkontrolliertes, kommunistisch regiertes Vietnam. 
Chinas verärgerte Reaktion auf diese neue Politik Kambodschas führte zu einer weiteren Abkühlung der Beziehung ${ }^{159}$.

Die neue außenpolitische Orientierung hatte auch innenpolitische Gründe. In Kambodscha lebten 400000 nach Peking orientierte Chinesen, die zunehmend mit den kambodschanischen, im Untergrund gegen den Prinzen arbeitenden Kommunisten und dem Vietkong zusammenarbeiteten ${ }^{160}$. Daher suchte sich die Regierung des Wohlwollens der Sowjetunion zu versichern. Vor diesem Hintergrund nahm Pnom Penh Beziehungen mit Ost-Berlin auf.

Die Maßnahme überraschte Bonn. Zehn Tage vor der Anerkennung der DDR hatte der Prinz dem neuen Botschafter der Bundesrepublik bei der Überreichung des Beglaubigungsschreibens nichts über das geplante Vorhaben mitgeteilt. Und dies, obwohl Sihanouk dem DDR-Außenminister Winzer schon im Frühjahr 1968 eine Zusage für die diplomatische Anerkennung gegeben haben soll ${ }^{161}$. Wenn man die der Bundesregierung abgegebenen Erklärungen von Pnom Penh betrachte, dann sei die Entscheidung wirklich schwer verständlich, meinte Brandt am 20. Mai 1969 vor der Gesellschaft für Auslandskunde in München ${ }^{162}$.

Am Nachmittag des 14. Mai traf das Kabinett in Bonn zusammen, um über den Fall zu verhandeln. Es ging um eine Grundsatzentscheidung. Denn innerhalb von sechs Tagen hatten noch zwei weitere Länder, der Irak und der Sudan, die DDR anerkannt. Allerdings waren diese beiden arabischen Länder nicht mit Kambodscha zu vergleichen. Als Reaktion auf die Anbahnung diplomatischer Beziehungen zwischen der Bundesrepublik und Israel im Jahre 1965 hatten sie die Beziehungen zu Bonn abgebrochen mit dem Hinweis, die Aufnahme verstoße gegen arabische Interessen. Aber die Araber nahmen damals, im Gegensatz zu Kambodscha 1969, nicht gleichzeitig die Beziehungen zur DDR auf. Dies geschah erst nach weiteren vier Jahren.

In der Bundesregierung wurde nur die Entscheidung Kambodschas heftig diskutiert. Sie sah sich mit der Frage konfrontiert, ob die diplomatischen Beziehungen zu dem asiatischen Land nun beendet werden sollten oder nicht. Die Meinungsunterschiede zwischen den beiden Koalitionspartnern konnten nicht größer sein. Im Außenpolitischen Ausschuß des Bundestages, der am selben Tag zusammengerufen worden war, seien „die beiden Extreme“ vorgeschlagen worden, berichteten Bahr und der Parlamentarische Staatssekretär im Auswärtigen Amt, Gerhard Jahn, nach der Sitzung. Eine Seite forderte, die Beziehungen sofort abzubrechen, die andere wollte gar nicht reagieren und das bestehende Verhältnis einfach so belassen, wie es sich entwickelt hatte. Die Trennlinie der Befürworter der einen oder anderen Lösung sei genau zwischen den beiden Parteien verlaufen ${ }^{163}$. Der sich abzeichnende Wahlkampf bestimmte hier bereits die beiderseitigen Positionen. Die Kluft zeigte sich deshalb auch im Ausschuß des Bundestages deutlich. Der CDU-Abgeordnete Werner Marx beschrieb Kiesinger die Lage: „Die Tendenz des Vortrages und der Diskussionsbeiträge von seiten der SPD [...] sei eindeutig gegen einen

159 Vgl. Gauers, Kambodscha zwischen Peking und Washington, S. 677 f.; die Chinesen legten Demarchen ein, lehnten weiter jede Konferenz in Kambodscha ab und distanzierten sich sogar von dem Genfer Abkommen über Vietnam von 1954, das den endgültigen Rückzug der Vietminh aus Kambodscha vorgesehen hatte.

$160 \mathrm{Vgl}$. Roll, Die Außlandschinesen in Südostasien, S. 238 f.

161 Vgl. Braun, Außenpolitik, S. 327.

162 Vgl. Bulletin, 22.5.1969.

163 Vgl. AdKASt, Kiesinger I - 226, D/IV.6, A 006, Marx an Kiesinger vom 28.5.1969, S. 1; dort auch das folgende Zitat. 
Abbruch gelaufen." Man habe für Verständnis der äußerst schwierigen Lage des Prinzen Sihanouk plädiert. Marx fügte hinzu: „Dr. Jaeger (CSU) ${ }^{164}$ und ich selbst sprachen uns für einen Abbruch aus und wollten die eigenen Interessen vorrangig behandelt wissen." Eine Abstimmung habe nicht stattgefunden.

Auch das Kabinett beschloß, die endgültige Entscheidung zu vertagen, und zwar bis der deutsche Botschafter aus Pnom Penh Bericht erstattet hatte. Auch wollte man den kambodschanischen Vertreter hören. Jede Seite der Koalition legte diesen Beschluß allerdings als Sieg der eigenen Argumentationslinie aus. Der Außenminister machte darüber hinaus deutlich, daß er für die Aufhebung der Hallstein-Doktrin plädiere. Auf der Bundeskonferenz der Sozialistischen Jugend Deutschlands Die Falken erklärte er wenige Tage später, es sei ein Fehler, eine ideologisch eingeengte Außenpolitik zu führen. Wer ausschließlich mit demokratischen Staaten diplomatische Beziehungen unterhalten wolle, könne nur mit einem kleineren Teil der Staaten dieser Welt verkehren. Diplomatische Beziehungen seien kein Gunstbeweis, sondern ein Instrument, um eigene Interessen zu vertreten. $\mathrm{Er}, \mathrm{Brandt}$, halte es für falsch, der DDR in einzelnen Ländern ein Alleinvertretungsrecht einzuräumen ${ }^{165}$.

Kiesinger stand zunächst erneut zwischen beiden Positionen. Er hatte sich für keine der diskutierten Optionen entschieden, sondern den Vorschlag eingebracht, den deutschen Botschafter abzuberufen und dann den in Paris lebenden kambodschanischen Botschafter einzubestellen. Man werde mit dem Diplomaten ein Gespräch führen, sagte er, und dann entscheiden. Der Kanzler versuchte, die Bedeutung der diplomatischen Anerkennung der DDR durch Kambodscha herunterzuspielen. Es handele sich um „ganz natürliche Vorgänge", die nicht aus der Welt zu schaffen seien. Und so hitzig sei es zwischen den Parteien in dieser Sache denn doch wieder nicht zugegangen ${ }^{166}$.

Scheinbar setzte Kiesinger alles daran, so kurz vor dem Ende der Legislaturperiode den Koalitionsfrieden zu wahren, und gab sich daher den Anschein, selbst zur SPD-Argumentation zu tendieren. Aber in Wahrheit war er von Beginn an dafür, die nicht angekündigte, offenbar völlig unmotivierte Aufnahme der Beziehungen Kambodschas mit dem Abbruch der Beziehungen zu Pnom Penh zu beantworten. Das zeigte sich schon in der Erklärung des Regierungssprechers Diehl vom 14. Mai, man wolle zunächst den kambodschanischen Botschafter hören, und falls diese Rücksprache unbefriedigend verlaufe, werde man die Beziehungen abbrechen ${ }^{167}$. Aber jetzt zog Staatspräsident Sihanouk die Initiative erneut an sich und ließ über die französische Presseagentur $A F P$ am 17. Mai verlauten, er betrachte angesichts der Reaktionen der Bundesregierung die diplomatischen Beziehungen zu Bonn als abgebrochen. Für eine Weile schien nicht sicher zu sein, ob der Prinz diese Aussage tatsächlich getroffen hatte und ob der kambodschanische Botschafter noch nach Bonn kommen würde oder nicht. Das Auswärtige Amt erklärte eben-

164 Richard Jaeger war von 1953-1980 Mitglied des Bundestages. Von 1953-1965 und von 1969-1976 übte er das Amt des Bundestagsvizepräsidenten aus; unter Bundeskanzler Erhard war er seit 1965 bis zur Gründung der Großen Koalition Bundesjustizminister.

165 Vgl. Frankfurter Rundschau, 19.5.1969.

166 BPA, Kiesinger in der ARD am 16.5.1969, Anhang I, S. 2. Die Zahlen zeigen die Größenordnung zur damaligen Zeit. Von 126 Mitgliedstaaten der Vereinten Nationen unterhielt die Bundesrepublik zu 105 Staaten diplomatische Beziehungen, so viele wie kein anderes Land der Welt! Die DDR besaß dagegen nur mit 12 kommunistischen Staaten volle diplomatische Beziehungen, zu denen jetzt drei neutrale Staaten hinzukamen. Es handelte sich also um keine dramatische Verschlechterung der Situation, meint Braun (Außenpolitik, S. 325).

167 Vgl. Frankfurter Rundschau, 19.5.1969. Die Süddeutsche Zeitung (23.6.1969) ist der Meinung, daß Kiesinger in diesem Fall auf den Ratschlag Diehls gehört habe. 
falls am 17. Mai, die Äußerungen Sihanouks seien offenbar durch Falschmeldungen aus Ost-Berlin verursacht worden ${ }^{168}$. In Paris fanden dann am 19. Mai Gespräche statt zwischen dem deutschen Botschafter Sigismund von Braun und Botschafter Sonn Voeunsai. Das war ein Versuch des Auswärtigen Amtes, die Beziehungen nicht einfach und automatisch preiszugeben. Brandt bemühte sich darum, den Meinungsaustausch von der Ebene der Regierungssprecher und der jeweiligen öffentlichen Meinung auf die diplomatische Ebene zu verlagern, und er erklärte öffentlich, die Bundesregierung werde sich weder durch frühere Doktrinen noch durch „jetzige Überlegungen über eine bestimmte Auswahl von Schritten“ zu Entscheidungen zwingen lassen ${ }^{169}$.

Der Kanzler und die Experten der Union plädierten jedoch für einen sofortigen Abbruch. Marx, außenpolitischer Sprecher der Union, erklärte beispielsweise in dem bereits zitierten Schreiben vom 28. Mai 1969 an Kiesinger: „[...] meine persönliche vieljährige Beschäftigung mit Kambodscha erlauben mir, Sie dringend zu bitten, auf einen möglichst sofortigen Abbruch der Beziehungen zu drängen. Wir haben bereits zu lange gezögert. " 170 Kiesinger äußerte sich zu dem Thema am gleichen Tag öffentlich und deutete an, er werde die kambodschanische Entscheidung nicht tolerieren. Vor der Hauptversammlung des Deutschen Städtetages erklärte er, die Anerkennung Ost-Berlins sei eine "negative“ Vorwegnahme des Selbstbestimmungsrechts der Deutschen. Es wäre töricht, "so etwas resignierend einfach hinzunehmen“171.

Als Brandt, der sich zu einem Besuch in der Türkei aufhielt, am 27. Mai über einen Bericht der Nachrichtenagentur DPA von einer Erklärung Diehls erfuhr, wonach Bonn plane, die Beziehungen zu Kambodscha abzubrechen ${ }^{172}$, wurde er wütend. Seit langem war er davon überzeugt, daß sich mit diesem Koalitionspartner keine vernünftige Außenpolitik mehr bewerkstelligen lasse. „Drastische Schilderungen, wie unwirsch - ,Mir reicht's!" - ich hierauf reagierte, waren zutreffend“, schrieb er später ${ }^{173}$. Was den Außenminister so sehr in Rage brachte, war die Torpedierung des Versuches, sich von der strikten Anwendung der Hallstein-Doktrin zu lösen ${ }^{174}$. Brandt ging es darum, der Bundesregierung für die Zukunft einen Freiraum zu schaffen und im Falle der Anerkennung der DDR durch einen dritten Staat jeweils nach der Sachlage zu entscheiden. Das war noch keine Abkehr von der Hallstein-Doktrin, sondern entsprach der von ihrem Erfinder beabsichtigten Handhabung. Der Außenminister wollte verhindern, daß künftig automatisch die schärfste Sanktion, der Abbruch diplomatischer Beziehungen zur Bundesrepublik, bei der Anerkennung Ost-Berlins durch einen dritten Staat angewandt wurde. Kambodscha sollte nach dem Willen Brandts ein Präzedenzfall werden. Daher sprach er sich gegen einen Abbruch aus, als das Kabinett am 30. Mai zusammentrat, um den Fall

$168 \mathrm{Vgl}$. AdG, S. $14716 \mathrm{ff}$.

169 AdG, S. 14717.

170 AdKASt, Marx an Kiesinger vom 28.5.1969, S. 2.

171 AdG, S. 14171.

$172 \mathrm{Vgl}$. Frankfurter Allgemeine Zeitung, 28.5.1969.

173 Brandt, Erinnerungen, S. 184.

174 Vgl. Frank (Entschlüsselte Botschaft, S. 330), der der Meinung ist, daß es zu Beginn zu einer Absprache der Koalitionsparteien gekommen war, wonach ein Anerkennungsfall zwar als „unfreundlicher Akt“ betrachtet werden, aber nicht zum Abbruch der Beziehungen führen sollte. Frank, Leiter der Politischen Abteilung I im Auswärtigen Amt, war Zeuge des Wutausbruchs von Brandt. Seiner Erinnerung nach hat der Außenminister folgendes gesagt: „Wenn die da glauben, sie könnten dieses Spiel hinter meinem Rücken mit mir treiben und mich für ihre innerparteilichen Interessen mißbrauchen, dann haben die sich gründlich getäuscht. Ich kann auch anders!“ 
abschließend zu beraten. Über sieben Stunden dauerte die Sitzung, die mehrfach unterbrochen wurde, weil sich die SPD-Minister wie ihre CDU/CSU-Kollegen jeweils untereinander berieten.

Eine Entscheidung über Kambodscha wurde aber wieder verschoben. Dafür einigte sich das Gremium auf eine sogenannte Deutschland-Erklärung. Wehner hatte sich rechtzeitig darüber Gedanken gemacht, wie die Hallstein-Doktrin abgeändert und neu definiert werden konnte. Am 22. Mai hatte der Minister dem Kanzler seinen Vorschlag mit den handschriftlich begleitenden Worten gesandt: „Ich glaube, daß er geeignet ist, zu tragen und zu stützen." ${ }^{175}$ An Wehners Vorschlag überraschte, daß nach seiner Überzeugung die Bundesregierung weiterhin an der Hallstein-Doktrin festhalten sollte. Nach wie vor war vom „unfreundlichen Akt" die Rede, falls ein Staat die DDR anerkannte. Und was vorher umstritten war, blieb auch weiterhin unklar, nämlich welche Maßnahmen die Bundesregierung ergreifen sollte. Wörtlich hieß es: „Wenn Länder, mit denen wir diplomatische Beziehungen unterhalten, uns gegenüber den unfreundlichen Akt begehen, durch Aufnahme diplomatischer Beziehungen zu Ostdeutschland einer Regelung der nationalen Frage des deutschen Volkes auf der Grundlage des Selbstbestimmungsrechts vorzugreifen, sind wir genötigt, den politischen Interessen der Bundesrepublik Deutschland entsprechend uns zu verhalten. " 176 Die offizielle Erklärung hatte am Ende nicht den gleichen Wortlaut wie die Wehners, aber den gleichen Sinn: Die Doktrin blieb weiter in Kraft ${ }^{177}$.

Brandt sah in der Erklärung dagegen einen Fortschritt in der Deutschlandpolitik. Damit sei die Grundlage dafür geschaffen, daß die Bundesrepublik künftig nicht mehr im „Zwang einer Automatik“ zu entscheiden habe, sondern sich nach den Gegebenheiten des jeweiligen Falles richten könne. Über das aktuelle Problem Kambodscha sagte er, das Kabinett sei gespalten: Die CDU/CSU-Minister träten für den Abbruch ein, während die SPD-Minister diese Haltung „nicht unbedingt “ teilten ${ }^{178}$. Die Entscheidung über Abbruch oder Fortsetzung der Beziehungen fiel daher in einer Sitzung des Kreßbronner Kreises, die vom Abend des 2. Juni bis zum folgenden Morgen um 5 Uhr dauerte ${ }^{179}$. Die Koalitionsparteien einigten sich dort darauf, daß die Beziehungen nicht abgebrochen, sondern nur „eingefroren“ werden sollten. Der abberufene deutsche Botschafter sollte also in Bonn, die deutsche Botschaft in Pnom Penh unbesetzt bleiben. Am 4. Juni bestätigte das Kabinett die Entscheidung. Spöttisch sprachen die Gegner dieses halbherzigen Beschlusses vom „Kambodschieren“180.

Es war ein letzter Kraftakt der Koalition. Er kam zustande, weil keine der Koalitionsparteien die Schuld am Bruch des Bündnisses auf sich laden wollte. Die Stimmung der Beteiligten war von dem Bewußtsein geprägt, man werde sowieso demnächst aus-

175 AdKASt, Kiesinger I - 226, D/IV.6, Wehner an Kiesinger vom 22.5.1969.

176 Ebenda, Anlage.

177 Vgl. TzD, S. 254 f. Im entscheidenden Teil heißt es: „Die Bundesregierung muß daher die Anerkennung der DDR als unfreundlichen Akt betrachten. Sie wird in einem solchen Fall ihre Haltung und ihre Maßnahmen gemäß den Interessen des ganzen deutschen Volkes von den gegebenen Umständen abhängig machen.“

178 AdG, Brandt im Deutschen Fernsehen, S. 14718.

179 Vgl. Schwarz (Die Bundesregierung und die auswärtigen Beziehungen, S. 62), der im Zusammenhang mit der Kambodscha-Frage auf die Notwendigkeit von förmlichen Kabinettsentscheidungen hinweist, wenn die Koalitionsparteien unterschiedliche Meinungen vertreten, aber weder eine Regierungskrise noch einen Kanzlersturz riskieren wollen.

180 Bender (Neue Ostpolitik, S. 143) spricht von „halben Maßnahmen“. Für die Koalition sei diese Auseinandersetzung aber, so Schmoeckel/Kaiser (Vergessene Regierung, S. 159), „ein weiterer Punkt des Auseinanderlebens" gewesen. 
einandergehen ${ }^{181}$. Heribert Knorr hat diese letzte Phase der Koalition als Periode des „Kuhhandels“ bezeichnet. Da keiner der Partner mit einem allzugroßen Katalog unerledigter Gesetzentwürfe belastet werden wollte, habe man Zugeständnisse in einer Frage durch Zugeständnisse in einer anderen eingetauscht. Das galt gerade auch in der Kambodscha-Frage. Die SPD honorierte den Verzicht von CDU/CSU auf einen Abbruch der Beziehungen mit Pnom Penh durch eine Konzession in der Frage des Lohnfortzahlungsgesetzes ${ }^{182}$. Brandt rechtfertigte diesen „Deal“ vor der Fraktion am 10. Juni. Man habe in dieser Frage nicht ausweichen können, sondern auf der Fortsetzung der Beziehungen zu Kambodscha beharren müssen, erklärte er. „Wir müssen den Fuß in der Tür behalten, damit unsere Interessen dort gewahrt werden. "183 Am Ende schien Brandt über die Entscheidung froh zu sein, obwohl er die Sitzung vorzeitig deprimiert verlassen hatte. „Tatsächlich hatte ich mich aus jener nächtlichen Kabinettssitzung vorzeitig davongestohlen und an Rücktritt gedacht", berichtete er ${ }^{184}$. Aber der Außenminister trat dann doch nicht zurück. Dies wäre keine angemessene Reaktion gewesen, schrieb er später.

Als Niederlage Brandts hat Kiesinger im Rückblick dagegen die Zustimmung des Ministers zur Deutschland-Erklärung vom 30. Mai gewertet. Kiesinger fand später diese Haltung des Ministers, gelinde gesagt, verblüffend: „Man muß sich vorstellen, was da im Kopf von Brandt vor sich gegangen ist, als er diese Sache mitbilligte. Wenn er dann wenigstens so dicht vor der Wahl gesagt hätte: ,Nein, so will ich's nicht!'“ 185 Brandt habe nie den Mut dazu gehabt.

Und Kiesinger selbst? Welche Erklärung hatte er für seine harte Haltung in der Kambodscha-Frage? Kiesinger meinte später, er habe gegenüber der Politik des Auswärtigen Amtes mit Härte auftreten wollen. Der Kanzler fand es im wachsenden Maße unerträglich, daß der Außenminister öffentlich eine ganz andere Außenpolitik propagierte, als man sie einmal gemeinsam beschlossen hatte. Brandt signalisierte eine Konzessionsbereitschaft an den Osten, die der Kanzler nicht billigte. Er sei damals der Meinung gewesen, daß dem "Geriesel aus dem Auswärtigen Amt“ einmal ein Ende bereitet werden müsse. Man habe ganz klar sagen müssen: „[...] jetzt mal Obacht, jetzt mal Schluß. So kann Politik nicht gemacht werden, in einem Auflösungsprozeß kann das nicht vor sich gehen. Wir bleiben bei dem, was vereinbart worden ist." 186 Als es um Kambodscha, diesen „unangenehmen Fall“, und die Deutschland-Erklärung gegangen sei, habe er als Kanzler die Meinung vertreten, man solle „ruhig mal ein bißchen kräftiger“ auftreten. Obwohl das Bündnis bereits deutliche Ermüdungserscheinungen zeigte, legte es der Kanzler auf einen Konflikt mit Brandt an. Für einen einmaligen Prestigegewinn setzte er damit die Existenz des Bündnisses insgesamt aufs Spiel. Hätte Brandt sich gegen die Deutsch-

181 Vgl. Hildebrand, Erhard, S. 330, und Knorr, Entscheidungsprozeß, S. 150.

182 Vgl. Knorr, Entscheidungsprozeß, S. 125 und 143; die Union stellte ein Junktim her zwischen der alten Forderung der SPD nach Lohnfortzahlung im Krankheitsfall und der Einführung einer Krankenkassenreform. Die SPD war zunächst gegen die Reform, stimmte aber jetzt zu. Knorr bezieht sich im wesentlichen auf den Artikel Rolf Zundels, Die Koalitionszwillinge, Die Zeit, 29.11.1968.

183 AdsD, Protokolle interner Sitzungen der Führungsgremien, SPD-Fraktionssitzung vom 10.6.1969, S. 3.

${ }^{184}$ Brandt, Erinnerungen, S. 184; Brandt täuscht sich. Es handelte sich nicht um eine Kabinettssitzung. Das Kabinett hat erst zwei Tage später den Beschluß des Kreises sanktioniert; vgl. Schmoeckel, Zeittafel.

185 AdKASt, Kiesinger I - 226, A 322, Gespräch mit Löwe, 31.1.1978, S. 45 f.

186 AdKASt, Kiesinger I - 226, F, Kiesinger am 8.6.1972 für den NDR, Zeugen der Zeit, S. 116; dort auch die folgenden Zitate. 
land-Erklärung ausgesprochen, wäre die Koalition vermutlich noch weniger handlungsfähig geworden und vielleicht bald auseinandergebrochen. Trotzdem hatte die Demonstration der Härte die Gräben zwischen beiden Parteien vertieft.

Zum Glück gab es noch Wehner. Diesmal war er es, der die beiden Fraktionen zusammenhielt und mit seinem Entwurf der Deutschland-Erklärung eine Brücke zwischen beiden Parteien schlug. Die Erklärung war ganz auf den Kanzler und seine Partei zugeschnitten. Da sie die Hallstein-Doktrin bestätigte und ausdrücklich an dem Grundsatz des „unfreundlichen Aktes“ festhielt, kam sie in dieser Frage der scheinbar kompromißlosen Haltung Kiesingers entgegen. Vermutlich wollte Wehner durch seine Bereitschaft zu kooperativem Handeln auch eine Verstimmung im persönlichen Verhältnis zu Kiesinger ausräumen. Als sich der Kanzler auf einer Reise in Japan aufhielt, hatte ihn der Minister erstmals öffentlich attackiert. Das war ein schwerer Bruch der ungeschriebenen Gesetze im Verhältnis der Gründungsväter. Kiesinger sei dem CSU-Vorsitzenden Strauß mehr als notwendig zu Willen, sagte der Sozialdemokrat einer Zeitung ${ }^{187}$. Der Kanzler hörte von der Kritik an Bord einer Maschine, die ihn von seiner Reise aus Japan nach Bonn zurückbrachte, und war sichtlich betroffen. Er bedauere die Äußerung Wehners, erklärte er Journalisten. Er habe sich dem CSU-Vorsitzenden gegenüber nicht zu nachgiebig verhalten. „Wenn ich eine Maßnahme für notwendig hielt, habe ich nie gezögert, sie selbst gegen die Mehrheitsauffassung meiner Partei durchzusetzen“, beteuerte er. Aber der Vorfall bestätigte, daß seit dem März 1969 das Verhältnis der Gründungsväter beschädigt war.

Der Minister für gesamtdeutsche Fragen wollte durch seinen Entwurf der Deutschland-Erklärung, den er nicht zufällig am Tag der Rückkehr des Kanzlers aus Japan vorlegte, die Sache bereinigen. Auch wenn sich beide Politiker nicht mehr zu persönlichen Gesprächen im Kanzleramt trafen, sondern sich lediglich in den gemeinsamen Gremien begegneten, blieb doch ihre Aufgabe, das Bündnis so gut es eben ging beisammenzuhalten. Übrigens nutzte am Ende auch der erzielte Kompromiß nichts. Der unberechenbare Staatspräsident Sihanouk brach die diplomatischen Beziehungen zur Bundesrepublik von seiner Seite aus ab.

\section{Irritationen um die Aufwertungsfrage und um die Oder-Neiße-Linie}

In der Kambodscha-Frage war gerade noch einmal ein Kompromiß gefunden worden. $\mathrm{Zu}$ einer Verständigung über Lösungsmöglichkeiten der seit langem schwelenden Währungskrise kam es dagegen nicht mehr. Dabei war die Frage, ob die DM aufgewertet werden sollte oder nicht, schon im Kabinett am 9. Mai 1969 entschieden worden. In einer viereinhalbstündigen Diskussion, in der sich Kiesinger und Strauß gegen die Aufwertung aussprachen, während Schiller und Bundesbankpräsident Blessing dafür plädierten, stellten sich alle CDU/CSU-Minister hinter Strauß und Kiesinger. Der Kanzler konnte ohne Abstimmung feststellen, daß die Mehrheit des Kabinetts gegen die Aufwertung sei, da die Union die größere Anzahl von Ministern stellte. Nach dieser Entscheidung fühlten sich allerdings die Sozialdemokraten nicht mehr an die Kabinettsdisziplin gebunden und kritisierten öffentlich die Regierungspolitik, sie empfahlen statt dessen eine Aufwertung der DM.

Der Streit wurde ausgelöst durch eine Währungskrise, die im Jahre 1968 ausbrach und ausgerechnet die drei westlichen Schutzmächte der Bundesrepublik besonders hart traf.

187 Vgl. Badische Neueste Nachrichten, 23.5.1969; dort auch das folgende Zitat. 
Der Dollar, das Pfund und der Franc waren seit geraumer Zeit durch die Außenhandelsdefizite ihrer Länder gegenüber der Mark überbewertet. Währungspolitisch gesehen bestand das Problem des Welthandels in einem Überschuß an Geld und damit in einer wachsenden Inflation, die einerseits durch den Vietnam-Krieg und andererseits durch hohe Kapitalinvestitionen von Amerikanern im Ausland entstanden ${ }^{188}$. Mit der Inflation wurden die Deutschen am besten fertig, vermutlich weil sich die Erinnerung an die Wertlosigkeit des Geldes nach den beiden Weltkriegen und die Erfahrung der Währungsreform von 1948 tief in den Menschen eingegraben hatten. Im Jahre 1968 stiegen in den USA die Preise beispielsweise um 4,1 Prozent, in England um 4,9 Prozent und in Frankreich um 4,6 Prozent; in der Bundesrepublik waren es nur 1,55 Prozent ${ }^{189}$. Hinzu kam der hohe Exportüberschuß der Deutschen, der durch die von den Vereinigten Staaten bewußt gegenüber dem Dollar unterbewertete DM gefördert wurde. Das galt im übrigen für einige westeuropäische Währungen und diejenige Japans auch. Washington gewährte damit diesen Ländern quasi eine Exportsubvention, da es billiger war, Waren und Rohstoffe von dort zu beziehen. Auf diese Weise entwickelte sich die ökonomisch starke Bundesrepublik bald zum Gläubigerland der westlichen Welt mit hohen Leistungsbilanzüberschüssen und einer Vergrößerung ihrer Währungsreserven ${ }^{190}$. Nur ein einziges Mal - 1961 - wurde die DM um 5 Prozent aufgewertet: zu wenig, wie sich jetzt herausstellte.

Die Krise vom Spätherbst 1968 wurde vor allem durch den Kontrast zwischen Preisstabilität und Währungsstärke der Bundesrepublik einerseits und der sozialen und wirtschaftlichen Instabilität Frankreichs hervorgerufen. Paris versuchte zwar durch restriktive Maßnahmen wie Devisenbeschränkungen, durch zeitlich befristete Einfuhrkontingente und durch Exportsubventionen die Zahlungsbilanz auszugleichen. Aber das reichte nicht. Es kam zu einer Kapitalflucht nach Deutschland, die vor allem mit der Aufwertung der DM spekulierte ${ }^{191}$. Paris, aber auch Washington und London verlangten die Aufwertung der deutschen Währung. Doch die Bundesregierung dachte anders. Allen voran der Finanzminister, der glaubte, daß eine Aufwertung die Exportchancen der eigenen Wirtschaft zu stark gefährden könne. Kiesinger, in Finanzfragen auf den Rat der Experten angewiesen, schloß sich ihm an ${ }^{192}$. Auch Schiller schien zu diesem Zeitpunkt noch zu zögern. Bonn suchte nach einem Ausweg und fand ihn im „Gesetz über Maßnahmen zur außenwirtschaftlichen Absicherung gemäß Paragraph 4 des Gesetzes zur Förderung der Stabilität und des Wachstums der Wirtschaft“. Hinter dem schwerver-

188 Vgl. Baring (Machtwechsel, S. 139), der auf die These des amerikanischen Wirtschaftswissenschaftlers Robert Triffin verweist. Triffin warnte Anfang der sechziger Jahre vor einer Dollarlücke, falls die USA nicht ihr Zahlungsbilanzdefizit beseitigten; vgl. auch Hankel, Währungspolitik; zu den Faktoren, die zum Ende des Systems von Bretton Woods führten, siehe Möller, Weltwährungsordnung.

189 Vgl. Scharrer, Währungssystem, S. 389.

190 Vgl. ebenda. Zwischen 1958 bis 1962 betrug das Aktivsaldo der Handelsbilanz durchschnittlich 5,4 Mrd. DM.

191 Vgl. Hildebrand, Erhard, S. 320.

192 Vgl. Schmoeckel/Kaiser, Vergessene Regierung, S. 341 f. Im November 1968 erklärte Kiesinger, solange er Kanzler sei, werde es keine Aufwertung geben. Schmoeckel/Kaiser machen drei Faktoren für Kiesingers Haltung verantwortlich. Erstens wollte er sich nicht durch eine Spekulation dazu drängen lassen; zweitens fürchtete er, daß die Bauern Zusagen staatlicher Hilfen als Ausgleich durch den Währungsverlust skeptisch gegenüberstehen würden; und drittens hatten Meinungsumfragen gezeigt, daß das Thema sich als Wahlthema nicht eignete, da es für den Bürger schwer zu verstehen war. 
ständlichen Namen verbargen sich eine Verteuerung der Exporte um vier Prozent und eine Verbilligung der Importe um die gleiche Prozentzahl ${ }^{193}$.

Den Amerikanern reichte diese Maßnahme dennoch nicht, obwohl Schiller dem amerikanischen Finanzminister Henry Hamill Fowler am 19. November 1968 versicherte, die Deutschen würden auf diese Weise ihren Zahlungsbilanzüberschuß um 4 Mrd. DM reduzieren. Sie bestanden während der Verhandlungen auf der von den Deutschen angeregten Konferenz der führenden westlichen Industrienationen, des sogenannten Zehnerclubs, darauf, die Bundesrepublik müsse ihre Währung aufwerten ${ }^{194}$. Vom 20 . bis zum 22. November sahen sich der deutsche Finanz- und der Wirtschaftsminister einer Front der Defizitländer gegenüber, die auf eine Aufwertung drangen und die von der Bundesregierung getroffenen Maßnahmen als nicht ausreichend kritisierten ${ }^{195}$. Aber Strauß und Schiller blieben hart und weigerten sich, einer Aufwertung zuzustimmen. Erstmals widerstand dabei die Bundesrepublik einem starken amerikanischen und vor allem französischen Druck. Den Bündnispartnern blieb neben dem Ärger über die Weigerung der Deutschen auch die Erkenntnis einer neuen Machtstellung der Bundesrepublik ${ }^{196}$. Die Londoner Times kommentierte, nunmehr sei die Macht in Europa von Paris nach Bonn übergegangen ${ }^{197}$. Aber die Machtverlagerung weckte Ängste vor einem neuen Größenwahn der Deutschen, wie er sich etwa in der Schlagzeile der Bild-Zeitung andeutete. Sie lautete: „Jetzt sind die Deutschen Nr. 1 in Europa - Das Ausland gratuliert - Verteidigung der Mark gelungen." 198 Die Germanen drückten ihren Brustkorb wieder heraus, stellte der französische Botschafter in Bonn, Seydoux, alarmiert fest ${ }^{199}$.

Die Umkehr Schillers und der SPD zu einer Aufwertungspolitik fand im Frühjahr 1969 statt, als sich erwies, daß der eingeschlagene Weg nicht zum Erfolg führen würde. Zwar normalisierte sich der Währungsverkehr zwischen Frankreich und der Bundesrepublik wieder - die Bundesbank besaß im Februar 1969 weniger Währungsreserven als vor der Herbstkrise $1968^{200}$-, aber die Spekulationsgefahr war nach wie vor nicht gebannt. Noch im Januar 1969 hatte Schiller die Entscheidung der Bonner Konferenz des Zehnerclubs als „Sieg des Prinzips der kooperativen internationalen Stabilitätspolitik “ gefeiert. Es habe sich die Einsicht verbreitet, daß der Bundesrepublik allein nicht die Verantwortung aufgebürdet werden dürfe ${ }^{201}$. Drei Monate später aber schlug er im kleinen Kreis dem Kanz-

193 Vgl. Hildebrand, Erhard, S. 321, und Baring, Machtwechsel, S. 143; ausgenommen blieben die landwirtschaftlichen Erzeugnisse, die der Agrarmarktordnung der EWG unterlagen.

194 Vgl. Hildebrand, Erhard, S. 321.

195 Vgl. Baring, Machtwechsel, S. 143; Bundesbankpräsident Blessing verließ die Tagung noch in der Nacht des ersten Tages, weil er das Geschimpfe seiner ausländischen Kollegen nicht anhören wollte.

196 Vgl. Grosser, Frankreich und seine Außenpolitik, S. 281. Für Paris sei sichtbar geworden, meint Grosser, daß künftig Europa mit dem wirtschaftlichen Potential Bonns rechnen müsse. Langfristig sei es daher vernünftig geworden, mit dem Eintritt Großbritanniens ein Gegengewicht zur Bundesrepublik zu schaffen.

197 Vgl. The Times, 22.11.1968.

198 Bild-Zeitung, 23.11.1968.

$199 \mathrm{Vgl}$. Seydoux, Botschafter in Deutschland, S. 152. Seydoux hatte nicht ganz unrecht. Der frühere Staatssekretär im Wirtschaftsministerium (1958-1963) und Kölner Ordinarius für Wirtschaftspolitik Alfred Müller-Armack etwa schrieb dem Kanzler am 8.7.1969, die Rolle der Bundesrepublik als Gläubigerland mit hohem Kapitalexport diene dem Wiederaufbau „der uns seit dem Ersten Weltkrieg verlorengegangenen deutschen Kapitalposition im Ausland"; AdKASt, Kiesinger I - 226, D/IV.6, A 006, Müller-Armack an Kiesinger.

200 Vgl. Emminger, Bilanz der Währungskrisen, S. 143.

201 Schiller, Die Lage nach der Bonner Konferenz, S. 3. 
ler vor, man solle die DM aufwerten ${ }^{202}$. Während der Haushaltsdebatte drückte er sich noch vorsichtig aus. Man habe sich „auf jeden Fall [...] für die weiteren Wege und auch für mögliche weitere Schritte alles offengehalten "203. Bereits mit dieser Bemerkung löste er erneut eine Spekulantenwelle aus.

Im April 1969 unternahm die Bundesbank den Versuch, die Bundesregierung zur Aufwertung zu zwingen, indem sie den Diskontsatz um 1 auf 4 Prozent anhob. Als Folge dieser Dämmung der Konjunktur und der Preisentwicklung erhöhte sich die Auslandsnachfrage, die allerdings ohnehin schon zu stark war. Die nächste Spekulationswelle ergoß sich über die Republik, als Strauß am 29. April die Bereitschaft der Bundesregierung zu einer multinationalen Änderung der Währungsparitäten verkündete. In den folgenden Tagen kam es wegen der Spekulationen um eine Aufwertung auf den Devisenmärkten teilweise zu einem Chaos. Nunmehr beschloß die Regierung am 9. Mai „endgültig, eindeutig und ewig", wie Ahlers hinterher sagte, die Deutsche Mark nicht aufzuwerten ${ }^{204}$.

Im Kabinett war es freilich nicht zur Abstimmung gekommen. Der Bundeskanzler stellte nach langer Aussprache, bei der die Meinungsverschiedenheiten offen zu Tage traten, fest, eine Mehrheit habe beschlossen, nicht aufzuwerten ${ }^{205}$. Aber Kiesinger erreichte damit nicht, was er wollte, nämlich die Währungsfrage aus der Diskussion zu nehmen. Im Gegenteil: Nun wurden die Gegensätze in aller Öffentlichkeit ausgetragen. Schiller und Strauß, die man am Anfang noch wegen ihrer vorzüglichen Zusammenarbeit als Plisch und Plum bezeichnet hatte, wurden nun zu Gegenspielern in einer Frage, die sich zu einem der wichtigsten Wahlkampfthemen entwickeln sollte ${ }^{206}$. Schiller kritisierte den $\mathrm{Be}-$ schluß des Koalitionsgremiums. Am 26. Mai ließ ihm der Kanzler, erbost über die Kritik und ständigen Kommentare seines Wirtschaftsministers, folgenden Protest telefonisch übermitteln: „Sie wissen, daß ich Ihre persönliche Auffassung stets respektiert habe. Ich muß Sie nun aber auf das dringlichste bitten, kritische Äußerungen gegen diesen Kabinettsbeschluß zu unterlassen. “207

Schiller antwortete drei Tage später in einem Brief, dessen Tenor auf die Martin Luther zugesprochenen Worte hinauslief: Hier stehe ich und kann nicht anders. Selbstverständlich habe er volles Verständnis für die schwierige Lage und für die Verärgerung des Kanzlers über seine Ausführungen zum Thema Preisstabilität und Nichtaufwertung. Auch sei er der Auffassung, daß manche Gründe, und nicht nur solche kabinetts- oder parteipolitischer Natur, dafür sprechen würden, die Diskussion einschlafen zu lassen. „Nur -

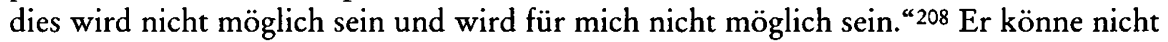
schweigen zu Preissteigerungen und ihrer Bekämpfung, zu außenwirtschaftlichen Gefahren und ihrer Beseitigung, eben zu den Geboten der Paragraphen 1 und 4 des Stabilitäts- und Wachstumsgesetzes. Es sei selbstverständlich, daß jedes Kabinettsmitglied den

202 Vgl. AdG, Schiller an Kiesinger vom 24.9.1969, S. 14946.

203 VdDB, 5. Wahlperiode, 222. Sitzung vom 20.3.1969, S. 12091.

204 AdG, S. 14691.

205 Vgl. AdG, S. 14690 f.; Schmoeckel/Kaiser (Vergessene Regierung, S. 340) stellen fest, daß die SPD nicht bereit gewesen sei, diese Frage zum Anlaß eines Bruchs der Koalition zu machen. Wegen des komplexen Themas wäre es den Wählern nicht zu vermitteln gewesen, habe man geglaubt.

206 Vgl. Baring, Machtwechsel, S. 145 f.; nach Aussage von Kiesinger ist dies vor allem auf Strauß zurückzuführen. Der Finanzminister hatte zu lange als zweiter Mann hinter Schiller zurückstehen müssen. In der Aufwertungsfrage sah er eine Möglichkeit, sich vorteilhaft in Szene zu setzen - sehr zum Kummer des Kanzlers, der das Problem gerne heruntergespielt hätte.

207 AdKASt, Kiesinger I - 226, D/IV.6, A 007, Kiesinger an Schiller vom 26.5.1969.

208 AdKASt, Kiesinger I - 226, D/IV.6, A 007, Schiller an Kiesinger vom 29.5.1969. 
Kabinettsbeschluß vom 9. Mai respektiere. Dies habe er getan und werde es weiterhin tun. „Es ist aber nicht möglich, den Beschluß oder seine Folgen langsam vergessen zu lassen", hieß es wörtlich. Schweigen würde nichts, aufklären könne viel helfen.

Wie über einen heiligen Gegenstand sprach Schiller von den „Geboten“ des Stabilitätsgesetzes, und auch der Hinweis auf die ersten Worte der Regierungserklärung, die noch einmal wörtlich wiedergegeben wurden, wirkte wie eine Mahnung. Der Brief deutete bereits an, daß Schiller mit der Währungsdiskussion in der Wahlkampfphase zum eigentlichen Kontrahenten Kiesingers heranreifen würde ${ }^{209}$ - ein ungleiches Duell, wenn man bedenkt, daß der Kanzler auf dem wirtschaftlichen Gebiet kaum Fachkenntnisse aufwies und sich auf Expertenmeinungen verlassen mußte.

Die Erklärung des Ministers, er werde sich auch weiterhin kritisch zum Kabinettsentscheid äußern, leitete die letzte Phase der Koalition ein, in der beide Parteien ihre unterschiedlichen Standpunkte öffentlich darlegten. Ab jetzt gab es keine Bereitschaft mehr, eine Erklärung in den umstrittenen Themen aus Rücksicht auf den Koalitionspartner abzuschwächen, umzuinterpretieren oder gar zurückzunehmen.

\section{Schütz und die Diskussion der Oder-Neiße-Grenze}

Am 27. Juni 1969 veröffentlichte das Wochenblatt Die Zeit einen Aufsatz des Regierenden Bürgermeisters von Berlin. Schütz hatte zuvor die Volksrepublik Polen besucht und schrieb unter dem Eindruck seiner Gespräche mit dortigen Regierungsmitgliedern, es müsse den Deutschen um die Veränderung des Charakters der bestehenden Grenzen gehen. Verbunden mit Gewaltverzichtsverträgen, solle Bonn die existierenden Grenzen anerkennen ${ }^{210}$. Es dauerte immerhin zwei Wochen, bevor der Bundeskanzler auf den Artikel reagierte. Am 11. Juli klagte er Brandt, der Aufsatz von Schütz enthalte Formulierungen, die "mit der Politik der Bundesregierung nicht übereinstimmen“. Er mache sich Sorgen wegen der möglichen Auswirkungen. Brandt solle mit Schütz sprechen ${ }^{211}$. Aber nichts geschah. Schütz wiederholte seine Aussagen und fügte andere, provozierendere hinzu. Am 24. Juli wandte sich Kiesinger erneut an den Außenminister und SPD-Vorsitzenden. Diesmal fand der Kanzler deutlichere Worte: „Ich habe bisher noch davon abgesehen, mich zu dem Artikel in der Zeit und zu den neuen Äußerungen des Regierenden Bürgermeisters zu äußern. Ich darf Ihnen gegenüber aber die dringliche Bitte aussprechen, daß Sie mit Herrn Schütz sprechen. “212 Die Antwort Brandts war konziliant. Er habe mit Schütz eingehend über dessen Reise nach Polen gesprochen, wolle aber auf bestimmte Aspekte des Artikels und des Fernsehbeitrages noch zurückkommen, ließ er am 25. Juli wissen 213. Über die Reaktion der SPD auf den Artikel von Schütz fügte Brandt in der Anlage eine von der Partei herausgegebene Pressemitteilung vom 28. Juni bei. Der Text verteidigte die Aussagen mit Blick auf die Vertriebenenverbände. Schütz besitze das Recht, wie jeder andere Deutsche auch, eine Meinung zu äußern, hieß es etwa. Für die SPD gäbe es zwei Konstanten in der Deutschlandpolitik, erstens den berechtigten Anspruch auf das Selbstbestimmungsrecht und zweitens ,die Notwendigkeit, in Mitteleuropa ein erträgliches und vertraglich geregeltes Verhältnis der Völker untereinander

209 Vgl. Baring, Machtwechsel, S. 137; Hildebrand, Regierung, S. $401 \mathrm{ff}$.

210 Vgl. Schütz, Unsere Politik gegenüber Polen, in: Die Zeit, 27.6.1969.

211 AdKASt, Kiesinger I - 226, D/IV.6, A 001, Kiesinger an Brandt vom 11.7.1969.

212 AdKASt, Kiesinger I - 226, Kiesinger an Brandt vom 24.7.1969.

$213 \mathrm{Vgl}$. AdKASt, Kiesinger I - 226, Brandt an Kiesinger vom 25.7.1969; dort die folgenden Zitate. 
zu finden“. Dieser letzte Punkt stützte die Anregung von Schütz, über Gewaltverzichtsabkommen die Grenzen in Europa anzuerkennen. Darauf deutet auch der Satz, der Regierende Bürgermeister habe auf nichts verzichtet, „das anderen gehört, auch nicht auf etwas, das den Heimatvertriebenen gehört".

Schütz blieb bei seinen Aussagen und wiederholte sie in regelmäßigen Abständen bis zur Bundestagswahl. Am 7. September nannte er die polnische Westgrenze wie die Existenz der DDR Realität. Beide müßten anerkannt werden ${ }^{214}$. Dazu gab es von Kiesinger keine Stellungnahme mehr. Nachdem er sich öffentlich von den Auffassungen distanziert hatte, wurde die Erklärung des Regierenden Bürgermeisters vermutlich als Wahlkampf gedeutet ${ }^{215}$.

Die Aufwertungsdebatte wurde unterdessen mit großer Heftigkeit weiter öffentlich ausgetragen. Als Frankreich unerwartet am 8. August 1969 den Franc gleich um 12,5 Prozent abwertete, wurde das vom Kanzler und seinen Beratern als Erfolg der bisherigen deutschen Währungspolitik beurteilt. Fritz Berg, langjähriger Präsident des Bundesverbandes der Industrie, gratulierte und rühmte die Haltung des Kanzlers: „Die Abwertung des Franc hat die Richtigkeit Ihrer festen währungspolitischen Haltung bestätigt. " ${ }^{216} \mathrm{Da}$ mit sei auch die letzte Begründung für eine etwaige DM-Aufwertung entfallen.

Aber auch die Sozialdemokraten fühlten sich bestätigt. Nach eigener Aussage versuchte Schiller am 10. August, den Kanzler - im Geist der europäischen Solidarität - von einer deutschen Aktion, eben einer Aufwertung oder ähnlicher schon vorgeschlagener Maßnahmen, zu überzeugen. Es war abzusehen, daß es kurz vor der Wahl am 28. September zu einer erneuten Welle von Spekulantengeldern in die Bundesrepublik kommen würde.

Drei Tage vor der Wahl offerierte der SPD-Vorsitzende ein währungspolitisches Stillhalteabkommen für sechs Monate, um die Spekulationsflucht der schwächeren Währungen in die DM zu stoppen. Gleichzeitig sollte auf einer Sondersitzung des Kabinetts am nächsten Tag, dem 26. September, noch einmal über das Stabilisierungsprogramm Schillers beraten werden. Beides kam dann nicht mehr zustande. Die Union war mit einem Stillhalteabkommen ohne Kabinettssitzung einverstanden, die SPD wollte das Abkommen nur dann treffen, wenn auch die Vorschläge Schillers behandelt würden. Auf Anraten der Bundesbank schloß der Wirtschaftsminister die deutschen Devisenbörsen für zwei Tage, am 25. und 26. September. Das Ersuchen Kiesingers um eine Schließung für den Montag nach der Wahl lehnte Schiller allerdings ab217.

\section{Kiesinger und die Wablnacht}

Trotz aller wahltaktischen Dispute und öffentlich ausgetragener Gegensätze sprach sich Kiesinger, je näher der Wahltermin rückte, desto stärker für eine Fortsetzung der Großen Koalition aus. Zwar erklärte der Kanzler auch, ihm sei die Kleine Koalition lieber; aber

214 Vgl. AdG, Schütz in der Berliner Waldbühne am „Tag der Heimat“, 7.9.1969, S. 14896.

215 Vgl. Der Deutsche Ostdienst, 18.8.1969; das Organ des Bundes der Vertriebenen druckte einen

Brief Kiesingers, in dem der Kanzler betonte, die Bundesregierung teile nicht die Auffassung des Regierenden Bürgermeisters.

216 AdKASt, Kiesinger I - 226, Berg an Kiesinger vom 12.8.1969.

217 Am 29.9. trat das Kabinett aufgrund einer Initiative des Bundesbankpräsidenten Blessing zusammen, der entweder eine sofortige Aufwertung der DM oder eine Freigabe des Wechselkurses forderte. Die amtierende Bundesregierung gab daraufhin den Devisenmarkt vorübergehend frei. 
das schien mehr ein Lippenbekenntnis zu sein. Ungleich stärker setzte sich der Kanzler für eine Fortsetzung des Bündnisses zwischen Union und SPD ein, was besonders daraus deutlich wurde, daß er noch immer ein Mehrheitswahlgesetz propagierte. Schon am 7. Juli - zweieinhalb Monate vor der Wahl - meinte Kiesinger vor den Kameras des Deutschen Fernsehens, selbst wenn CDU/CSU eine absolute Mehrheit erreichten, würden sie sich nicht der Forderung entziehen können, mit ihrer Mehrheit eine Änderung des Wahlrechts zu beschließen ${ }^{218}$. Unter diesem Aspekt mußten seine Aussagen zur angestrebten Koalition mit den Liberalen unglaubwürdig erscheinen. Hinzu kam, daß sich inzwischen die ost-, besonders aber die deutschlandpolitischen Ziele der FDP von denen der Union noch stärker unterschieden als von denen der SPD. Am 24. Januar 1969 hatten die Liberalen den Entwurf für einen „Vertrag zur vorläufigen Ordnung der Beziehungen zwischen der Bundesrepublik und der DDR " veröffentlicht. Der Grundgedanke darin war einfach. Er kombinierte die Forderung der DDR nach völkerrechtlicher Anerkennung mit der Forderung der Bundesregierung nach menschlichen Erleichterungen. Gegenüber der DDR sollte ein Gewaltverzicht ausgesprochen werden, allerdings nur für die Übergangszeit bis zur Wiedervereinigung, also ohne daß die deutsche Frage dadurch präjudiziert worden wäre. Im Gegenzug sollte die DDR ihrer Bevölkerung freien Reiseverkehr gestatten und die politischen Inhaftierten begnadigen ${ }^{219}$.

Solche Vertragsentwürfe fanden vor allem den Beifall von Wehner, der Scheel, Genscher und Mischnick am Tage vor der Deutschlanddebatte, am 24. April 1969, bei sich zum Frühstück empfing, um ihnen mitzuteilen, daß er im Bundestag den Entwurf dennoch leider ablehnen müsse 220 . Aber für Kiesinger und die CDU/CSU war diese Politik nicht tolerabel. In dem oben zitierten Fernsehgespräch sprach der Kanzler von Konzeptionslosigkeit und erklärte auf die Frage nach der Koalitionsfähigkeit der FDP: „Wir müssen in der Deutschlandpolitik und der Ostpolitik uns nicht an Worten berauschen, sondern wir müssen eine klare Linie ziehen. Es ist in der Großen Koalition möglich gewesen, trotz gelegentlicher Abweichungen, doch diese Linie zu halten. Mit der FDP würde es so, wie jetzt mindestens einige ihrer Politiker die Dinge aussprechen, sehr schwierig sein. "221 Das war deutlich genug. In den folgenden Wochen betonte er mit Blick auf die Liberalen, eine Koalition könne man nur dann schließen, wenn die Basis einer gemeinsamen Außenpolitik gegeben sei. Falls die Partei sich einer solchen Außenpolitik versagen würde, „gibt es eben keine Koalition“222. Und am 16. September erklärte der Kanzler in einem Gespräch mit der Westfalenpost, die parlamentarische Demokratie könnte ein Bündnis der beiden großen Parteien bis 1973 noch einmal ertragen, „vielleicht sogar mit Gewinn"223.

Das war die Lage am Abend des 28. September. Es sah zunächst so aus, als ob die $\mathrm{CDU} / \mathrm{CSU}$ einen überwältigenden Wahlsieg errungen hatte. Bis gegen $20 \mathrm{Uhr}$ konnte Kiesinger sogar glauben, die Union habe die absolute Mehrheit der Mandate erzielt und

218 Vgl. BPA, Kiesinger im Deutschen Fernsehen am 7.7.1969, Anhang, S. 7.

219 Vgl. Baring, Machtwechsel, S. 226 ff.; der Entwurf stammte vom Journalisten Hans Dieter Jaene.

220 Vgl. Baring (Machtwechsel, S. 228), der das Treffen als ein Signal sieht: „Ließ es doch erkennen, daß Wehner, der sich seit vielen Jahren nicht mit ihnen ausgesprochen hatte, seit der Wahl Heinemanns am 5.3.1969 die Liberalen positiver einzuschätzen begann als vorher, wenn er auch noch nicht so recht an eine mögliche Zusammenarbeit glaubte."

221 BPA, Kiesinger am 7.7.1969, S. 5.

222 Bulletin, Kiesinger im Südwestfunk am 10.8.1969, 14.8.1969.

223 Westfalenpost, 16.9.1969. 
sei daher sämtlicher Koalitionsprobleme ledig. Den ganzen Abend und sogar noch am nächsten Morgen war er sicher, gegen die CDU/CSU könne keine Regierung gebildet werden. Von seinen Beratern dazu überredet, richtete er jetzt seine Hoffnungen ganz auf die FDP. Im Kanzlerbungalow saßen im Hochgefühl des Sieges zusammen die engsten Berater Guttenberg, Diehl, Carstens, Kohl, die Ehefrau Marie-Luise und Sohn Peter. Die CDU/CSU konnte 46,1 Prozent erzielen und verlor damit nur 1,5 Prozentpunkte gegenüber den Wahlen von 1965. Die SPD gewann immerhin 3,4 Prozentpunkte hinzu und erhielt 42,7 Prozent der Stimmen. Starke Verluste hatte die FDP hinzunehmen, die von 9,5 Prozent auf 5,8 Prozent rutschte (ein Verlust von 3,7 Prozentpunkten).

Die politischen Berater waren von Beginn an auf ein Bündnis mit der FDP eingestimmt. Kohl sagte, nur eine Kleine Koalition sei denkbar, und man stimmte zu$^{224}$. Allein Guttenberg blieb der Großen Koalition treu. Er sei der einzige gewesen, berichtet er später, der sich nicht für die christlich-liberale Koalition ausgesprochen habe ${ }^{225}$. Aber sonst war die Meinung ungeteilt. Dahinter stand wohl zunächst das Gefühl, frei zu sein und selbst bestimmen zu können. All die Mühsal der Kompromißfindung schien nun im Rückblick ein Alptraum gewesen zu sein. Warum sollte man sich wieder in diese Lage begeben? Nur weg von der SPD, mit der man bis zuletzt gestritten hatte, lautete die Parole der Stunde. Mit Erleichterung kommentierte beispielsweise Barzel vor den Fernsehkameras das Ergebnis: Diesmal sei es die Union, die das Rennen gemacht habe. Und zu Schmidt, zu dem er in der Koalition ein kameradschaftliches Verhältnis entwickelt hatte, meinte er hochmütig: Der Herr Kollege werde sich daran gewöhnen müssen, wer jetzt den Ton angebe ${ }^{226}$.

Alle sprachen von der FDP. Das war ein Fehler, der Kiesinger vielleicht das Kanzleramt und der Union die Regierungsbeteiligung kostete. Der Kanzler hätte unter allen Umständen geradlinig auf die Fortsetzung der Koalition zusteuern müssen. Vielleicht hätte es genutzt, sich in dem Moment, da die Hochrechnungen in den beiden Fernsehanstalten nicht mehr die absolute Mehrheit der Mandate für die Union vorhersagten, sofort um die SPD zu kümmern und Kontakt zu denjenigen aufzunehmen, die noch an eine Große Koalition glaubten. Aber wie schon in den Monaten zuvor, überließ der Kanzler die Initiative den Beratern um sich herum. Jede Hoffnung auf eine Fortsetzung der Koalition, die er im Wahlkampf nährte, war am Wahlabend schnell aufgegeben. Kiesinger hatte sich in den Monaten zuvor nicht eindeutig genug in seiner Partei für das Bündnis eingesetzt. Jetzt war es dafür zui spät.

Man muß einerseits von der tragischen Seite des Wahlabends sprechen, wenn das knappe Wahlergebnis sowie die Rolle der NPD bedacht werden, die zwar selbst nicht den Sprung in den Bundestag schaffte, aber mit ihren Stimmen eine absolute Mehrheit der Union verhinderte. Andererseits darf nicht übersehen werden, daß der Kanzler sich zu wenig um die Koalitionsfrage in den eigenen Reihen bemüht hatte. Es fehlte ihm dabei an Voraussicht und Entschlossenheit. Kiesinger hatte unbestritten einige eindrucksvolle Erfolge in der Außenpolitik erzielen können - in seiner Koalitionspolitik wirkte er dagegen konzeptionslos. Der Eindruck trifft zu, daß er sich weitgehend treiben ließ. Die plötzliche Wendung zur FDP am 28. September ist der letzte Akt in einem politischen Drama, das zwar Höhepunkte, aber weder Struktur noch einen verständlichen Zusammenhang aufweist. Sicherlich reizte Kiesinger jetzt die Möglichkeit, mit der FDP und damit mit größe-

224 Vgl. Peter Kiesinger, Gespräch mit dem Verfasser, 16.2.1989.

225 Vgl. Guttenberg, Fußnoten, S. 108.

226 Vgl. Nau, Gespräch mit Baring, 10.3.1977; Der Spiegel, 6.10.1969, S. 28. 
rer Unabhängigkeit zu regieren, aber das entsprach nicht der Politik, die er drei Jahre lang verfolgt hatte. Er unterschätzte auch den Willen der Liberalen, ein Bündnis mit den Sozialdemokraten einzugehen. Dort hatte man die stiefmütterliche Behandlung durch ihn nicht vergessen. Zudem existierten schon seit der Wahl Heinemanns ausgeprägte Kontakte zwischen den Spitzen von FDP und SPD. Schließlich sprach auch die große Annäherung in der Deutschland- und Ostpolitik zwischen diesen Parteien für eine sozialliberale Koalition.

Kiesinger suchte trotzdem noch in der Wahlnacht über Kohl das Gespräch mit den Liberalen. Ganz im Gegenteil zum Kanzler hatte der Ministerpräsident die Verbindung zur FDP nie abreißen lassen und brachte auch an diesem Tag den Gedanken der Kleinen Koalition auf. Kohl, der als junger erfolgreicher Landespolitiker schon seit einiger Zeit in den Kreis der Berater um Kiesinger aufgestiegen war und der sich überhaupt häufig um ältere und verdiente Politiker seiner Partei kümmerte ${ }^{227}$, traf sich auf Geheiß Kiesingers mit Genscher - mit Wissen und Zustimmung anderer FDP-Präsidiumsmitglieder und vor allem des Vorsitzenden Scheel. Über das Treffen hat es unterschiedliche Aussagen gegeben. Baring hat über Kohls Eindruck berichtet, der CDU-Politiker habe in dem Gespräch das herausgehört, was er herauszuhören wünschte, nämlich Genscher strebe die CDU/CSU-FDP-Koalition an, sie sei sogar schon abgemachte Sache228. Hier täuschte sich Kohl allerdings, so Baring, denn der Parlamentarische Geschäftsführer der FDP-Fraktion hatte sich seit Monaten eindeutig für die sozialliberale Koalition ausgesprochen. Wenn er in dem Gespräch Kohl ein anderes Bild gezeichnet habe, dann nur, weil er den Weg zu den Christdemokraten offenhalten wollte, falls das Bündnis mit den Sozialdemokraten nicht zustande kommen sollte ${ }^{229}$.

Ein ganz anderer Eindruck von der Motivation Kohls bei diesem Gespräch hat sich beim Chefkorrespondenten der Süddeutschen Zeitung und genauen Beobachter des Bonner Parketts über Jahrzehnte, Dreher, gebildet. Genscher habe später von dem Gespräch in der Septembernacht 1969 berichtet, es sei kurz, förmlich und frostig gewesen. Kohl habe angedeutet, daß Scheel wieder Entwicklungshilfeminister werden könne. Die Union sei bereit, seinem Amt einige erweiterte Kompetenzen aus dem Auswärtigen Amt zuzubilligen. Es seien auch „Vereinbarungen“ zwischen beiden Parteien angesprochen worden, also die freiwillige Abtretung von Direktmandaten für zehn Jahre. Aber Genscher erhielt den Eindruck, handfeste Angebote seien nicht gemacht worden ${ }^{230}$. Dreher glaubt, Kohl habe während des Gespräches absichtlich große Zurückhaltung geübt. Aus persönlichen Gründen habe er eine weitere Regierungsbeteiligung der Union nicht für rat-

227 Vgl. Dreher, Gespräch mit dem Verfasser, 5.7.1988; beispielsweise war es der CDU-Vorsitzende von Rheinland-Pfalz, der Strauß 1963 bat, erstmals nach der Spiegel-Affäre bei ihm im Wahlkampf aufzutreten. Und auch als Gerstenmaier sein Amt als Bundestagspräsident aufgeben mußte, lud ihn Kohl zu einem Abendessen nach Mainz ein. Baring (Machtwechsel, S. 161) betont, daß sich Kohl besonders um die älteren Politiker kümmerte, da sie keine Konkurrenz für ihn darstellten.

228 Vgl. Baring, Machtwechsel, S. 162.

229 Vgl. ebenda, S. 162 f.

230 Dreher, Gespräch mit dem Verfasser, 5.7.1988; das Protokoll der FDP-Vorstandssitzung vom 30.9. bestätigt diese Aussage allerdings nur in beschränkter Weise. Genschers Worte (zitiert nach Baring, Machtwechsel, S. 162) lassen sich so deuten, als ob Kohl über vage Andeutungen nicht hinausgegangen sei: „Er hat mir gesagt, daß bei ihnen die Bereitschaft, eine Koalition mit der Freien Demokratischen Partei zu bilden, sehr stark sei, mit sehr weitreichenden Konsequenzen auch auf die Landespolitik, mit einer großzügigen, die Wunden heilenden Behandlung hinsichtlich der Vergabe von Kabinettsposten." 
sam gehalten. Kohl habe kalkuliert, daß er zu Beginn der achtziger Jahre selbst Bundeskanzler werden könne. Er sei überzeugt gewesen, daß es leichter sei, aus der Opposition heraus Kanzler zu werden ${ }^{231}$. Möglicherweise ist diese These zu sehr vom Ende her gedacht. Sie zeigt aber, wie stark sich der Eindruck festgesetzt hat, daß Kiesinger in der Wahlnacht die Zügel der Führung längst entglitten waren.

Am Wahlabend schien Kiesinger noch der sichere Sieger des Tages zu sein. Aber das änderte sich schon bald: Kurz vor Mitternacht verabredeten Brandt und Scheel, eine Regierung zu bilden. Brandt begab sich vor die Kameras und erklärte: „SPD und FDP haben mehr als CDU und CSU."232 Damit war der Versuch angekündigt, eine sozialliberale Koalition zu gründen. Im Morgengrauen des Montags schlich das Gespenst einer neuen Regierungskoalition in Bonn um das Bundeshaus, meinte Mende später ${ }^{233}$. Aber Kiesinger hielt eine solche Koalition zunächst für unwahrscheinlich. Zu knapp erschien ihm der Vorsprung einer Mehrheit von nur sechs Abgeordneten. Dennoch unterbreitete der amtierende Kanzler den Liberalen am 30. September ein derart großzügiges Angebot, daß es schwerfallen mußte, es einfach auszuschlagen. Er offerierte Dauerbündnisse im Bund, den Ländern und Gemeinden für die gesamten siebziger Jahre234. Das Paket enthielt noch andere Zusagen. Einmal würde die Union auf die Bildung einer Großen Koalition verzichten und nicht länger die Änderung des Wahlrechts fordern. Zum anderen sollte die FDP sechs Ministerposten erhalten, und Kiesinger bot Scheel ausdrücklich das Außenministerium an.

Zu schön, um wahr zu sein, mußte sich nicht nur die FDP-Delegation denken. Auch in der Union fand das Angebot keine ungeteilte Zustimmung. Es trug zu sehr den Charakter, panikartig zusammengestellt worden zu sein, um die SPD aus dem Feld zu schlagen. Besonders die Offerte, Scheel das wichtigste Amt der Bundesregierung nach dem Bundeskanzler zu überlassen, stieß auf Ablehnung. Das galt übrigens nicht nur für die Union. Als „Herrn Leichtfuß“ schätzte ihn der Altliberale Reinhold Maier ein, als rheinischen "Windhund“ sah ihn die den Linksliberalen nahestehende Publizistin Dönhoff ${ }^{235}$. Im Wahlkampf nannte man ihn bei der Union einen „Traumtänzer“. Auch Kiesinger mußte am 1. Oktober einräumen, daß er Scheel eine Politik des „Wunschdenkens und der Illusionen“ vorgeworfen habe ${ }^{236}$. Für die meisten Unionspolitiker, gerade auch für Kohl, war er als ernstzunehmender Politiker nicht qualifiziert genug. Man konnte ihm allerhöchstens das Entwicklungshilfeministerium anvertrauen, das er schon einmal bis zum Bruch der Regierung Erhard geleitet hatte. Als Kiesinger Scheel am 3. Oktober in einem Schreiben die Angebote bestätigte, ging er auf das Außenministerium nicht mehr ein. Im Gegenteil, der Brief enthielt einige einschränkende Äußerungen zur Außenpo-

231 Vgl. ebenda.

232 Baring, Machtwechsel, S. $166 \mathrm{ff}$.

233 Vgl. Mende, Wende, S. 309.

234 Vgl. Baring, Machtwechsel, Protokoll der Vorstandssitzung der FDP am 3.10.1969, S. 157. Mischnick bestätigte auf der FDP-Vorstandssitzung: „Es war deutlich zu spüren, daß dieses Angebot Bund, Länder und Gemeinden umfassen sollte und daß es bis Ende der siebziger Jahre gelten sollte. (Zuruf: Ein Fusionsangebot!) Weil Sie das sagen: so eine Art wie damals die BürgerblockGeschichte in Hamburg, also praktisch eine Absicherung der F.D.P. bis Ende der siebziger Jahre. So war der Grundgedanke. " Sogar eine Wahlabsprache mit der FDP war angeboten worden. CDU/CSU zeigten sich bereit, den Liberalen drei Wahlkreise zur Verfügung zu stellen, damit sie über die Landesliste in ein Parlament einziehen konnten, falls sie die 5-Prozent-Hürde nicht überspringen sollten.

235 Baring, Machtwechsel, S. 158.

236 BPA, Kiesinger im ZDF am 1.10.1969, Anhang, S. 3. 
litik: „Auf dem Gebiet der Außenpolitik und der Deutschlandpolitik“, hieß es da, „wird es notwendig sein, durch eine gründliche Beratung die beiderseitigen Standpunkte zu klären und zu prüfen, ob eine gemeinsame Politik möglich ist. " 237 Der offensichtliche Rückzug in dieser Frage sowie die als Fusionsangebot aufgefaßten, im Brief nur vage angedeuteten sachlichen Zugeständnisse trugen dazu bei, daß sich die Liberalen nicht beirren ließen und auf die Koalition mit der SPD zusteuerten.

Im Grunde war alles schon vorher entschieden. Mende gab dem Kanzler am 2. Oktober folgende Einschätzung: Die Düsseldorfer Koalition werde nun nach dreijähriger Bewährung auch durch das persönliche Verhältnis von Kühn und Weyer als Modell für eine Brandt/Scheel-Koalition gehandelt. Die Linken hätten alle Einwände vom Tisch gewischt und befänden sich in einer Aufbruchsstimmung. Es sei zu spät, daran noch etwas ändern zu wollen ${ }^{238}$. Kiesinger habe sich betroffen von seiner Beurteilung der Koalitionslage gezeigt, beschrieb Mende später Kiesingers Reaktion. Er sei bereit, den Liberalen die gleichen Ressorts anzubieten wie die SPD. Auch die Wahlreform sei allemal vom Tisch, wenn die FDP zur Zusammenarbeit bereit wäre, betonte Kiesinger noch einmal. Dazu konnte Mende nur antworten: „Dieses Angebot kommt drei Jahre zu spät, Herr Bundeskanzler!“

Diese Aussage traf Kiesinger um so härter, als er sich von den Konservativen in der liberalen Fraktion Schützenhilfe gegen die sich anbahnende sozialliberale Koalition erhofft hatte. Das war ihm auch in der Wahlnacht bestätigt worden. Mindestens zehn Abgeordnete würden gegen ein solches Bündnis stimmen, meinte Kohl, der sich auf Mende berief. Tatsächlich hatte es diese kleine Gruppe von Verschwörern gegeben, darunter die beiden Bayern Ertl und der frühere Finanzminister Starke sowie die niedersächsischen Abgeordneten Fritz Logemann und Carlo Graaff. Noch am Montag, dem 29. September, waren sich diese einig, daß eine Koalition mit der SPD keineswegs beschlossene Sache sei. Doch dann setzte eine Werbekampagne ein, der sich viele Liberale nicht zu entziehen vermochten. Ertl köderte man mit dem Bundesministerium für Landwirtschaft, Logemann wurde der Posten eines Parlamentarischen Staatssekretärs angeboten. Beide nahmen an. Graaf erhielt die Zusage, seine Waggonfabrik werde künftig stärker berücksichtigt ${ }^{239}$. Von anfänglich zehn Abgeordneten blieben am Ende vier Gegner einer Koalition mit der SPD. Mende, Starke und Siegfried Zoglmann verließen im Oktober 1970 ihre Partei und schlossen sich der CDU/CSU an. Im Juni 1972 trat Kühlmann-Stumm sein Mandat an Menne ab.

Kiesingers Gewißheit, am Ende doch zu triumphieren ${ }^{240}$, beruhte ganz auf der Hoffnung, daß Brandt bei der Kanzlerwahl im Parlament nicht die erforderliche Mehrheit erzielen würde. In der Zeit bis zum zweiten oder dritten Wahlgang würde die Union versuchen, den Rest der FDP auf ihre Seite zu ziehen. Als sich aber herausstellte, daß die Liberalen mit großer Geschlossenheit das Bündnis mit der SPD anstrebten, lud er seinen Ärger und seine Frustration öffentlich auf dem vermeintlichen Koalitionspartner ab. In der Sendung Bonner Perspektiven kündigte er am 5. Oktober 1969 an, die Union gedenke jene Partei aus vier der nächsten fünf anstehenden Landtagswahlen „herauszuka-

${ }^{237}$ Baring, Machtwechsel, Kiesinger an Scheel vom 3.10.1969, S. 158 f.

238 Vgl. Mende, Wende, S. 310; dort auch das folgende Zitat.

239 Vgl. Mende, Wende, S. 308; Baring, Machtwechsel, S. 163.

240 Vgl. Barzel, Gespräch mit dem Verfasser, 10.6.1988; siehe auch Baring, Machtwechsel, S. 161.

Sogar noch am Tage nach der Bundestagswahl staunte Barzel, als der Kanzler ihn fragte, ob er, Barzel, der neue Außenminister werden wolle. Der Fraktionschef erwiderte entgeistert: „Aber wir werden die Regierung verlieren, Herr Bundeskanzler! “ 
tapultieren, die sich jetzt als Schlüsselfigur der Bundesrepublik betätigt" ${ }^{241}$. Damit verdarb er das Verhältnis zur FDP endgültig und erschwerte eine Annäherung zwischen den beiden Parteien für die nächsten Jahre.

Warum setzte Kiesinger nicht auf die Erneuerung der Großen Koalition? Er selbst hat die Schuld ganz bei der SPD gesehen. Am 1. Oktober erklärte er auf die Frage, warum es keinen Versuch gegeben habe, mit der SPD eine zeitlich begrenzte Große Koalition zu bilden: „Es kam gar nicht mehr dazu. Wir waren in einer Situation, wo uns die SPD so rasch und so vor ein Fait accompli gesetzt hat, daß eine derartige Verhandlung von unserer Seite aus keine Aussicht eröffnete. "242 Offenbar maß der Kanzler auch der scheinbar verächtlichen Haltung Wehners gegenüber der FDP kein großes Gewicht bei, als der stellvertretende SPD-Vorsitzende am Wahlabend von der FDP als "Pendler-Partei“ sprach $^{243}$. Im Jahre 1980 schrieb Kiesinger allerdings, „Wehner wäre wohl zu einer Fortsetzung der Großen Koalition bereit gewesen“. Dafür spräche dessen Antwort auf die Frage eines Journalisten in der Wahlnacht, ob die SPD nun mit der FDP koalieren werde: „Mit den Pendlern?" 244 Das war allerdings eine falsche Einschätzung, glaubt man Wehner. Im Jahre 1977 erklärte der SPD-Politiker, man müsse seine Äußerung genau ansehen! Er habe gesagt: Jetzt werde sich zeigen, ob die FDP eine Pendlerpartei bleiben wolle ${ }^{245}$.

Entscheidend für das Ende der Großen Koalition war aber, daß die beiden wichtigsten Befürworter dieses Regierungsbündnisses in der SPD sich dem Parteivorsitzenden nicht in den Weg stellten, als Brandt fest entschlossen auf die sozialliberale Koalition zusteuerte. „Wenn du's willst, mach's doch“, soll Schmidt Brandt in der Wahlnacht nach eigenem Bekunden gesagt haben ${ }^{246}$. Wehner und Schmidt wollten nicht für die Fortsetzung der alten Regierung kämpfen. Kiesinger erklärte sich diese Tatsache später damit, daß Wehner zu diesem Zeitpunkt die Mehrheit der SPD-Fraktion nicht mehr „hinter sich“ gehabt habe247. In der Fraktion sei man sich offensichtlich darüber einig geworden, daß die zu lösenden Sachfragen eher von einer sozialliberalen Regierung bewältigt werden konnten als vom bestehenden Bündnis.

Aber die Entfremdung zwischen dem Kanzler und seinem Minister spielte die entscheidende Rolle. Auf die Frage, warum das Bündnis der Großen Koalition zerbrochen sei, zitierte Wehner in einem Interview 1980 Guttenbergs Bemerkung: „Es war das Drumherum um die Bundespräsidentenwahl 1969."248 Wehner stimmte dem zu. Damals habe die SPD knapp verhindern können, daß ein Bundespräsident mit den Stimmen der NPD gewählt worden wäre, meinte er. Und damals hätte Kiesinger sich nicht nur geweigert, das Angebot einer Passierscheinausgabe für die Verlegung der Bundesversammlung anzunehmen, sondern auch erklärt, er glaube nicht an die Notwendigkeit, mit Ost-Berlin unbedingt Kontakt anzuknüpfen. An diesem Abend endete für Wehner das persönliche Bündnis mit Kiesinger. Es gab keine gemeinsame deutschlandpolitische und damit all-

241 BPA, Kiesinger im ZDF am 5.10.1969, Anhang I, S. 6. Kiesinger versuchte später die Bedeutung dieser Entgleisung herunterzuspielen. Bei den Rhöndorfer Gesprächen am 20.11.1986 zitierte er Theodor Fontanes Wort: „Fremdwörter haben immer etwas Gesteigertes." Kiesinger gebrauchte dieses Dichterwort öfters, vgl. Oberndörfer (Hrsg.), Große Koalition, S. 132.

182 Ebenda, S. 5.

243 Guttenberg, Fußnoten, S. 107.

${ }^{244}$ AdKASt, Kiesinger I - 226, E/IV.1, A 355, Kiesinger an Dichgans vom 9.1.1980, S. 4.

$245 \mathrm{Vgl}$. Wehner, Gespräch mit Baring, 25.1.1977.

246 Baring, Machtwechsel, S. 174.

${ }^{247}$ AdKASt, Kiesinger I - 226, Kiesinger an Dichgans vom 9.1.1980, S. 4.

248 Terjung (Hrsg.), Der Onkel, Wehner für NDR am 5.1.1980, S. 161. 
gemein gültige Basis mehr. Das wichtigste Element der Stabilität in der Koalition, das Verhältnis der beiden Gründungsväter, war zerstört und ließ sich nicht wiederherstellen.

\section{Versöbnung nach Jabren}

Neben dem fundamentalen Streit zwischen Kiesinger und Wehner gab es andere Gründe, die eine Fortsetzung der Großen Koalition unmöglich machten. Mittlerweile bestimmten ganz andere Themen die politische Diskussion als noch drei Jahre zuvor. Im Herbst 1966 ging es um die Frage des Ausgleichs für die entstandene Haushaltslücke und die Überwindung der Rezession. Inzwischen war das Problem nicht nur gelöst, sondern auch die Wirtschaftskrise überwunden. Die Zahl der Arbeitslosen sank von $673572 \mathrm{im}$ Februar 1967 auf $341000 \mathrm{im}$ September und ging bald ganz zurück ${ }^{249}$. Im Mai 1969 wurde ein Nachkriegsrekord in der Zahl der offenen Stellen erreicht: Es gab 807200 freie Arbeitsplätze! Das reale Bruttosozialprodukt wuchs im Jahre 1968 um 6,9 Prozent ${ }^{250}$. Die durch das hohe Wachstum zu erwartenden steuerlichen Mehreinnahmen schienen die in der Großen Koalition höheren Haushaltsausgaben des Bundes aufzufangen. Trotz dieser Erfolge wirkte im Herbst 1969 die Frage zwischen beiden Regierungsparteien, ob die DM aufgewertet werden sollte oder nicht, gegen die Fortsetzung der Koalition. Die Polarisierung trug dazu bei, daß das Einverständnis zwischen beiden Parteien in der Wirtschafts- und Sozialpolitik bei der Bildung der Regierung im Herbst 1969 diesmal nicht zum Tragen kam.

Auch die erfolgreiche Durchführung derjenigen Projekte, die eine Zweidrittelmehrheit im Bundestag benötigten, sprach gegen die Fortsetzung der Großen Koalition über 1969 hinaus. Das galt insbesondere für die Notstandsgesetze. Die Einführung eines Mehrheitswahlrechts dagegen - einziges gestecktes Ziel, das die Koalition nicht erreichte wäre wahrscheinlich auch bei einer Fortsetzung des Regierungsbündnisses am Widerstand der Sozialdemokraten gescheitert.

Unerledigt und dringlich blieb die Fortsetzung der Deutschland- und Ostpolitik. Da die wirtschaftliche Entwicklung zufriedenstellend verlief, war vorauszusehen, daß sich die Regierung von 1969 im wesentlichen auf diesem Gebiet würde profilieren müssen. Und gerade hier hatte die Erfahrung des Frühjahrs und Sommers 1969 gelehrt, daß eine gemeinsame Linie von Union und SPD immer schwerer zu finden und durchzuhalten war. Dagegen sprach die sich schon 1966 deutlich abzeichnende Gemeinsamkeit von Liberalen und Sozialdemokraten in der Deutschlandpolitik für ein gemeinsames Regierungsbündnis.

Vor diesem Hintergrund war auch Brandts Votum für die Koalition mit der FDP entschlossener als drei Jahre zuvor. Hinzu kam, daß er seit dem Sommer 1967 als Außenminister stärker an Profil hatte gewinnen können. Seit dieser Zeit zeigte er sich selbstbewußter im Umgang mit Kiesinger, beharrte auf seinen Forderungen in der Ostpolitik, auch wenn er im Kabinett weiterhin nicht die Auseinandersetzung mit dem Kanzler suchte. Im Laufe des Jahres 1969 wurde ihm klar, daß seine Ostpolitik sich nicht zusammen mit den Christdemokraten werde durchführen lassen. In der Zustimmung der Bundesregierung zum Sperrvertrag hatte er die einzige Möglichkeit gesehen, die gemeinsame Politik der Annäherung an die osteuropäischen Staaten erfolgreich voranzubringen. Aber da sich die Union, vor allem Kiesinger, gegen die Unterzeichnung wandte, galt ihm das als Zeichen für die Notwendigkeit eines Koalitionswechsels.

249 Vgl. Schneider, Große Koalition, S. 93. 250 Vgl. ebenda, S. 96. 
Es war daher auch Brandt, der den Abschiedsbrief an Kiesinger verfaßte. Er, nicht Kiesinger, beendete die Große Koalition formell durch ein Dankesschreiben an den Kanzler. Brandt war nicht anwesend, als Kiesinger am 8. Oktober in der letzten Kabinettssitzung eine Bilanz des Regierungsbündnisses zog. Erst am nächsten Tag schrieb der SPDVorsitzende aus Münstereifel handschriftlich an den Bundeskanzler:

„Weder zurückliegende noch bevorstehende Kontroversen werden mich abhalten, zu dem zu stehen, was wir seit Ende 1966 miteinander geleistet haben; es ist unserem Vaterland nicht schlecht bekommen. Die künftige Regierung wird sich auf das zu stützen haben, was durch die Große Koalition konzipiert, angepackt und zu einem nicht geringen Teil ja auch verwirklicht wurde.

Wir stehen, so oder so, in gemeinsamer Verantwortung. Auch deshalb kann dies kein politischer Abschiedsbrief sein. Aber ich wollte Ihren gestrigen Rückblick doch nicht ohne eine Antwort lassen, in die der persönliche Respekt vor Ihrer Kanzlerschaft einbezogen ist. "251

Wehner meldete sich dagegen nicht. Im Terminkalender des Kanzlers ist in der Zeit nach der Wahl kein Eintrag über ein Treffen mit dem Sozialdemokraten zu finden. Nichts unmittelbar nach dem Ende und kaum ein Wort im Laufe der folgenden Jahre. Wehner schickte zwar einige freundliche Zeilen zum Geburtstag, und er übersandte selbst verfaßte Bücher, die er mit persönlichen Widmungen versah. Das war alles. Dennoch schätzte Kiesinger diese Geschenke hoch ein. Wenn er einmal ein Buch mit der Widmung „mit Respekt, herzlich Ihr Wehner“ erhielt, dann war der Christdemokrat davon überzeugt, daß sich „schon etwas Echtes“ hinter diesen Worten verbarg252.

Aber viele von Wehners Taten blieben Kiesinger auch im nachhinein unverständlich. So konnte der Altbundeskanzler beispielsweise den im Jahre 1968 veröffentlichten Artikel Wehners für die Festschrift von Alex Möller nie erklären. Der Beitrag ist schon oben ausführlich erwähnt worden. Kiesinger empörte, daß der Minister darin der CDU/CSU vorgeworfen hatte, sie habe nichts für die "demokratische Lösung der deutschen Frage“ getan. Er hielt nicht nur diese Feststellung für falsch, sondern nahm insbesondere den Zeitpunkt übel, zu dem sie getroffen wurde. „Er wirft der CDU vor, es sei eben nichts unternommen worden [...] Und das inmitten der Großen Koalition!“, bemerkte Kiesinger noch 1978 aufgebracht.

Hatte Wehner ihn „betrogen“? Hat der Minister eine ganz andere Politik gewollt und ausgeführt, als er dem Kanzler selbst erklärte? Kiesinger hat das nie angenommen und den Sozialdemokraten vor solchen Behauptungen aus der eigenen Partei immer verteidigt. Wehner habe ihm nie etwas vorgemacht, sondern habe die gemeinsam vereinbarte Linie in der Politik "treu durchgehalten“. Aber Kiesinger war sich bewußt, daß er und Wehner, zumindest im Frühjahr 1969, unterschiedliche Wege eingeschlagen hatten. Er bewunderte die Konsequenz, mit der Wehner seit damals seine politische Zielsetzung verfolgt hatte und weiter verfolgte.

Trotz aller Entzweiung im sachlichen Bereich blieb der persönliche Respekt erhalten, den beide Politiker füreinander empfanden. Zum 75. Geburtstag, am 6. April 1979, erhielt Kiesinger einen Brief Wehners, der - mit zehnjähriger Verspätung - auf den bis dahin zwischen beiden unausgesprochenen Bruch vom Frühjahr 1969 Bezug nahm:

„Mit meinem Gruß aus Anlaß Ihres ,75.' möchte ich Ihnen ein Zeichen geben, daß auch meine guten Wünsche Sie begleiten. Ich möchte Ihnen damit zugleich meine Dankbarkeit für vieles zum Ausdruck zu bringen versuchen, sowohl für Ihre persönliche als auch für Ihre politische Fähigkeit, mit-

251 AdKASt, Kiesinger I - 226, D/IV.6, A 001, Brandt an Kiesinger vom 9.10.1969.

252 AdKASt, Kiesinger I - 226, A 322, Gespräch mit Löwe, 31.1.1978, S. 45; dort auch die folgenden Zitate. 
einander umzugehen - auch bei gegensätzlichen oder unterschiedlichen politischen Einschätzungen oder Grundauffassungen.

So wie die ,Dinge' sich entwickelt haben und wohl weiter entwickeln werden, ist kaum zu erwarten, einander erklären zu können, woraus die oder jene Entscheidung zu erklären oder zu verstehen ist. Deshalb möchte ich Ihnen eben mit meinem Gruß und meinen guten Wünschen meine Wertschätzung ausdrücken. Ich erlaube mir, Ihnen ein Büchlein ${ }^{253}$ zu schicken, das Sie vielleicht deshalb interessiert, weil es Einblick gibt in das, was mich politisch bewegt hat - obwohl es nun so aussieht, als seien die Probleme zäher als die Fähigkeit, sie zu lösen. "254

Wie im Brief vom Dezember 1968 beschränkte sich Wehner auch hier auf das Vernünftige: Er versuchte nichts zu erklären, nichts zu beschönigen. Er erwähnte nur das, was ihm persönlich wichtig war: den Respekt für Kiesinger, ja vielleicht sogar eine gewisse Zuneigung. Der Brief war die Anregung, vielleicht auch die Bitte, die Ereignisse von 1969 auf sich beruhen zu lassen. Vielleicht hatte Kiesinger lange auf dieses Wort Wehners gewartet. Jetzt war es eingetroffen. Erst im April 1979 trugen die beiden Gründungsväter ihr Unternehmen, die Große Koalition, gemeinsam zu Grabe.

253 Es handelt sich um die von Wehner mit einem Geleitwort neu herausgegebene Dissertation Schumachers aus dem Jahre 1921, Der Kampf um den Staatsgedanken in der deutschen Sozialdemokratie, Stuttgart 1976.

254 Oberndörfer (Hrsg.), Begegnungen, Wehner an Kiesinger vom 6.4.1979, S. 479. 